\title{
A scenario planning of the sharing economy in \\ Bali accommodation 2030
}

By

Arya Galih Anindita

300344431

A thesis submitted to Victoria University of Wellington in partial fulfilment of the requirements for the degree of Master of Tourism Management

Victoria University of Wellington 
To Hagi and Hannah

The past is always tense, the future perfect 


\begin{abstract}
Defined as the economic system that allows ordinary people to share their underused/underutilized residences as tourist accommodation, the sharing economy in the accommodation sector may emerge into one of the most important trends to change the overall landscape of tourism. Given that the sharing economy is still in its infancy in a world full of contingencies, the future of the sharing economy in accommodation remains uncertain, and Bali, Indonesia provides no exception. In response, this study aims to take a 'sneak peek into the future' exploring the potential evolution of the sharing economy in Bali's accommodation through a comprehensive future study.

Utilizing Delphi-based scenario planning, a group of participating experts have been interviewed and their answers to multiple questionnaires analyzed. Through the two most important drivers to be identified, infrastructure development and ubiquitous Internet, a four-quadrant scenario matrix has been developed. Each of the scenarios is presented in a storyline by integrating the drivers of change, future thinking, and creative imagination to portray four alternative illustrations of the sharing economy in Bali's accommodation sector in 2030. The from local to global scenario emphasizes the vision of Bali's modernization whereby smart houses and a local sharing economy in accommodation are pervasive, and incumbent hotels decide to compete with such new rivals. The joint first prize scenario portrays the partnership between hotels and traditional villages, sophisticated features of the sharing economy in accommodation platforms, and the use of an integrative rating system to classify the shared houses. The volte-face scenario highlights a gloomy situation with no existence of a sharing economy in accommodation. Lastly, the what's yours is mine scenario envisages exclusive purpose-built second homes clustered in an area only accessible for highincome bracket visitors. Through an examination of strategic implications, the study explores potential risk and the consequences of each scenario coupled with key strategies to guide the relevant stakeholders with a range of possible approaches for resolution.

This study offers piece of document that contributes to the overall academic literature as this study expands the outcome of available researches focused in this topic, and also overlooks potential policy instruments to be undertaken by key stakeholders.
\end{abstract}


Keywords: Bali, sharing economy in accommodation, Delphi method, scenario planning, future. 


\section{Acknowledgments}

It is my pleasure to acknowledge the roles of several individuals who were instrumental for completion of my thesis, but first and foremost, thank you to Allah the almighty for his grace and blessings without which I would not be able to finish this life-changing ride.

An immeasurable gratitude dedicated to my much-loved wife, our beautiful babies: Hagi and (soon to come) Hannah, and my family back home. I know I would have not been able to go through this without your love, understanding and encouragement.

Thank you to my supervisor, Associate Professor Ian Yeoman for the guidance, support, and assistance. Sunderland FC still and may not be in the top of EPL table but you indeed have such top competencies to drive your students to achieve greater success.

Thank you to all other Tourism Management lecturers at Victoria University of Wellington, Prof. Karen Smith, Associate Professor Mondher Sahli, Dr. Adam Weaver, and Dr. Christian Schott. You have taught me something that I am sure is beneficial for myself and my upcoming endeavors.

My master thesis fellows: Bernadeth, Linh, and Margaret. Thank you for sharing the hardship and happiness until we eventually made it.

And finally, I would like to express my gratitude and appreciation to New Zealand Aid Scholarship for giving me the opportunity of living in this beautiful country and studying in the world-class university. Ka kite (anō) 


\section{Contents}

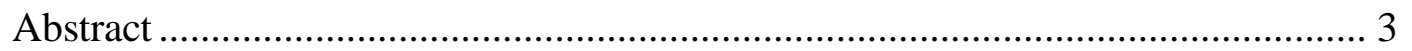

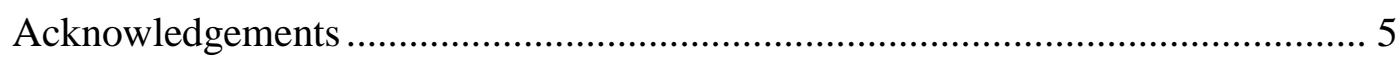

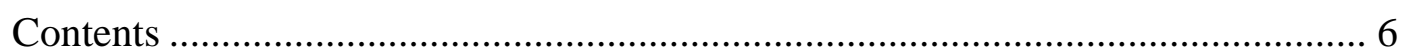

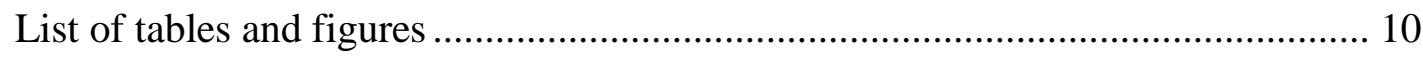

Chapter 1 - Introduction ................................................................................ 12

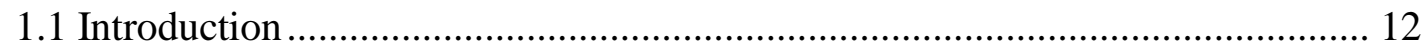

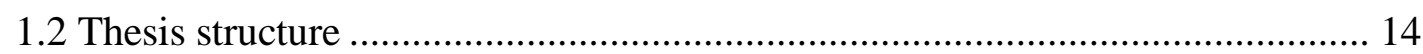

Chapter 2 - An Overview of the Sharing Economy in Accommodation ........... 16

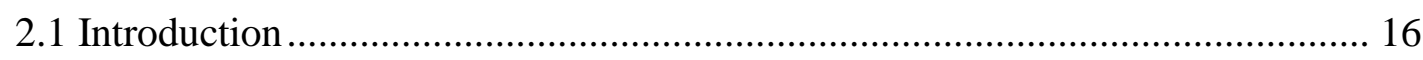

2.2 The development of the sharing economy in accommodation......................... 16

2.2.1 The plethora of the sharing economy ................................................... 16

2.2.2 The sharing economy in tourism and accommodation........................... 19

2.2.3 The exponential growth of Airbnb ......................................................... 22

2.2.3 Critical reflection on the development of the sharing economy

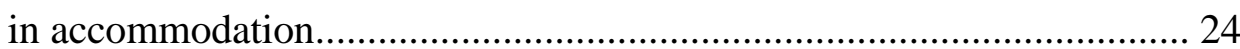

2.3 The sharing economy in accommodation in Bali........................................... 26

2.3.1 The sharing economy in accommodation in Bali ................................. 26

2.3.2 The development of homestay in Bali................................................. 27

2.3.3 Critical reflection on the sharing economy in accommodation in Bali .. 29

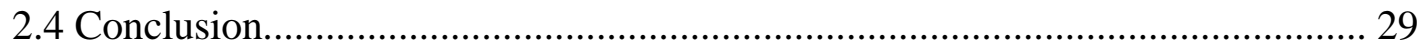

Chapter 3 - Research Methodology...................................................................... 31

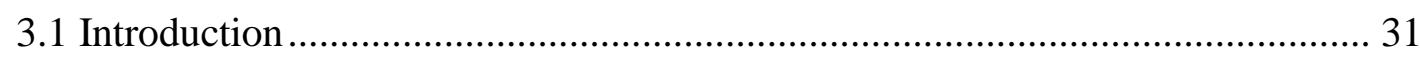

3.2 Literature review on research methodology.............................................. 34

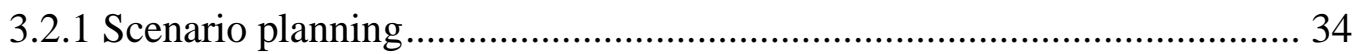

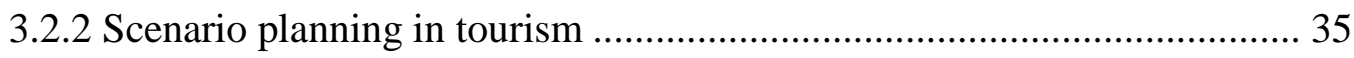

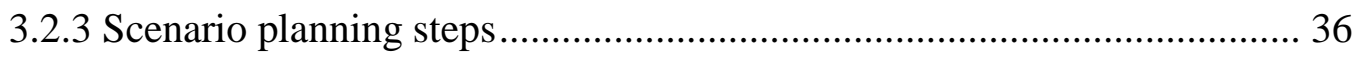

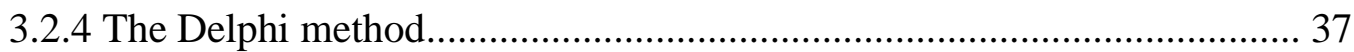

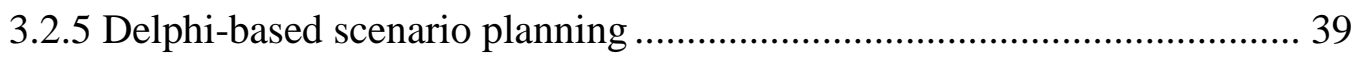

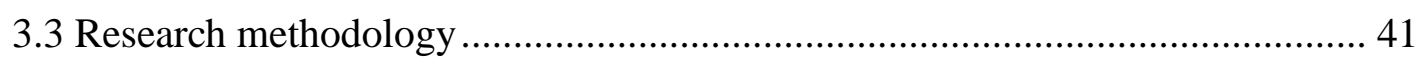

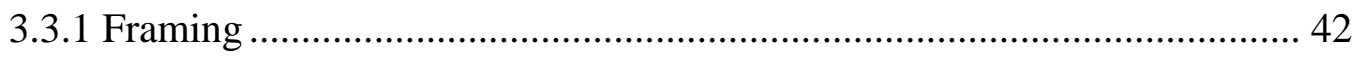

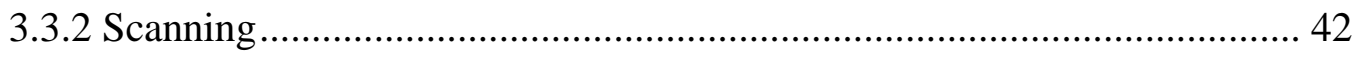

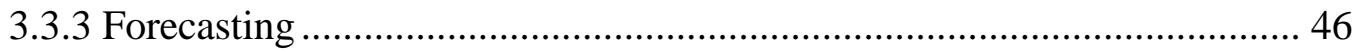


3.3.4 Visioning 50

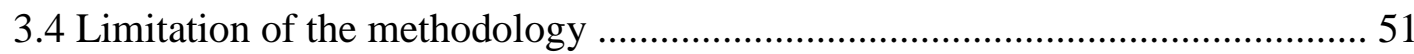

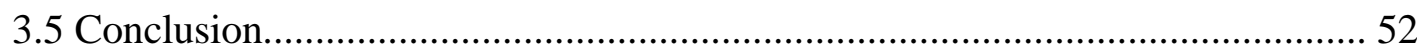

Chapter 4 - The Drivers of Change................................................................... 53

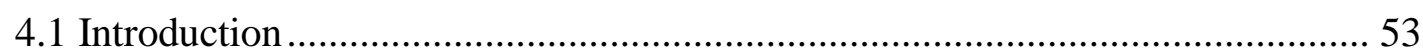

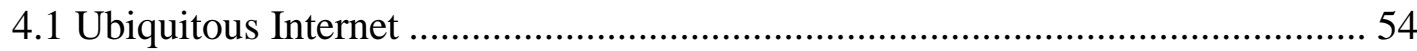

4.1.1 Literature review relating to ubiquitous Internet................................... 54

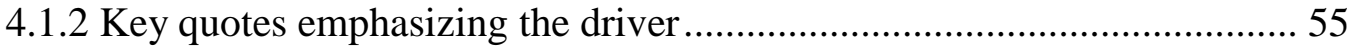

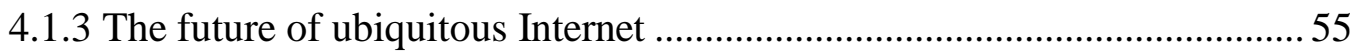

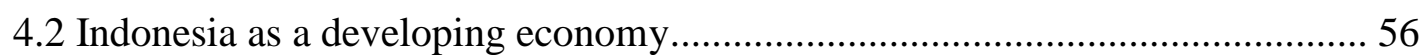

4.2.1 Literature review relating to Indonesia as a developing economy ............ 56

4.2.2 Key quotes emphasizing the driver .................................................... 57

4.2.3 The future of Indonesia as a developing economy................................ 57

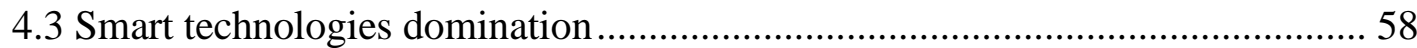

4.3.1 Literature review relating to ubiquitous Internet................................... 58

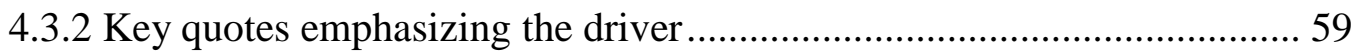

4.3.3 The future of smart technologies........................................................ 59

4.4 Political decision on the sharing economy in accommodation..........................6 60

4.4.1 Literature review relating to political decision....................................... 60

4.4.2 Key quotes emphasizing the driver....................................................... 61

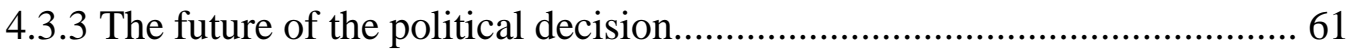

4.5 Domination of Generation Y/Millennial Generation ...................................... 62

4.5.1 Literature review relating to domination of Generation Y ....................... 62

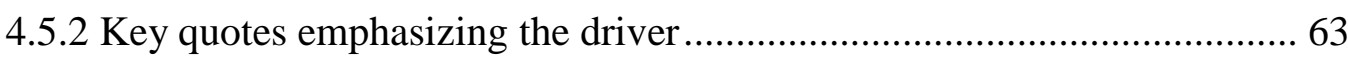

4.5.3 The future of Generation Y/Millennial Generation.................................. 63

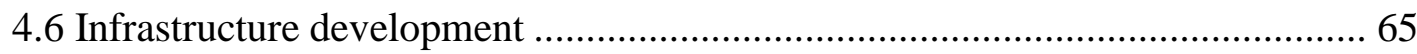

4.6.1 Literature review relating to infrastructure development ........................ 65

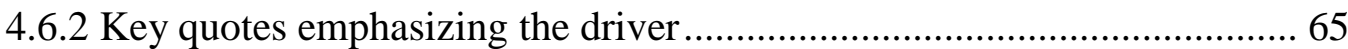

4.6.3 The future of infrastructure development in Bali ..................................... 66

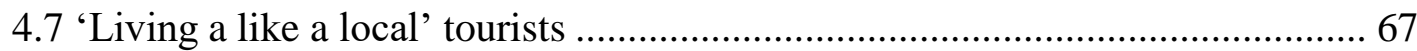

4.7.1 Literature review relating to 'Living like a local' tourists....................... 67

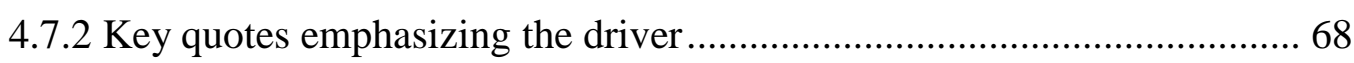

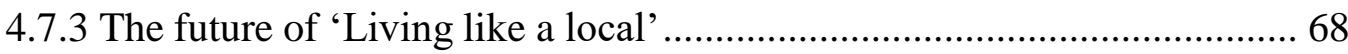


4.8 Innovation of the sharing economy in accommodation platform.

4.8.1 Literature review relating to innovation of sharing economy platform .. 69

4.8.2 Key quotes emphasizing the driver ................................................... 73

4.8.3 The future of innovation of sharing economy platform ......................... 73

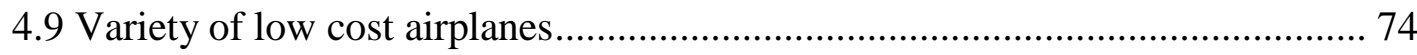

4.9.1 Literature review relating to variety of low cost airplanes ....................... 74

4.9.2 Key quotes emphasizing the driver .................................................... 75

4.9.3 The future of the low cost carriers ...................................................... 75

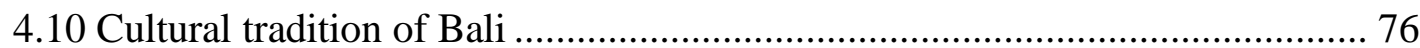

4.10.1 Literature review relating to cultural tradition of Bali ........................... 76

4.10.2 Key quotes emphasizing the driver .................................................... 77

4.10.3 The future of cultural tradition of Bali .................................................. 77

4.11 Oversupply of hotel rooms in Bali ............................................................. 78

4.11.1 Literature review relating to oversupply of hotel rooms in Bali ............. 78

4.11.2 Key quotes emphasizing the driver .................................................... 79

4.11.3 The future of oversupply of hotels rooms in Bali ................................ 79

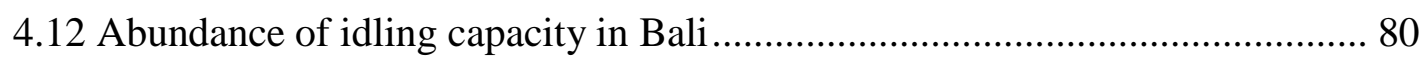

4.12.1 Literature review relating to abundance of idling capacity in Bali ......... 80

4.12.2 Key quotes emphasizing the driver ................................................. 81

4.12.3 The future of idling capacity in Bali .............................................. 81

4.13 The disruptive innovation of the sharing economy in accommodation ........... 82

4.13.1 Literature review relating to the disruptive innovation ........................ 82

4.13.2 Key quotes emphasizing the driver .................................................... 84

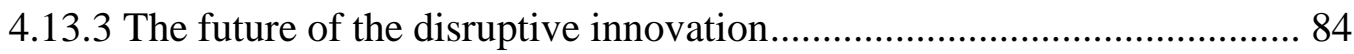

4.14 Popularity of reputation and rating system................................................. 85

4.14.1 Literature review relating to reputation and rating system.................... 85

4.14.2 Key quotes emphasizing the driver .................................................. 86

4.14.3 The future of reputation and rating system.............................................. 86

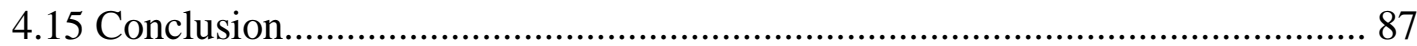

Chapter 5 - Scenarios .............................................................................................. 91

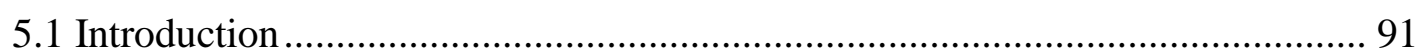

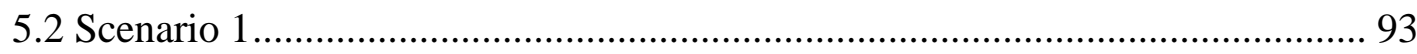

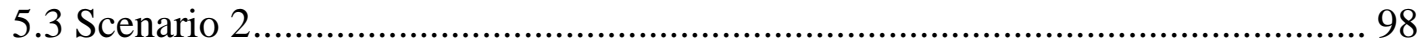

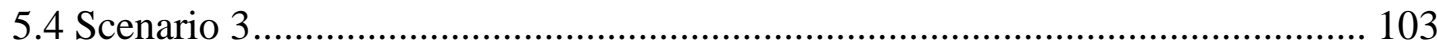




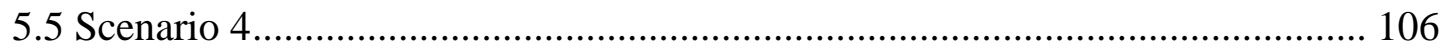

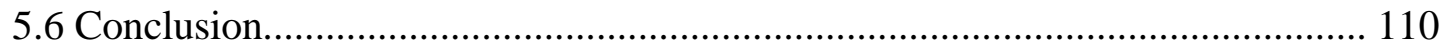

Chapter 6 - Strategic Implications .................................................................................. 111

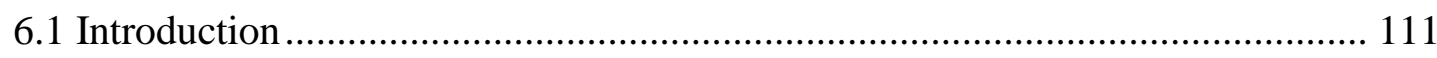

6.2 Overall strategies to manage the sustainability of the sharing economy

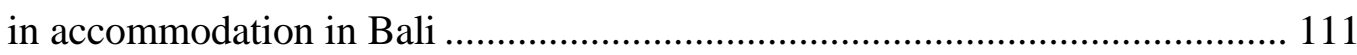

6.3 Implications and strategic decisions based on the individual scenarios .............. 118

6.3.1 Implications and strategic decisions for the from local to global ............. 119

6.3.2 Implications and strategic decisions for the joint first prize ..................... 121

6.3.3 Implications and strategic decisions for the volte-face ............................. 122

6.3.4 Implications and strategic decisions for the what's yours is mine ............ 123

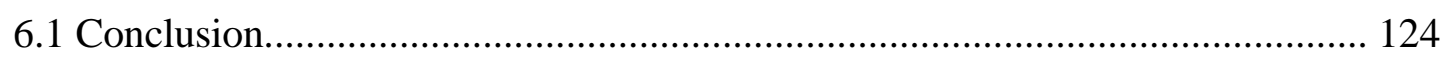

Chapter 7 - Conclusion .................................................................................................. 125

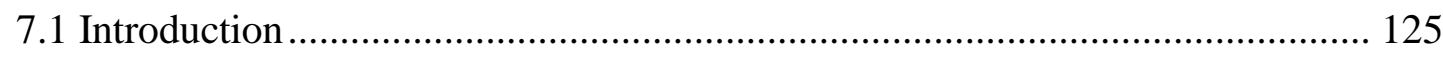

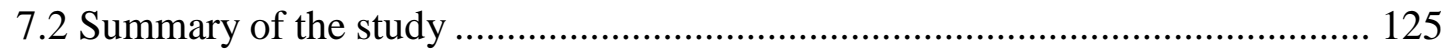

7.3 Contribution and value of the study ................................................................. 128

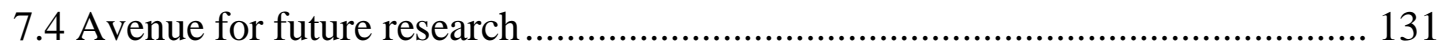

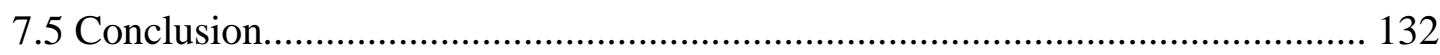

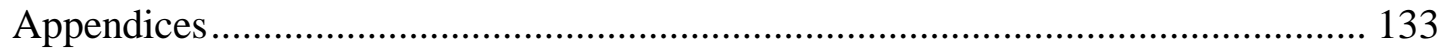

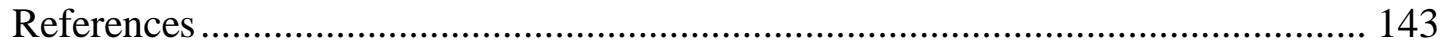




\section{List of tables and figures}

Table 2.1: Example of the sharing economy platforms ...................................... 18

Table 2.2: Number of homestays and rooms in Bali ........................................... 28

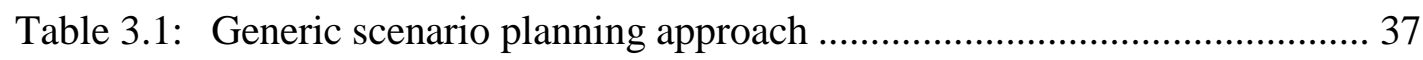

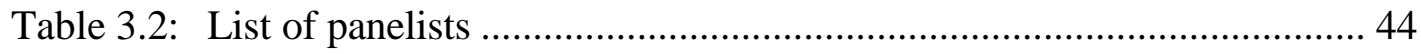

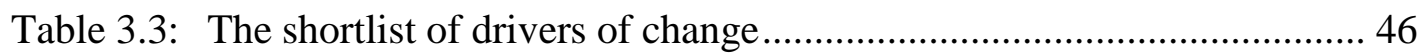

Table 3.4: Ranking of the importance of drivers of change................................... 47

Table 3.5: Ranking of the likelihood of drivers of change occurring..................... 48

Table 4.1: Indonesia's domestic travels and spending .......................................... 56

Table 4.2: Regulations on Airbnb in different municipalities .............................. 61

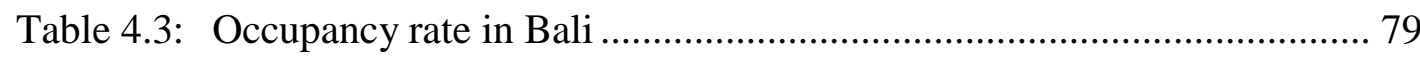

Table 4.4: Top 10 of luxury property and second home locations ......................... 82

Table 4.5: Valuation and revenue comparison of accommodation providers

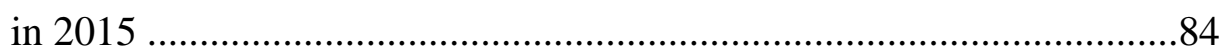

Table 4.6: Critical reflection of how driver of change impacts the future of the sharing economy in accommodation in Bali ....................................8

Table 6.1: Implications and key strategies of from local to global ........................ 119

Table 6.2: Implications and key strategies of joint first prize .............................. 121

Table 6.3: Implications and key strategies of volte-face ....................................... 122

Table 6.1: Implications and key strategies of what's yours is mine ...................... 123

Figure 2.1: Sharing economy in tourism ......................................................... 20

Figure 2.2: Lodging segmentation by region in 2015......................................... 22

Figure 2.3: Distribution of Airbnb active rental in Bali ....................................... 26

Figure 2.4: The Bale of Balinese homestay........................................................ 28

Figure 3.1: Integration of the Delphi method within the generic scenario

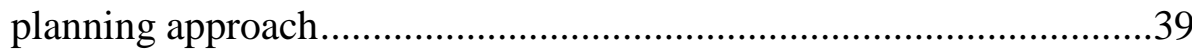

Figure 3.2: Delphi-based scenario planning steps ............................................ 41

Figure 3.3: Four-quadrant scenario matrix …................................................. 50

Figure 4.1: Global Internet users .................................................................... 54

Figure 4.2: Estimated addition to the Indonesia's consuming class by 2030 ........ 58

Figure 4.3: Smartphone users and penetration worldwide, 2013-2018 _............... 59

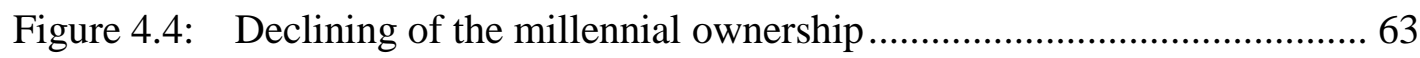

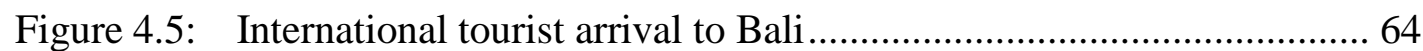

Figure 4.6: Bali national tourism destination development plan.......................... 66

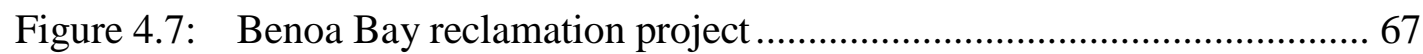

Figure 4.8: The interface of Airbnb.............................................................. 71

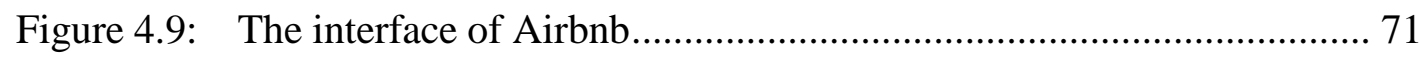

Figure 4.10: The searching and payment process in Airbnb ................................. 72

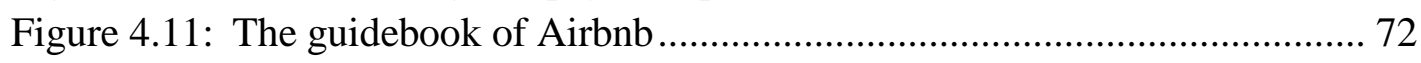

Figure 4.12: Domestic routes served by Lion Air ................................................ 75 


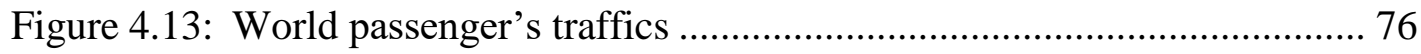

Figure 4.14: Cumulative supply of star rating hotel projects............................... 80

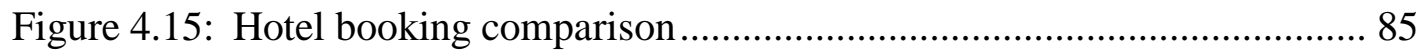

Figure 4.16: Example of rating and review in Airbnb........................................ 86

Figure 5.1: The four-quadrant scenario-planning matrix ..................................... 92

Figure 5.2: The essence of from local to global scenario and the influencing drivers ...................................................................................... 93

Figure 5.3: The essence of joint first prize scenario and the influencing drivers 98

Figure 5.4: The essence of volte face scenario and the influencing drivers .......... 103

Figure 5.5: The essence of what's yours is mine scenario and the influencing

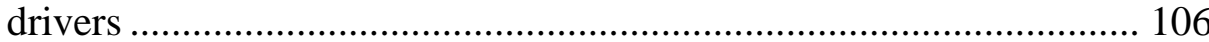

Figure 6.1: Proposed management flow of the sharing economy in accommodation in Bali ................................................................ 118

Figure 7.1: The four-quadrant scenario planning matrix and their key features . 126

Figure 7.1: The four-quadrant scenario planning matrix and their implications and key strategies 


\section{Chapter 1 \\ Introduction}

\subsection{Introduction}

In early 2013, The Economist, a globally popular magazine-format newsletter published a very important article with the title "All eyes on the sharing economy" summarizing the landscape of the sharing economy and capturing the larger rise of this sector, which possibly came to prominence between 2008 and 2010 (Economist, 2013). The fundamental principle of the sharing economy its roots in consumer demand to access goods or services temporarily and therefore pay for temporary access rather than to buy and own them (Bardhi and Eckhardt, 2012; Belk, 2013). Today, the sharing economy is getting very big and is rising at a very fast pace as such temporary access can be given to numerous physical goods and services (Economist, 2013). The sharing economy can apply to dog-kennel services, car-parking spaces, musical instruments, kitchen appliances, and outdoor gear, to name only a few. On a global basis, the five key sharing economy sectors - travel, car sharing, finance, staffing and music and video streaming - have the potential to increase global revenue from the current $\$ 15$ billion to around $\$ 335$ billion by 2025 (PwC, 2015). In the UK alone, these five sub-sectors were worth around $£ 500 \mathrm{~m}$ in 2014 , and could be worth up to $£ 9$ billion by 2025 (Wosskow, 2014).

Interestingly, most sharing economy sectors are tourism-related, of which accommodation and transportation are considered the most important (Peeters et al., 2015; Economist, 2013). Take Airbnb as an example; this worldwide popular platform through which ordinary people can share their privately owned houses, spare rooms, or any property as accommodation for tourists (Guttentang, 2015), has accommodated more than 150 million guests since the first year of operation in 2008, indicating how global consumers are showing a robust appetite for this sector. The sharing economy in general, and the accommodation sector in particular, has just reached what Gladwell (2000) named as the 'tipping point', where new ideas or products become a contagious behavior; or the 'critical mass' as described by Botsman and Rogers (2010) where a product acquires enough momentum within the community to make it self-sustaining. 
In "All eyes on the sharing economy" and other relevant literature, the multiple benefits of the sharing economy in accommodation are explored, among which are to provide an antidote to overconsumption and materialism, thereby advantaging the natural environment; the opportunity to gain "rich social experience" by connecting intensively with local communities; and the potential of creating more part-time-preneurs or microentrepreneurs (micro-preneurs) from ordinary people who can make substantial income by sharing their underused assets without having to comply with problematic regulations. Despite these appealing effects, many have addressed the undesirable impacts of this sector, mainly related to legality, taxation, and the potential disruption to large and incumbent companies. Airbnb has been accused of driving hotel rates and revenues down, (Oskam \& Boswijk, 2016), but beyond that there are also concerns that invite attention from policymakers such as public safety and quality control, the prevalence of non-standardized services, privacy of consumer data, security of transaction, and land use/zoning regulation (Psarros, 2015, Peeters et al., 2015).

In Indonesia, while the sharing economy in accommodation is slowly attracting more participants, its transportation sector counterpart receives massive attention from Indonesia residents especially those who reside in the big cities, Bali included (Liem, 2015). Local transportation sharing platforms include Gojek, along with San Franciscobased Uber and Singapore-based Grab, all of which provide car and motorbike ride sharing and are highly popular among Indonesians looking for cheap and easy transportation. Nevertheless, despite their growth, they also receive violent protests from incumbent taxi and motorbike drivers who have complained about unfair rules and competition, and have urged the Indonesian government to ban the platforms (Liem, 2015).

Given the dynamics of the sharing economy and the fact that the system is still in its infancy, one cannot precisely predict and comprehend what the sharing economy in accommodation will become in the next few decades. What may change and what are the long term challenges? Will the platforms or properties being shared remain the same or will there be significant transformations? Too many unanswered questions enhance the complexity of this sector. The foreseeing is even more complicated given the unique character of Bali and the Balinese and specific issues revolving around it. 
The above arguments and facts lead to the construction of two main research problems that justify the importance of studying the particular topic:

- The sharing economy in the accommodation sector in Bali will bring about changes in the accommodation industry through its broad spectrum of benefits and issues.

- Following the global trend, the sharing economy in the accommodation sector in Bali will eventually reach a 'tipping point' or 'critical mass'.

Driven by these research problems, this study offers a comprehensive future study to explore the future evolution of the sharing economy in the accommodation sector in Bali and to give meaning and relevance to the key players; therefore a clearer, broader perspective and forward-looking regulations can be formulated. The overarching research question of this study asks 'What will the sharing economy in accommodation in Bali look like in 2030?', with three sub-questions set out in order to precisely answer the research question:

- What are the drivers of change that will shape the sharing economy in the accommodation sector in Bali?

- What are the possible scenarios for the future of the sharing economy in the accommodation sector in Bali in 2030?

- What are the strategic implications of these scenarios?

The value of this research is twofold. The theoretical contribution is to extend the understanding of the sharing economy in accommodation as a new consumption paradigm, with a particular focus on its potential evolution and the factors that drive such evolution. The practical contribution is to overlook consequences and potential policy instruments to be undertaken by different stakeholders in order to manage the evolution of the sharing economy in the accommodation sector.

\subsection{Thesis structure}

It is important to note that the structure of this study may seem unconventional as a research approach, however the sequence of this structure has been widely used in scenario planning literature and future studies in general (Amer et al., 2013), as will be further discussed in chapter 3 . The structure of this thesis is presented as follows:

a. Chapter 1, "Introduction", presents a brief examination of the sharing economy and the sharing economy in the accommodation sector as a problem of today with 
certain issues and challenges, thus a formulation of the research problem and research questions can be drawn, together with the contribution of the study.

b. Chapter 2, "An Overview of the Sharing Economy in Accommodation", familiarizes the reader with the development of the sharing economy in tourism and accommodation, accompanied by the rise of Airbnb, and a snapshot of the homestay experience in Bali as the closest example of sharing economy in accommodation practice.

c. Chapter 3, "Research Methodology", begins with an exploration of the research paradigm to give a solid foundation to the way the researcher does this study. Then this chapter familiarizes the reader with the methodology of this research by discussing two interrelated parts. This involves, firstly, a discussion about scenario planning, the Delphi technique, and Delphi-based scenario planning as applied in this study. Secondly, the chapter offers an in-depth explanation of the conceptual framework being used in this study, by explaining a step-by-step process of scenario construction.

d. Chapter 4, "The Drivers of Change", focuses on the discussion of fourteen drivers of change that have been identified along the scenario construction. The drivers are a pivotal part of the future study in the sense that each of them shapes the future scenario in a different degree of influence.

e. Chapter 5, "Scenarios", portrays four different but plausible future evolutions of the sharing economy in accommodation in Bali, written in the form of individuals' travel memoirs to help the reader comprehend the emergence of key issues and trends of each driver.

f. Chapter 6, "Strategic Implications", proposes subsequent potential risks and consequences of key issues and trends of each scenario, coupled with alternative strategies.

g. Chapter 7, "Conclusion", ties together the study by reflecting upon on the original research questions, the value of the study, and avenues for future research. 


\section{Chapter 2}

\section{An Overview of the Sharing Economy in Accommodation}

\subsection{Introduction}

Learning stories about the past is the key factor in determining how future decisions are framed (Van der Heijden et al., 2002). Some futurists and historians believe that the past may not continuously reoccur in a cycle and the present is, simply, a completely different situation than the past. Nevertheless, the past always leaves an essential guide to understanding what mistakes have been made in order to furnish knowledge of the present with a view of the future (Hobsbawm, 2000). In fact, questions about recent history, such as "what key lessons (positive or negative) should we learn from the past?", are always asked of respondents in scenario-building processes as the basis of structuring future alternatives (Van der Heijden et al., 2002).

For that purpose, this chapter provides a brief overview of the current situation because the present will, sooner or later, present itself as the past for a future, just as the past has once been a future. Karlsen et al (2010, p. 63) put it clearly: "what is subjective and mental exercise today will be objective and real tomorrow". The chapter therefore, covers the development of the sharing economy, the sharing economy in accommodation, the exponential growth of Airbnb as the epitome of this sector, as well as offering a snapshot of the sharing economy in accommodation in Bali with a focus on the development of the Balinese homestay. As a traditional model of house sharing practice, a description of homestays in Bali is included to give the reader some evidence about the model of long-established sharing practice in the local context, an example that is especially relevant given the very limited data/study about the current sharing economy in accommodation in Bali. Once the reader comprehends the dynamic of the sharing economy in accommodation in Indonesia, the next step of investigating the future state will become better understandable and justifiable.

\subsection{The development of the sharing economy in accommodation}

\subsubsection{The plethora of the sharing economy}

For decades people have been borrowing books from the library, getting rides, renting movies, or staying in local resident houses while traveling overseas, all of which 
highlight long-established sharing behavior and the benefit of shared resources. Sharing by all means is an old phenomenon, as old as time itself, but has remarkably intertwined with fruitful evolutions over time (Belk, 2013). Powered by the incremental development of the Internet, new technologies, and cultural networks, the 'sharing economy' has emerged as one of the most important, exciting mega trends (World Economic Forum, 2015).

However, the emergence of the sharing economy is still too recent to be thoroughly fostered in academic literature despite the ubiquity of the buzzword along with associated language such as "peer to peer economy", "collaborative consumption", “ondemand economy", and "collaborative economy" (Zervas \& Byers, 2015; Botsman, 2015). These terms are often used interchangeably owing to the absence of common agreement on each definition. Notwithstanding, some writings appear to shed light on definitions and agree on the underlying principles of the sharing economy. The sharing economy is thus defined as an economic system that allows individuals or groups to share underused/underutilized assets or services, making them accessible online for free or for a fee (Botsman, 2014; Stephany, 2015; PwC, 2015). In more detail, some key characteristics of the sharing economy are identified to supplement its primary definition (Stephany, 2015; Beck, 2013):

a. Sharing economy platforms are usually revenue-generating e-commerce sites, or have the potential to be revenue generating even if the revenue apparently exists only to assure sustainability of the particular services;

b. It optimizes underutilized assets in the sense that it extracts extra value from those assets over a period of time (the idling capacity);

c. It increases utilization of assets by making them accessible online. Thus, sharing economy platforms rely on the Internet, particularly Web 2.0 which allows users to contribute content and connect with other users;

d. It makes the underutilized assets move within a community, which each transactional action constructed on trust;

e. It reduces the need for asset ownership because the sharing economy offers mutual benefit by providing temporary access to goods by consumers to each other, but without the transfer of ownership of that good. 
Botsman (2015) believes that sharing economies can take place in multiple forms and exemplifies the most notable sharing economy platforms in table 2.1. Nonetheless, Botsman underlines that care needs to be taken when applying the term 'sharing economy' to an efficient model matching supply with demand, rather than involve a single practice of sharing and collaboration. Botsman pinpoints platforms such as Washio that enables consumers to instantly access laundry services by placing an order within the platform and simply wait for the clothing to be picked up and delivered at the next day; or Pizza Hut One Hour Delivery that is the mobile-driven versions of point-to-point pizza delivery. Botsman argues that such platforms do not implement principles of sharing and collaboration. Both examples, she asserts, are a consequence of the rising use of smartphones that lead to changes in the way a product is delivered to modern consumers.

Table 2.1: Example of the sharing economy platforms

Source: Botsman, 2015

Sharing economy Scope of sharing platform

\begin{tabular}{|c|c|}
\hline & $\begin{array}{l}\text { Airbnb facilitate ordinary people to renting out their spaces as } \\
\text { accommodation for tourists. Tourists have to make payment through } \\
\text { the website (Airbnb, 2016). }\end{array}$ \\
\hline & $\begin{array}{l}\text { BlaBlaCar offers empty seats to passengers looking for a ride. } \\
\text { Passengers have to make payment online in order to get a booking } \\
\text { code (BlaBlaCar, 2016). }\end{array}$ \\
\hline COHEALO & $\begin{array}{l}\text { Cohelao allows different hospitals within the same health care } \\
\text { system to share expensive medical equipment and bring treatment to } \\
\text { patients (Cohealo, 2016). }\end{array}$ \\
\hline & $\begin{array}{l}\text { JustPark connects drivers in search of parking with anyone who has } \\
\text { a space going spare. Thus, drivers pay online using debit card, credit } \\
\text { card, PayPal (Justpark, 2016). }\end{array}$ \\
\hline
\end{tabular}

In addition to the example in table 2.1, Wosskow (2014) classifies systematically the four sharing economy sectors that have been established in the UK:

1. Shared space and accommodation, including personal accommodation; office space; shared space in which people can share equipment and ideas with like-minded 
people; pop-up commercial space whereby retailers and food and beverages businesses share empty spaces for short term operations; loft-space sharing; and fields sharing.

2. Shared task, time, and skills from altruism to sharing capabilities in exchange for money.

3. Shared approaches to transport, which have various models of car ride sharing; bike sharing; and motorbike sharing.

4. Growing models of sharing that include sharing clothes and fashion; all stages of production and distribution for food, such as, for example connecting people with spare land for those who need land to farm.

The rapid growth of sharing economies is believed to drive noticeable shifts in societal value and interaction, global consumer preferences and behaviors, as well as new marketplaces, business ecosystems, and 'micro-preneurs', while in tourism it may change the way people travel (Wosskow, 2014; Botsman, 2015; World Economic Forum, 2015).

\subsubsection{The sharing economy in tourism and accommodation}

The impact of the sharing economy is not only limited to changing the structure of the tourism industry but also general tourist behavior (Trivett and Staff, 2013; Tussyadiah $\&$ Zach, 2015). There are abundant varieties of sharing economy platforms in tourism, documented by researchers, that are classified on a needs basis as seen in figure 2.1 (Psarros, 2015; Botsman, 2014), from finding places to stay and how to get around in tourist destination, to finding local counterparts with local knowledge to organize selfmade tour packages, or learn about native gastronomy and access dining experiences cooked by local hosts. 
Figure 2.1: Sharing economy in tourism

Source: Psarros, 2014 \& Botsman, 2014

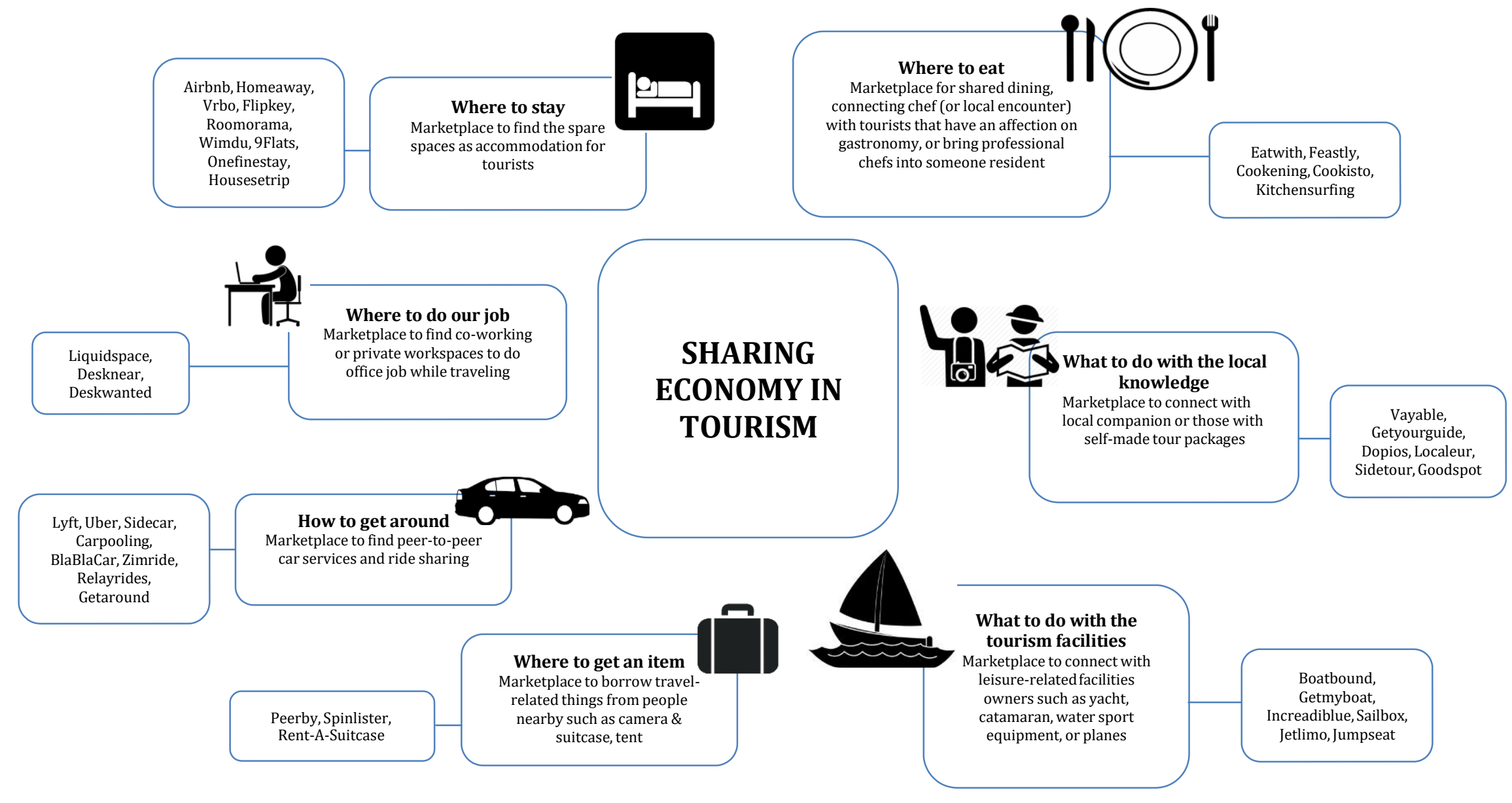


Evidence suggests that sharing accommodation is among the most prominent examples of the tourism-related sharing economy by far (Economist, 2013; Ert et al., 2016). Geerts (2016) classifies types of sharing in accommodation into three categories:

a. Peer-to-peer. In this model the platform allows direct interaction between an owner and a user, or a host and guest. The platform serves merely as a facilitator while communication is made directly between host and guest. Some of the main players in this category are: Airbnb, HomeAway, VRBO, Wimdu and 9Flats (both are German-based), Tujia (China-based), Homestay, Travelmob, Flipkey, and Roomorama.

b. Business-to-peer. This model is very unusual in lodging as it bears some semblance to the traditional accommodation model but is established particularly in respect of bike-sharing and car-sharing, where the platform or business owns bikes/cars and allows peers to share.

c. Peer-to-business-to-peer. In this model the host shares a spare house through the platform/business who works as the middleman. Onefinestay is the key example, as it still serves as an accommodation matchmaking platform, while its local team also prepares the host's home, stocking towels and toiletries in every bathroom, changing the bed sheets, introducing guests to the home and delivering house keys to guests, iPhone for data and local calls, as well as local recommendations.

Nonetheless, the above three different models, collated in the category 'short term rentals' by Geerts (2016), remain on the fringes of the global travel accommodation market. According to Geerts (2016), of the US\$611.8 billion lodging industry, short term rentals accounted for only US $\$ 64.8$ billion, or around $10 \%$, whereas 'hotels' still dominate with a share of around US $\$ 458.4$ billion, or $75 \%$, with 'other lodging' accounting for around $15 \%$. As seen in figure 2.2, luxury and mid-market hotels still dominate the industry in all regions, with Western Europe and North America the main regions for 'short term rentals'. A very promising percentage, however, is shown by Australasia with over a fifth of total sales. 
Figure 2.2: Lodging segmentation by region in 2015

Source: Geerts, 2016

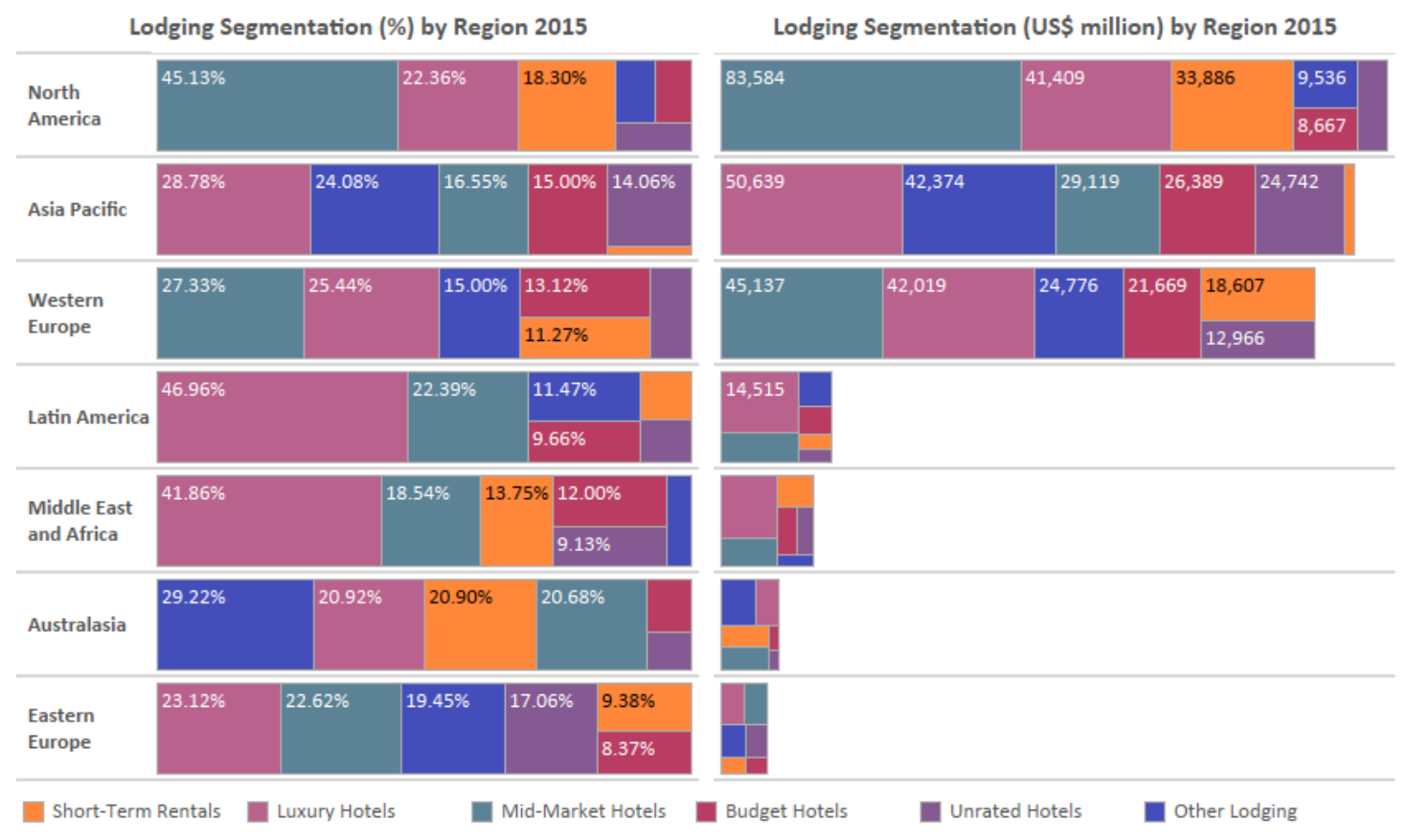

Derived from a scatter plot comparison between domestic-international tourist arrivals and penetration of 'short term rentals' during 2015-2020, Geerts (2016) believes that countries with the largest landmasses, particularly the US, China, and India, will likely have slow future growth in 'short term rentals' despite the considerable increase in tourist arrival. Whereas developed countries such as Japan, Australia, Portugal, and Czech Republic are projected to have substantial additional supply of 'short term rentals', arguably due to high household incomes that influence the ownership of second homes and spare rooms. Indonesia is predicted to have a very minor 'short term rentals' market with a less than $10 \%$ share of total national lodging volume. However, possible changes are expected as Geerts also asserts the potential of the Asia Pacific region mainly due to the increase in household incomes in China and considering the high value of the lodging industry in this region.

\subsubsection{The exponential growth of Airbnb}

As the most researched platform, Airbnb has been demonstrating exponential growth, changing consumption patterns by producing 'network hospitality', where sharing with strangers becomes a direct part of tourism practice, as well as disrupting the existing tourism accommodation industry (Bialski, 2016; Zeryas et al., 2015). From the first 
official founding in mid-2008 until late June 2012, the company booked a total of 10 million nights. In the same time, an average of 38,000 people were using Airbnb listings every night (Airbnb, 2012 as cited in Guttentag, 2015). To date, in eight years of operation, Airbnb has more than two million listings/properties in more than 190 countries and market valuation of US\$13bn in 2014, exceeding the Hilton Hotels and Resort Group with their 610,000 rooms in 88 countries after 93 years of operation, and also the InterContinental Hotels Group, the world largest hotel chain, with 4697 hotels and about 690,000 rooms in nearly 100 countries and market valuation of US $\$ 9 \mathrm{bn}$ (Airbnb, 2016; Arias Sans \& Dominguez, 2016; Botsman, 2014).

Airbnb itself has commissioned a series of impact studies estimating the positive impacts in different countries. In 2013, when the company booked 20 million nights globally and attracted over six million guests, Airbnb recorded $\$ 2$ billion in revenues and created tremendous employment in several big cities such as Barcelona with 4,000 jobs and New York with 4,577 jobs (Euromonitor, 2014). Just recently, their research in Japan counts up a total 221.9 billion Yuan in economic impact, with 21,800 jobs supported as a result of host and guest spending. Interestingly, the study also reveals how the experience of staying with an Airbnb host leads to $79 \%$ of international guests returning to Japan. Furthermore, by spending less on accommodation, these guests can spend more on shopping and dine in local restaurants (Airbnb, 2016a). Similarly, 68\% of guests to Paris reveal how their Airbnb experience made them more likely to return (Airbnb, 2016b).

With regard to the effect on the incumbent lodging industry, Zervas et al (2015) suggest that there is valid statistical evidence to support the view that a significant increment of Airbnb listings leads to Airbnb bookings that finally substitute hotel stays and impact hotel room revenue, specifically for the lower-end hotels due to better price offers. Oskam and Boswijk (2016) also confirm that Airbnb can drive hotel rates and revenues down due to oversupply. However, many believe that international chain hotels are less likely to be impacted due to their systematically preserved standard of services; segmented market, especially for business travelers (and despite the fact that Airbnb has started to tap into this market); large budgets allocated on advertising; and guest loyalty programs (Guttentag, 2015). Other issues with the rapid growth of Airbnb revolve around illegal status; taxation; public safety and quality control; the prevalence 
of non-standardized services; privacy of consumer data; security of transactions; and land use/zoning regulations (Psarros, 2015, Peeters et al., 2015)

\subsubsection{Critical reflection on the development of the sharing economy in accommodation}

Earlier description about the plethora of the sharing economy pinpoints how the sharing economy has a fundamentally different way of capturing value through the benefits of efficient use of resources, relatively lower price, opportunity to engage in intimate involvement with communities, customized products, and many others. However, the potential of massive expansion through such benefits is not without the probability of reversible development. The heavy reliance on social networking might be problematic for the sharing economy, especially in dealing with trusts issues and sharing culture, not to mention the complex challenge of maintaining a sustainable business model (Daunoriene et al., 2015).

As mentioned earlier, the current and future popularity of the sharing economy in accommodation practice is also challenged not only by taxation, housing supply, and legal issues, but also the disruptive effect to traditional accommodation providers. The rise of Online Travel Agencies (OTA) like Expedia for example, has disrupted the longestablished bricks-and-mortar travel agent by capturing an increasing share of the mainstream market, thus giving the traditional enterprises a struggle to survive. By referring to the lodging segmentation graphic shown in diagram 2, one can claim the possibility of the sharing economy in accommodation properties to further disrupt the hotels' segment and eventually dominate the lodging industry given the positive growth of the sector. However, in a world of uncertainties, we can never deny the potential of the opposite possibility, whereby the sharing economy in accommodation is unable to become mainstream and struggles to compete with traditional lodging providers.

Given the above risks and challenges, the future of the sharing economy in accommodation remains uncertain. Although the sharing economy may become increasingly mainstream and lucrative, very limited research and scientific predictions are undertaken to investigate the future of the sharing economy in accommodation, especially in the Indonesian context. As mentioned implicitly in the previous section, academic literature on the sharing economy has already covered the map of current 
knowledge of sharing (Dredge \& Gyimothy, 2015), psychological perspectives (Bardhi \& Eckhardt, 2012; Belk, 2013), impacts on incumbent industry (Guttentag, 2015; Zervas, Proserpio, Byers, 2014), drivers and deterrents of participating in travel-related sharing economy (Tussyadiah, 2015; Hamari, Sjoklint, Ukkonen, 2015; Tussyadiah \& Pesonen, 2016), key drivers, inhibitors and likely future development in collaborative consumption (Barness \& Mattsson, 2016), desirable attributes of shared properties (Tussyadiah \& Zach, 2015), impacts on tourism industry employment (Fang, Ye, Law, 2016), sustainability of sharing business models (Daunoriene, Draksaite, Snieska, Valodkiene, 2015), consumer trust (Ert, Fleischer, Magen, 2016; Finley, 2013), and consumer protection (Koopman, Mitchell, Thierer, 2015; Katz, 2015; Miller, 2015). There are also empirical studies on government intervention and the need for better policies to regulate the sharing economy (Hotrec, 2015; Wosskow, 2014).

The closest comparison to this research is arguably the academic literature written by Oskam and Boswijk (2016) which applies a similar approach of submitting several questions to a group of experts known as the Delphi panel to investigate future scenarios in respect of Airbnb and the impact on tourism, hotels, and city destinations. Oskam and Boswijk's research notifies two key points for future research: firstly, the need to monitor the potential evolution and innovation of Airbnb or other 'network hospitality companies' as it is sensible not to prevent business innovation. Secondly, the need to consider the characteristics of a destination when formulating policies to regulate the likes of Airbnb as there is no "one-size-fits-all" future vision of destination and shortterm rentals. To that end, this research takes into account these two key points as an underlying principal for scenario construction. This research is certainly among the first to discuss the phenomena of the sharing economy in accommodation in Indonesia and Bali in particular, because emerging literatures are limited to the exploration of Indonesia's sharing economy in transportation. 


\subsection{The sharing economy in accommodation in Bali}

\subsubsection{The sharing economy in accommodation in Bali}

Already mentioned in chapter 1, sharing in the accommodation sector in Indonesia has not obtained similar growth, broader publications, and academic attention in comparison with the sharing economy platform in transportation (Bohang, 2016). Currently Airbnb has begun to emerge in only a few provinces like Bali and Jakarta. According to Airdna (2016), Bali had quite a large number of active rentals (21,468 in mid-August 2016) located mainly in the southern part of the island where the development of tourism infrastructure is focused (see Figure 2.3).

Figure 2.3: Distribution of Airbnb active rentals in Bali

Source: Airdna, 2016

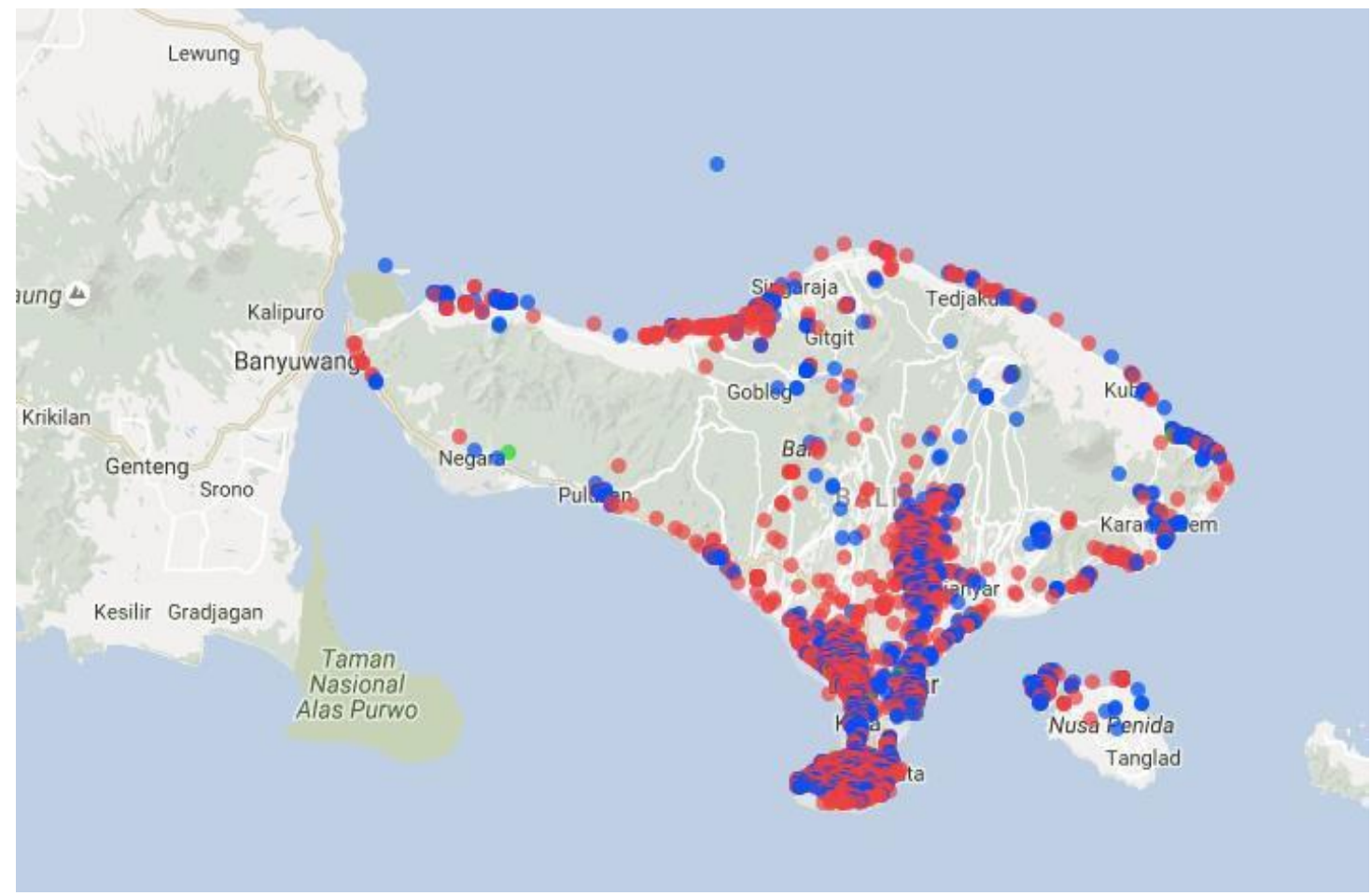

Furthermore, the other sharing platforms, namely Roomorama and HomeAway, have relatively fewer users. Despite these facts, the practice of a customer-to-customer $(\mathrm{C} 2 \mathrm{C})$ business model on an online basis where buyers and sellers meet to trade second-hand and underutilized goods is growing tremendously through the likes of Tokopedia.com or OLX.co.id (Darmawan, 2016). This growth indicates positive acceptance toward online-based transactions, which make the climate of the sharing economy in Indonesia, the accommodation sector included, likely to be even more vibrant in the future. 


\subsubsection{The development of homestay in Bali}

Referring to Law Number 10 of 2009 concerning tourism, Indonesian accommodation enterprises are mainly classified into hotels, youth hostels, villas, homestays, and other minor types of accommodation (such as motels, bungalows, and cottages). Further, hotels themselves are categorized into star hotels (comprising 5 star hotels to 1 star hotels) and non-star hotels.

To share one's own home or spare room to tourists/non-family members is a longestablished practice in tourism, mainly popularized by the 'homestay'. Indonesian homestays, Bali's in particular, are closely related to village-based tourism as the 'shared' houses are situated in traditional villages in which villagers live, sharing positive dialogue and their cultural norms with tourists (Sutawa, 2012). Homestays are believed to be an indigenous response to the pervasive development of enclave resorts and international chain hotels throughout Bali, as well as communities' means of benefiting from the economic opportunities that tourism has brought. According to the ethnographic study by Wall and Long (1993), usually there are a number of homestays within one neighborhood in a village, along with restaurants, stores and warung (food stalls). Most of them are owned and operated by resident families in which women and children are usually responsible for cooking, cleaning, laundry, and shopping. The study also reveals that the existence of Balinese homestays is made possible partly by the structure and layout of Balinese housing compounds whose adaptability has been proven in changing circumstances to supplement tourists' uses. Unlike Western houses, the Balinese house is rather a rectangular walled enclosure, with considerable open space inside, and bale, raised pavilions with specific functions such as sleeping rooms for parents or workplaces. Visiting tourists usually occupy one whole house or modified bale. During their stay, tourists are included in ceremonies and participating in dance performances. 
Figure 2.4: The Bale of Balinese homestay

Source: personal photo

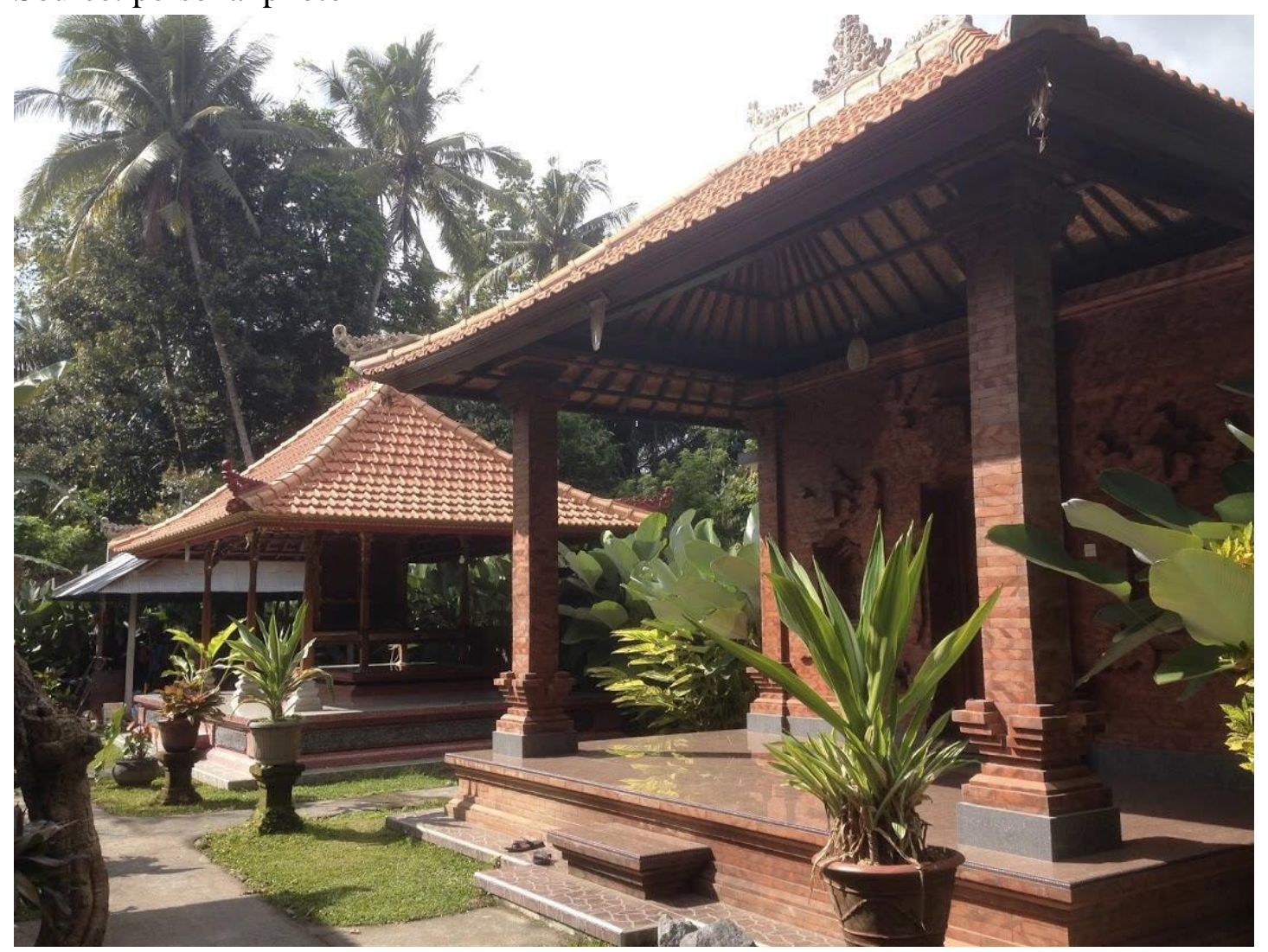

Over the years, central and local governments have been expanding their attention towards the enhancement of Balinese homestays, partly due to the incremental increase in homestays in Bali (see table 2.2).

Table 2.2: Number of homestays and rooms in Bali Source: Bali government tourism office, 2015

\begin{tabular}{|c|ccccc|}
\hline & $\mathbf{2 0 1 0}$ & $\mathbf{2 0 1 1}$ & $\mathbf{2 0 1 2}$ & $\mathbf{2 0 1 3}$ & $\mathbf{2 0 1 4}$ \\
\hline $\begin{array}{c}\text { Number of } \\
\text { homestay }\end{array}$ & 996 & 1.016 & 1.025 & 1.259 & 1.644 \\
\hline Room & 4.445 & 4.478 & 4.642 & 5.580 & 7.128 \\
\hline
\end{tabular}

A ministerial decree regarding the standardization of homestays was introduced in 2014 to give homestay owners some sort of knowledge about what the minimum requirements of homestays are. To tackle the lack of managerial ability and increase understanding of the basic principles of hospitality, the Ministry of Tourism and local government conduct regular training for homestay owners. Lastly, in cooperation with 
the Ministry of Public Work and Public Housing and the national bank, the Ministry of Tourism commenced a homestay architectural design competition followed by establishing 100,000 homestays in 10 national priority tourism destinations, but Bali is not one of them.

\subsubsection{Critical reflection on Indonesia accommodation industry}

Uncertainties and contingencies are common in Indonesia's accommodation industry since volatile political decisions play a decisive role in shaping the general tourism industry. There are cases when radical changes by way of political decisions have put tourism and the accommodation industry into unfavorable situations. For example, in the early period of his incumbency in 2014, the newly elected president of Indonesia, Joko Widodo, banned civil servants from hosting meetings in hotels in order to reduce the budget deficit. The ban was repealed several months later and successfully saved the government 24 trillion rupiahs, equivalent with $\$ 1.9$ billion, on the 2015 budget, but has caused a severe occupancy drop to accommodation with MICE facilities (Brummit et al., 2015).

The collaborative work to establish more standardized homestays is also deemed political as its continuity is questionable. However, if this effort remains a national priority, while real time technologies and the sharing economy platform are introduced to wider Balinese residents, the way in which homestays are promoted and designed in the future will definitely change. Emphasizing these uncertainties and probabilities, the researcher is urged to highlight that in this sector, the further we look into the future, the more an increased degree of uncertainty and lack of direction prevails, hence the urgency for future study and the reason to use a multiple future perspective.

\subsection{Conclusion}

This chapter briefly outlined the development of the sharing economy by specifically presenting the progression of the sharing economy in tourism and accommodation. The sharing economy in accommodation in Bali and the unique traits of Balinese homestay are also briefly portrayed, regardless of the limitation on data availability. Additionally, table 2.2 in this chapter also indicates an accretion of the number of homestays and rooms, along with encouraging intervention from government. The key learning points from tracing the current situation are that today the sharing economy in accommodation 
in Bali is faced with an uncertain future through the impacts of various determinants, globally and nationally. Therefore, it is not enough for national and local stakeholders to construct a simple hypothesis about the most favorable future of the sharing economy in accommodation in Bali and build the strategic development plan around it. The accommodation sector needs to undertake a comprehensive, multiple option, and forward-looking research to better understand the future, which will be discussed in the following chapter. 


\section{Chapter 3}

\section{Research Methodology}

\subsection{Introduction}

There is a clear lesson learnt from chapter 2 that the future of the sharing economy in accommodation in Bali remains uncertain, faced with challenges and determinants in both national and global level. To begin with, it is important to pinpoint the paradigm of this research as it declares the position and comprehension of the researcher on the topic being studied, outlining the purpose of research, its methodology and its application rules. In the realm of future study, futurists have already established some sort of 'distinctive' paradigms of future studies in order to go beyond the 'traditional' research paradigm and to capture thoroughly the unique embedded traits in the future research. Mannermaa (1991) proposes one of the most solid presentations by dividing the paradigms in future studies into three approaches:

a. The Descriptive Paradigm, which refers to objective forecasting, based on the consistent repetition of trends from the past. The future is seen as both static and predictable, thus dominant quantitative methods are used.

b. The Evolutionary Paradigm, which refers to understanding the futures as a turbulent and complex world with emphasis on acknowledgement of the evolutionary laws and phase of chaotic bifurcation.

c. The Scenario Paradigm, which refers to perceiving the future as a state that is not completely predictable, therefore a number of alternative sketches of the future, and paths to them, are constructed in order to help decision-makers imagine what lies ahead. In this paradigm the methodological degree of freedom is much greater.

Whilst descriptive paradigm focuses only on objective trends, the evolutionary paradigm never became mainstream because making future assessments in bifurcations and to forecast in linear phases is challenging and problematic (Borjeson et al., 2006). Furthermore the supporter of the evolutionary paradigm was unable to 'develop models which would have attached the discoveries of complexity research to future research' (Kuosa, 2010). Consequently, this research falls into Mannermaa's the scenario paradigm because the researcher agrees with the arguments of Erik Karlsen et al (2010) 
and Holden (2005) that the future is not to be described in objective terms simply because it is a different land. It is not transparent and lucid, it does not exist in a material or concrete sense but is constantly forming in many complicated interactions, and the fact that physical time travels to obtain a precise portrait of the future state may never be possible. Jim Dator's "First Law of Futures" (1995) also emphasizes 'the future cannot be "predicted" but alternative futures can be "forecasted" and preferred futures "envisioned" and "invented"-continuously'. Furthermore, if a closer look at the scenario paradigm is taken, one can conclude that it is completely consistent with the characteristics of foresight, just as the descriptive paradigm is to forecasting. Foresight itself is defined as an approach to make sense of the time ahead which takes into account broader uncertainties and irregularities based on the assumptions that patterns and trends from the past cannot be extrapolated linearly into the future because the complex and changing world will always bring about disruptions and discontinuities to current trends (van Asselt, 2012). In contrast, forecasting assumes continuity and a linear way of thinking so that contemporary occurrences can equally reoccur in the upcoming periods (Postma, 2013). To that end, it is decided to conceive of the future as the irregular and unpredictable outcome of multitude interactions between complex agents. As a consequence, this research serves as an attempt to disentangle the complexity of future through fantasy, self-conscious reflexivity, and empirical knowledge that is produced in all other disciplines, while time is treated as subjective and unpredictable (Kuosa, 2011; Cunha, 2002).

Applying the derived paradigm into the axiomatic ontologies and epistemologies of a 'conventional' research paradigm, the ontology of this research therefore, can be described as belonging to constructivism. The ontology of constructivism is rooted in the belief of multiple truths obtained by putting together local and specific personal realities (Lincoln et al., 2000). Therefore, this research is about exploring multiple realities in the form of multiple possible futures of the sharing economy in accommodation in Bali. It is not an attempt to predict the future with one accurate future forecast but rather an exploration of the wealth of thinkable and probable futures (van Asselt, 2012). The output of research does not provide a single identifiable transformation of the sharing economy in accommodation in Bali by 2030 but instead a spectrum of four alternative scenarios, each of which portrays different depictions of future transformation that are acquired by interpreting the creative and lateral thinking 
of participating experts.

Consistent with the ontology, this research is thus based on a constructivism epistemology. The epistemology of constructivism is grounded in the general notion that knowledge is an accumulation of subjective construction of individuals, and is the outcome of co-creation and negotiation among research participants (van Asselt, 2012; Postma, 2013). Therefore, the knowledge sought by this research is not a 'ready-made' entity, nor 'waiting to be discovered and collected'; instead the future portraits of the sharing economy in accommodation in Bali are co-constructed and are shaped by subjective assumptions and imaginations from each participating expert, identified as a 'panelist'. With the intervention of the researcher in interpreting panelists' knowledge, surveying the literature, and synthesizing these materials into a range of scenarios about the future of the sharing economy in accommodation in Bali, all research-related parties are co-constructing the very output of this research. Thus, having a broad diversity of panelists with different roles and social orders in society is important to give a breadth of multiple perspectives, in order to capture the complexity of issues being studied. In this research, expert knowledge from a broad range of selected panelists are explored through interviews in order to understand how change is happening and to elicit the drivers of change by which four future scenarios are constructed, whereas projective knowledge is drawn out to understand how change will happen and to confirm the final scenarios. Both sets of knowledge are subjective in the sense that they comprise experts' personal beliefs based on the personal experience of individual experts (Drescher et al., 2013). Further, given that the construction of realities in constructivism must depend on some form of consensus (Lincoln et al., 2000), some stages of data collection in this research acquire a collective voice and consensus through the iteration of questionnaires. The questionnaires are of use to help the researcher in making sense of the panelists' subjective thinking by ranking the drivers of change, and also serve as an instrument to obtain consensus among panelists by asking them to give final agreement or disagreement regarding the backbone of scenarios.

Considering the ontology and epistemology of this research, the researcher deploys scenarios to present probable futures as the answer to the research question. Scenarios are built through scenario planning, the well-tested technique within future studies that help this research to stretch out a space within which future development of the sharing 
economy in accommodation in Bali will occur. However, in this research scenario planning is combined with the Delphi method to acquire stronger validity and consensus among participating panelists. It is a triangulation method. Using the combination of scenario planning and Delphi method is relevant not only because it produces multiple pictures/stories of alternative futures but it also embodies collective voices. To conclude, the whole process of research embodies the character of inductive reasoning, or the bottom-up approach that moves from specific observation to broader generalization, the details of which will be discussed in the following section. This research follows the inductive approach as it begins with a series of specific observations on literature and intensive interviews, followed by detecting regularities and patterns in the form of drivers of change leading to the formulation of general conclusions represented by multiple scenarios (Trochim, et al., 2015).

This chapter has two objectives. The first is to familiarize the reader with the research method of scenario planning, the Delphi technique, and Delphi-based scenario planning. This is achieved by providing a brief overview of scenario planning, how scenario planning has been used in the tourism field, scenario planning steps, a brief overview about Delphi method, and the process of submerging the two approaches. The second objective is to explain the conceptual framework used in this research, which adopts the inclusion of Delphi techniques into scenario planning, step-by-step.

\subsection{Literature Review on Research Methodology}

\subsubsection{Scenario Planning}

Discussion about scenarios has already been touched on section 3.1. Scenarios are considered a valuable tool to help organizations to be well prepared, innovative, and flexible (Hiltunen as cited in Amer et al., 2013). Failure to be prepared for multiple plausible futures may fail individuals, business, or even countries looking to cope with surprising risks and unpredictable occurrences (Bishop et al., 2007). A scenario can be defined as "the set formed by the description of a future situation and the course of events that enables one to progress form the original situation to the future situation" (Godet, 2000, p.11). Therefore, the scenario is not a future reality but a way of foreseeing future depictions, challenging current paradigms of thinking, and only meaningful when its results are adopted in real actions. In other words, it is a mental model representation of the future held by a research participant. 
Scenario planning, on the other hand, may be defined as a disciplined methodology used for constructing multiple scenarios. It is a decision-making utility, and is applicable to planning needs that have been widely used by corporations and, in many cases, applied successfully at national level (Chermack et al., 2001). The ability to portray future overall environments and connections between trends has made scenario planning really popular among large size companies and capital intensive industries such as aerospace and petroleum (Linneman and Klein, 1983). Nevertheless, Gossling and Scott (2012) emphasize that scenario planning has continuously received enormous attention from government and international organizations such as the UN and IMF for anticipating a range of global issues including energy, demography, economic development, technology, biodiversity and ecosystem change, transportation mobility, agriculture and food production, and water security.

Looking back to the history of scenario planning, Sondeikjer (2009) pinpoints the substantial shift from mainly predicting the future in the 1950 s to exploring and anticipating the future in 1973, from a quantitative approach toward one more qualitative and process-oriented (Mietzned \& Reger, 2005). However, it has to be said that both quantitative and qualitative approaches have their own strengths, and that, when used together, the one complements and strengthens the other (Amer et al., 2013).

\subsubsection{Scenario Planning in Tourism}

One of the sectors that is highly affected by uncertainties and changes is tourism due to its dynamic and multi-sector nature. The interdependence of the tourism industry with many other sectors including the world's economies and transportation systems has made tourism a very sensitive industry to global changes and issues (Hall, 2010). The issues around climate change and $\mathrm{Co} 2$ emissions, oil depletion and prices, severe terrorist attacks and individual security, and downturn in wealth per capita, which influence the presence of accessible transportations and propensity to travel, could situate global tourism on the brink (Page et al., 2010). On the other hand, emerging social demographics such as the new middle-class of China, and the fast growth of 
information and communication technology (ICT) have been changing the landscape of tourism and providing potential for future growth (Yeoman, 2012).

The unique interconnection and complexity of tourism has made its future even more challenging to foresee. The use of future studies in tourism is therefore increasingly important for stakeholders, in order to understand how tourism might evolve in the decades ahead, and to cope better with uncertainty. In fact, scenario planning has been used for destination planning for at least 30 years (Goessling and Scott, 2012). Similar to the progression of general scenario planning described earlier by Sondeikjer, the first generation of scenarios in tourism was used to forecast developments with an emphasis on econometric models, demand forecast, and predicting the impacts of tourism (Getz, 1986). More recently, the newest generation has incorporated an integrative approach which combines qualitative and quantitative methods, complex scenario-building, quite often uses online-based tools (Goessling and Scott, 2012), and sometimes with the help of modern and innovative assisting tools, such as Lego Serious Play (LSP) or fictional personas (Tuominen \& Ascencao, 2016). Scenario planning in tourism has stretched from transportation and tourism (Page et al., 2010), national parks (Daconto \& Sherpa, 2010), tourism workforces in Asia Pacific (Solnet et al., 2014), demographic and social change (Yeoman et al., 2010), impacts of war (Yeoman et al., 2005), hotels and hospitality (Lub et al., 2016; Tuominen \& Ascencao, 2016), and local community transformation (McLennan et al., 2012).

\subsubsection{Scenario Planning Steps}

In order to obtain plausible scenarios, a systematic procedure of scenario planning needs to be undertaken. Literature reveals numerous scenario-building methods that have been developed as the popularity of scenario planning has become expansively widespread. Each of the most cited authors and practitioners regarding scenario development has his/her own perspective; most professional futurists and consultants also have favourite approaches that they have honed over time (Bishop et al., 2007). Schwarts (1991) explains eight steps to developing scenarios with an emphasis on presenting a core of logic to scenarios in the themes and plots of the story. Schoemaker (1995) proposed a comprehensive ten steps and highlighted putting positive and negative trends in segregated clusters in order to construct initial scenario themes. Bishop et al (2007) propose a generic approach in constructing the scenarios, which 
they further explore in their book Thinking about the Future (2013), as shown in the table 3.1.

Despite contestation of the methods, in general these scenario-building techniques embody key steps that involve: 1) defining the issues; 2) identifying key drivers, constraints, and other important issues; 3) ranking those drivers as a foundation to construct several different pathways (Amer et al., 2013).

Table 3.1: Generic scenario planning approach

Source: Bishop et al., 2007

\begin{tabular}{|c|l|}
\hline Step & \multicolumn{1}{c|}{ Description } \\
\hline Framing & $\begin{array}{l}\text { This step aims to define the scope and focus of work in order to shape the project } \\
\text { that relevant to the audience, the rationale, and the purpose. The outcome of this } \\
\text { process is a project plan. }\end{array}$ \\
\hline Scanning & $\begin{array}{l}\text { It is the stage where scanning the information that includes the system, history, } \\
\text { and context of the issues taking place, in order to pinpoint the trends and driving } \\
\text { forces that may structure the future. }\end{array}$ \\
\hline Vorecasting & $\begin{array}{l}\text { The purpose of this step is to create alternative futures by integrating key } \\
\text { drivers, uncertainties, implications, and outcomes. The essence of the forecast } \\
\text { encompasses generating the widest range of creative possibilities. }\end{array}$ \\
\hline Planning & $\begin{array}{l}\text { If the scenario is to make a better decision to face future uncertainties, then it } \\
\text { has to be interpreted into achievable strategies. This step is about evaluating } \\
\text { and reviewing on each scenario with opportunity to propose possible strategies }\end{array}$ \\
\hline Acting & $\begin{array}{l}\text { This step is about transitioning preferred future into a decisive strategic plan, } \\
\text { which lays out a path to that future with the details on resource managements. }\end{array}$ \\
\hline $\begin{array}{l}\text { Communicating and implementing the plans into concrete actions. This step } \\
\text { consists of continuous evaluation and scenario development repeat whenever } \\
\text { new issues and challenges arise. }\end{array}$ \\
\hline
\end{tabular}

\subsubsection{The Delphi Method}

Academic researchers point out that the Delphi method, a proven tool in information system (IS) research, can also be applied in forecasting (Okoli \& Pawlowski, 2004). Linstone and Turoff (1975, p.10) define Delphi as "a method for structuring a group communication process so that the process is effective in allowing a group of individuals, as a whole, to deal with a complex problem". It is a virtual meeting of experts (known as 'panelists') gathered to give solutions and to harmonize opinions on issues at stake, where each member of the panel is given the opportunity to respond to others' views and to assess the group judgment, but each individual response is kept anonymous (Okoli \& Pawlowski, 2004). Another distinct characteristic of Delphi as mentioned by Iqbal and Pipon-Young (2009) is the fact that it is conducted across a series of two or more sequential phases known as 'rounds'. 
The Delphi method is widely popular and survives because it is relatively cheap and offers the possibility to collect the information in a quick way, especially when shortages of data and time are an issue (Bell, 2011). Unlike other similar highperforming group decision analysis methods such as the nominal group technique, Dalkey and Helmer (1963) highlight that Delphi does not require the experts to meet physically, which is desirable, particularly if the panel is composed of experts residing in separated continents or regions. The absence of physical meetings allows experts to respond to another's view but avoid direct confrontation because the method produces a tendency to defend notions that have been previously stated and prevent the inclusion of novel ideas.

Okoli and Pawlowski (2004) and Nowack et al (2011) have extended the general function of the Delphi method into three functions: (1) Brainstorming for important factors, also known as the idea-generation function; (2) Narrowing down the original list to the most important, known as the consolidation function; (3) Ranking the list of most important factors known as the judgment function. The functions may be more explained in more detail as follows:

- The idea generation function

This function solicits experts to outline as many issues as possible relating to the objective of research. For this phase, it is fair to treat experts as individuals, not panels. Furthermore, in the context of scenario planning, the idea-generation function means the exploration of drivers of change and creative ideas related to the future of the research object.

- The consolidation function

The goal of this function is to understand the level of importance of each factor and eliminate the least important factor; accordingly, a manageable number of factors can be obtained.

- The judgment function

Despite the lack of rigorous procedures in the literature, it is fair to say that the underlying principal of this function is to sort the factors or options in order; 
therefore the top-ranked can be identified. It is commonly understood that the topranked has the highest priority to put attention on.

\subsubsection{Delphi-Based Scenario Planning}

With regard to scenario planning, the Delphi method is able to tackle the main limitations of the scenario-building process, which are the strong subjectivities of scenario planners. In scenario development, particularly in selecting the most impactful and uncertain drivers of change by which the scenario axes are formed, a lack of consent from all scenario-building participants occurs in favor of epistemological arguments from the scenario planner to legitimate the drivers' selection (van't Klooster \& van Asselt, 2005). Also, the personal opinion of the scenario planner usually dominates while sketching and narrating the scenarios. As an antidote to that limitation, Dalkey and Helmer (1963) point out the capacity of the Delphi method to produce a group decision from experts' judgments with a strong consensus among them that is indeed superior to the subjective conclusions made by individuals.

In an attempt to further improve the quality of the scenarios, recent studies have been endeavoring to combine scenario planning and the Delphi method. Nowack et al (2011) have constructed a combination of both methods with an emphasis on increasing creativity and credibility. The combination is built upon the generic approach in scenario construction by Bishop et al (2007) already discussed in earlier section (see table 3.1).

Figure 3.1: Integration of the Delphi method within the generic scenario planning approach

Source: Nowack et al., 2011

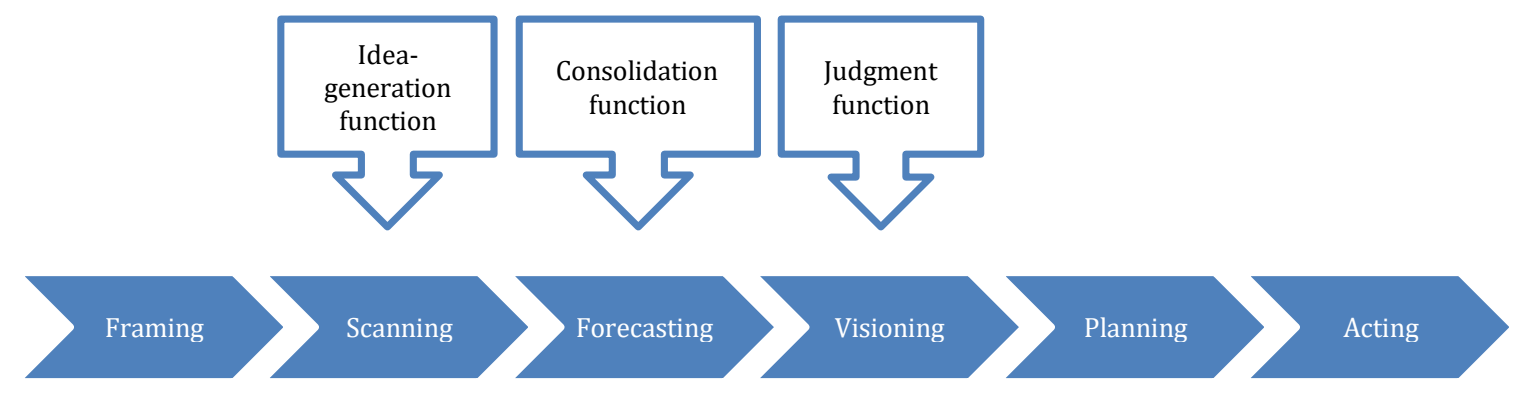

As seen in figure 3.1, this approach invites the creativity of experts to explore the possible futures and challenges of an issue via the idea-generation function on the 
scanning step, and to further solidify their ideas through feedback from other experts. In the forecasting step, the approach induces the experts to objectively evaluate the drivers to be included in further analysis, which represents the consolidation function. Subsequently, in the visioning step, or when the set of scenarios is prepared, experts are invited to give their evaluation and review each scenario with the opportunity to propose possible strategies through the judgment function of the Delphi method. It is important to underline that the judgment function in Nowack et al (2011)'s integration model has shifted from its original function, as to rank factors in order to resemble the idea-generation function by seeking experts' input and creative ideas on scenario evaluation.

In a slightly modified approach, Solnet et al (2013), in research about the future of the tourism workforce in Asia Pacific, establish three consultation rounds of Delphi format after the research framing process is completed.

- The Delphi round one corresponds to the idea-generation function that strengthens the scanning step because it generates opinions and feedback from expert panellists regarding the influential factors initially proposed by the scenario planner. Using the online survey and descriptive statistics, this round also asks panel members to shorten the long list of driving factors into four "key trends" which denote characteristic of the consolidation function

- The Delphi round two represents the judgment function since it requests the panellist to rank the likelihood of four key trends on a scale of 1 (least important) to 7 (most important), using the online survey, to determine the two most important trends by which the four-scenario matrix is developed.

- The Delphi round three is intended to seek a consensus in the ranking of the two most important trends by asking all panellists to agree or disagree on selected key trends, so they can be placed in the axes of the scenario planning matrix.

As acknowledged by the authors, they seek the guidance from the expert panel to counter the limitation in scenario planning methodology, which relies heavily on personal interpretation. Having utilized the online questionnaire and descriptive statistics, the authors have acquired a collaborative agreement in selecting the two most important drivers, used as a backbone of scenario construction. In this sense, they have minimized subjective decisions and attained greater objectivity. However, the authors 
alone, without the participation and input of ideas from experts, complete the interpretation of each quadrant of the scenario matrix. Here authors might miss the creativity benefits and the opportunity to eliminate the biases on each quadrant provided by the experts.

\subsection{Research Methodology}

The second half of this chapter concentrates on the presentation of this study adopting the Delphi-Based Scenario planning steps. The aim is to demonstrate each stage of the approach with a specific focus on data collection. This will familiarize the reader with the approach used in this research and guide them into the subsequent chapters.

Figure 3.2: Delphi-Based Scenario Planning Steps

Source: Adopted and modified from Nowack et al., 2011 and Solnet et al., 2013

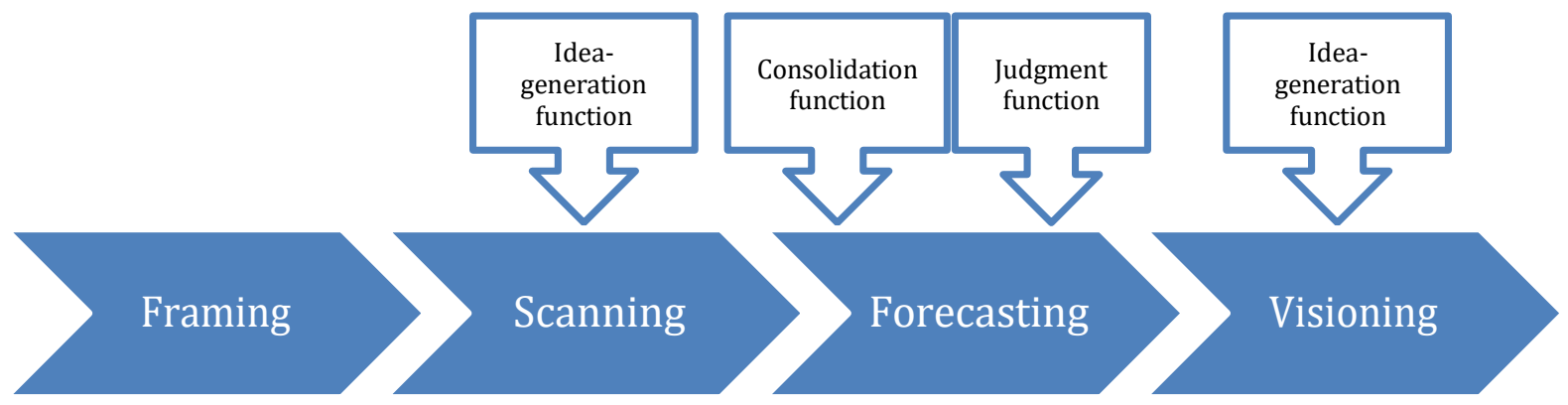

Having reviewed available literature on related fields, as already discussed in earlier sections, particularly the methods used by Nowack et al (2011) and Solnet et al (2013) in section 3.2.5, a modified integration of the Delphi method within the scenario planning approach is depicted in Figure 3.2. Considering the desired outcome of this research, to gain an insightful understanding into what the sharing economy in accommodation in Bali will look like in 2030, it was decided not to include the planning and acting steps as they consist of very technical aspects of resource management and implementation strategy. Whilst the inclusion of the two steps is necessary when the research aims to respond to policy planning concerns and to achieve specific targets (normative scenarios), omission of those is permissive when the utmost outcome is to present a range of exploration and alternative futures (Mietzned \& Reger, 2005).

Further, following the established process for incorporating the Delphi method into scenario planning (Nowack et al., 2011; Solnet et al., 2013), the researcher decides to 
invite the participation of each expert panelist in almost every step in the hope that it will emphasize the objectivity and creativity of the scenario from multiple points of view. Therefore, along the scenario construction process, four rounds of Delphi are undertaken in an appropriate format to denote each function:

- First round of Delphi represents the idea-generation function in the form of panel interviews to acquire key drivers of change

- Second round of Delphi represents the consolidation function in the form of questionnaires to rank the drivers and eliminate the least important

- Third round of Delphi represents the judgment function in the form of questionnaires to sort the remaining drivers in order and to select the two top-ranked drivers as the backbone of scenarios

- Fourth round of Delphi represents the idea-generation function in the form of second panel interviews to review initial scenarios and propose ideas and creativity for scenario enrichment

\subsubsection{Framing}

This phase aims to outline the fundamental scope of research including research objectives, research questions, and desired contribution, some of which has been explained in the introduction section. It is important to underline the boundary of the research venue that focuses in single location: Bali, Indonesia considering the reasons explained in chapter 2 regarding the number of active rentals.

\subsubsection{Scanning}

The purpose of this phase is to identify trends relating to the issues discussed in order to come up with an amalgam of drivers of change that may lead to alternative future sketches. In this phase, the idea-generation function is applied by conducting expert interviews with panelists in two locations: Jakarta and Bali, in the form of semistructured interviews. The use of semi-structured interviews was chosen because it offers flexibility with conversation-like style yet has a list of themes and questions to focus the interview, therefore giving the interviewer a broader scope to explore particular information through reciprocity and exchange issues (Jennings, 2005). 


\subsubsection{Selection of panelists}

As discussed in chapter 2, the sharing economy in accommodation in Indonesia and Bali in particular is a new phenomenon. Therefore it was problematic to find panelists with specialties in the sharing economy in accommodation or its impacts on local hotels or destinations. However, based on key micro issues relating to the topic and in combination with advice from the researcher's supervisor, the researcher carefully proposed 20 panelists who could help identify drivers of change that might shape the future scenarios. The nominated panelists came from different backgrounds. The aim was to get on board as many of the proposed panelists as possible in order to capture diversified knowledge; accordingly, solid foresight of the future of the sharing economy in accommodation could be developed.

Once permission to conduct fieldwork and ethics approval number 0000022918 from the ethics committee at Victoria University of Wellington were acquired, each of the nominated panelists were invited via email to participate in the research. The formal invitation included a brief covering the background, aims, and purposes of research, the reason why the person was selected, also the requirements expected of them. Proposed dates and the researcher's email address was also included to give them some sort of direction as to when the interview would take place and how to get in touch with the researcher to negotiate the schedule. A gentle remainder email was sent out after a week if the researcher did not receive any reply or feedback. Direct calls through online instant communication was made if further responses were not forthcoming, to confirm whether or not they would participate in the research.

\subsubsection{Fieldwork}

During two and a half months of fieldwork (June to early September 2016) in Indonesia, the researcher mainly stayed in Jakarta but travelled twice to Bali. Jakarta is the capital of Indonesia where central government offices are situated, as well as international institutions and many of business headquarters. Bali, on the other hand, is the research venue where the sharing economy activity takes place. 


\subsubsection{The First Round of Delphi (First panel interview)}

Out of the proposed 20 panelists, the researcher was able to undertake the semistructured interviews with 14 panelists composed of 7 panelists residing in Jakarta, 5 residing in Bali, and 2 overseas panelists in Singapore and The Netherland, respectively. The panelists are listed in the table below:

Table 3.2: List of panelists

\begin{tabular}{|cl|}
\hline No & Panelists \\
\hline 1 & Senior official of tourism destination and tourism industry, Ministry of Tourism \\
\hline 2 & Senior official of tourism industry, Ministry of Tourism \\
\hline 3 & Senior official of infrastructure development and the ecosystem, Ministry of Tourism \\
\hline 4 & Senior official of tourism investment, Ministry of Tourism \\
\hline 5 & Senior professor in international economics \\
\hline 6 & Senior official of informatics application, Ministry of Communication and Informatics \\
\hline 7 & Head of research and development for a Bali local government \\
\hline 8 & Director of public policy for Asia Pacific of a sharing economy platform \\
\hline 9 & Executive director of a hotel association \\
\hline 10 & Chairman of a MICE association \\
\hline 11 & Macroeconomics and fiscal management global practice of an global financial institution \\
\hline 12 & Director of the research center of a hotel school in Netherland \\
\hline 13 & Top Airbnb host in Bali \\
\hline 14 & Top Airbnb host in Bali \\
\hline
\end{tabular}

Each interview varied between 30-60 minutes. All the interviews were conducted in face-to-face format, whereas overseas panelists were contacted through Skype and Google Hangouts. Despite the limitation of online interviews, which hinder the researcher to actively and directly engage with the interviewee's body language and expression, both online interviews were successfully accomplished without any technical issue. At the beginning of all interviews, panelists were given a consent form to sign, thus with their permission the interviews were all digitally recorded.

\subsubsection{Interview questions}

In order to comprehend the core essence of the research objective, all interview questions were structured in the same way: panelists were asked to reflect upon the upward growth of nationally-known sharing economy platforms such as Gojek and Uber and to interpret the phenomena and its features in their own language, the pivotal changes in Indonesia and Bali since the 1990s, the status-quo of the sharing economy in accommodation in Bali, the key drivers occurring in Bali society, the key uncertainties and unusual events, and the envisioning of the future development of the 
sharing economy in accommodation in Bali; but all in regards of their own field of expertise (see Appendix 1 for a brief extract of interview questions). Whilst questions related to the key drivers and key uncertainties encouraged panelists to analyze the pattern of trends or unseen opportunities and threats that might be influential, questions regarding the future allowed panelists to be visionary and creative in order to highlight their personal views of possible future scenarios. All the information from this phase were recorded and stored because it would be of help in making sense of the scenarios in the later stages.

\subsubsection{Transcriptions}

Transcribing the interviews is important not only because it is part of the learning process, but also to keep track of what each specific panelist had to say about certain topics. Further, a panelist's key phrases are used as evidence of the drivers of change and can also be used to supplement the discussion in the later stages. During a three- week period all interviews in the first round were manually transcribed.

\subsubsection{Identification of drivers of change}

After transcribing all interviews in the first round, the next step was to identify a shortlist of drivers of change highlighted by panelists. This began with summarizing each transcript and adding all drivers together. Eventually the researcher ended up with a longlist of 47 drivers of change, which, according to the panelists, might shape the future of the sharing economy in accommodation in Bali. Subsequently, similar drivers of change were clustered together and designated an overall/representative key headline and a few key points in order to briefly explain what that driver encompassed (see table $3.3)$. 
Table 3.3: The shortlist of drivers of change

\begin{tabular}{|cl|}
\hline No & Drivers of Change \\
\hline 1 & Ubiquitous Internet \\
\hline 2 & Indonesia as a developing economy \\
\hline 3 & Smart technologies domination \\
\hline 4 & Political decision related to the sharing economy in accommodation \\
\hline 5 & Domination of Generation Y/Millennial Generation \\
\hline 6 & Infrastructure development \\
\hline 7 & 'Living like a local' tourist \\
\hline 8 & Innovation of sharing economy in accommodation platform \\
\hline 9 & Variety of low cost airplanes \\
\hline 10 & Cultural heritage of Bali \\
\hline 11 & Oversupply of hotel rooms in Bali \\
\hline 12 & Abundance of idling capacity in Bali \\
\hline 13 & The disruptive innovation of the sharing economy in accommodation \\
\hline 14 & Popularity of reputation and rating system \\
\hline
\end{tabular}

\subsubsection{Forecasting}

\subsubsection{The Second Round of Delphi (First Questionnaire)}

Shortly after acquiring the shortlist of drivers of change, a questionnaire based on the shortlist was prepared. The questionnaire aimed to narrow down the shortlist into four key drivers of change remaining for the next round. On a rating scale of 1 to 7 , with 1 being "extremely unimportant", 4 being "neutrally important, and 7 being "extremely important" the questionnaires asked panelists to rate how important each of the 14 drivers of change in influencing the future of the sharing economy in accommodation in Bali. Panelists were also invited to suggest corrections on wording that might more represent the core essence of drivers of change. Two methods were applied in distributing the questionnaires due to financial reasons. Printouts were handed to each panelist residing in Jakarta, while online questionnaires were sent out to each panelist living in Bali and overseas. Owing to time constraints, the researcher set out a time limit of one week starting from the day it was disseminated in order to give proportional time for the following phases. 
Table 3.4: Ranking of the importance of drivers of change

\begin{tabular}{|c|c|c|c|c|}
\hline Rank & Drivers & Sum & $\begin{array}{l}\text { Mean } \\
(n=12)\end{array}$ & $\begin{array}{c}\text { Std. } \\
\text { Deviation }\end{array}$ \\
\hline 1 & Ubiquitous internet & 82 & 6.83 & 0.37 \\
\hline 2 & Smart technologies domination & 79 & 6.58 & 0.78 \\
\hline 3 & Infrastructure development & 75 & 6.25 & 0.78 \\
\hline 4 & Cultural tradition of Bali & 75 & 6.25 & 2.14 \\
\hline 5 & Popularity of reputation and rating system & 74 & 6.17 & 0.9 \\
\hline 6 & $\begin{array}{l}\text { Domination of Generation Y/Millennial } \\
\text { Generation }\end{array}$ & 74 & 6.17 & 2.2 \\
\hline 7 & $\begin{array}{l}\text { Innovation of sharing economy in } \\
\text { accommodation platform }\end{array}$ & 72 & 6 & 0.95 \\
\hline 8 & $\begin{array}{l}\text { Political decision related to the sharing } \\
\text { economy in accommodation }\end{array}$ & 70 & 5.8 & 2.15 \\
\hline 9 & 'Living like a local' tourists & 70 & 5.8 & 2.21 \\
\hline 10 & Abundance of idling capacity in Bali & 69 & 5.75 & 1.07 \\
\hline 11 & Indonesia as a developing economy & 69 & 5.75 & 1.1 \\
\hline 12 & Variety of low cost airplanes & 68 & 5.66 & 1 \\
\hline 13 & $\begin{array}{l}\text { The disruptive innovation of the sharing } \\
\text { economy in accommodation }\end{array}$ & 67 & 5.58 & 0.9 \\
\hline 14 & Oversupply of hotel rooms in Bali & 66 & 5.5 & 1.13 \\
\hline
\end{tabular}

It is important to note that one panelist was not able to continue participating in the research for personal purposes. From the remaining 13 panelists, the researcher was able to collect 12 returned questionnaires (92.3\% response rate of the available panelists). Basic coding and descriptive statistics in Microsoft Excel were used to identify the overall means and standard deviations. A combination of means and standard deviations analysis were utilized to highlight areas of strong agreement as well as lack of consensus in other areas. Derived from the analysis, the top four of drivers of change were identified: ubiquitous Internet, smart technologies domination, infrastructure development, and cultural heritage (see table 3.4)

\subsubsection{The Third Round of Delphi (Second Questionnaire)}

The remaining four drivers of change became the basis of the second questionnaire. Presented in random order, the panelists were asked to rank those drivers based on their likelihood to occur in influencing the future of the sharing economy in accommodation in Bali. Panelists indicated their ranking by putting number 1 to 4 on the column provided. The panelists were informed that number 1 indicates the driver with the highest propensity to occur, whereas number 4 indicates the lowest. Employing the same methods to collect the questionnaire, online and offline, the researcher received 10 responses (77\% response rate of the available panelists). Again, the same basic 
coding and descriptive analysis in Microsoft Excel were used to determine the two topranked drivers. Despite a very small divergence among the drivers, as seen in table 3.5, the infrastructure development and ubiquitous Internet are clearly the drivers that panelists believe to be the most important and the most likely to influence the region's sharing economy in accommodation in Bali. However, to seek final agreement regarding the two drivers, all panelists were asked to give consent or comments if available. Here, all respondents indicated that they were in agreement with the selection of the two top-ranked drivers of change for the axes of the scenarios.

Table 3.5: Ranking of the likelihood of drivers of change occurring

\begin{tabular}{|clccc|} 
Rank & \multicolumn{1}{c}{ Drivers } & Sum & $\begin{array}{c}\text { Mean } \\
(\mathrm{n}=10)\end{array}$ & $\begin{array}{c}\text { Std. } \\
\text { Deviation }\end{array}$ \\
\hline 1 & Infrastructure development & 20 & 2 & 1.5 \\
\hline 2 & Ubiquitous Internet & 25 & 2.5 & 1.5 \\
\hline 3 & Smart technologies dominate & 27 & 2.7 & 0.5 \\
\hline 4 & Cultural tradition of Bali & 28 & 2.8 & 1.5 \\
\hline
\end{tabular}

\subsubsection{The initial four-quadrant scenario planning construction}

Having achieved the drivers and agreement from the panelists, the researcher plotted the first driver, infrastructure development, on the vertical axis and the second driver, ubiquitous Internet, on the horizontal axis to develop a four-quadrant scenario-planning matrix (refer to figure 3.3).

a. Vertical Axis

The infrastructure development driver depicts the progressive condition of Bali where central and local government are expanding basic tourism infrastructure to attract more tourists and also to distribute equal tourists' visitation flow throughout the island. For years, major infrastructure development and accommodation have been built in the southern region of Bali. This, as well as the concentration of tourist activity, have left the rest of the island largely unnoticed by visitors. The axis depicts, on one end of the spectrum, a massive improvement of infrastructure development, and the substantial stagnancy of infrastructure on the other spectrum.

1. Improvement

Infrastructure improvement depicts the additions or revitalization on existing hard infrastructure. Some of the potential hard infrastructure improvements mentioned by panelists are the new international airport, high quality road 
throughout the island, sufficient electricity through alternative energy, quality drinking water, and waste management system (Respondent 7, 2016).

2. Stagnancy

This side reflects the different side of the well-off spectrum. As a result of political decisions, collaborative agreement or economic stagnancy, basic infrastructures do not expand or degrade. Nonetheless, there is a tendency towards congestion, water shortage, power outage, and environmental problems as some of the conceivable circumstances that may occur.

\section{b. Horizontal Axis}

Ubiquitous Internet is characterized by the highly accessible and mobility of digital platforms and devices to facilitate integrated communications between individuals or as self-monitoring lived experiences, and also the increasing application of intelligent devices for sustainable living, smart cities, and task relief such as driverless cars and robotic health care (Bechman \& Lomborg, 2015).

1. Digital society

Digital Society is a modern, progressive society that is formed as a result of the adoption and integration of Information and Communication Technologies (ICTs) equipment, services, network and Internet at home, work, education and recreation. Digital societies heavily engage and interact in digital spaces and use online services that are not limited to economic activities but also involve social engagement and community interaction. (Middleton, 2014; Dapp, 2011).

2. Digital divide

According to OECD (2001) the digital divide refers to "the gap between individuals, households, businesses and geographic areas at different socioeconomic levels with regard both to their opportunities to access information and communication technologies (ICTs) and to their use of the Internet for a wide variety of activities". Determinants of digital divide as described by OECD (2001) and Rainie (2016) are inequity of household income, educational attainment, ethnicity and community tape, community type (urban, suburban, rural), digital skills and readiness (examples here include language barrier, confidence, needing someone to help with the set-up, or a resistance to the information on the Internet itself.) 
Figure 3.3: Four-quadrant scenario matrix

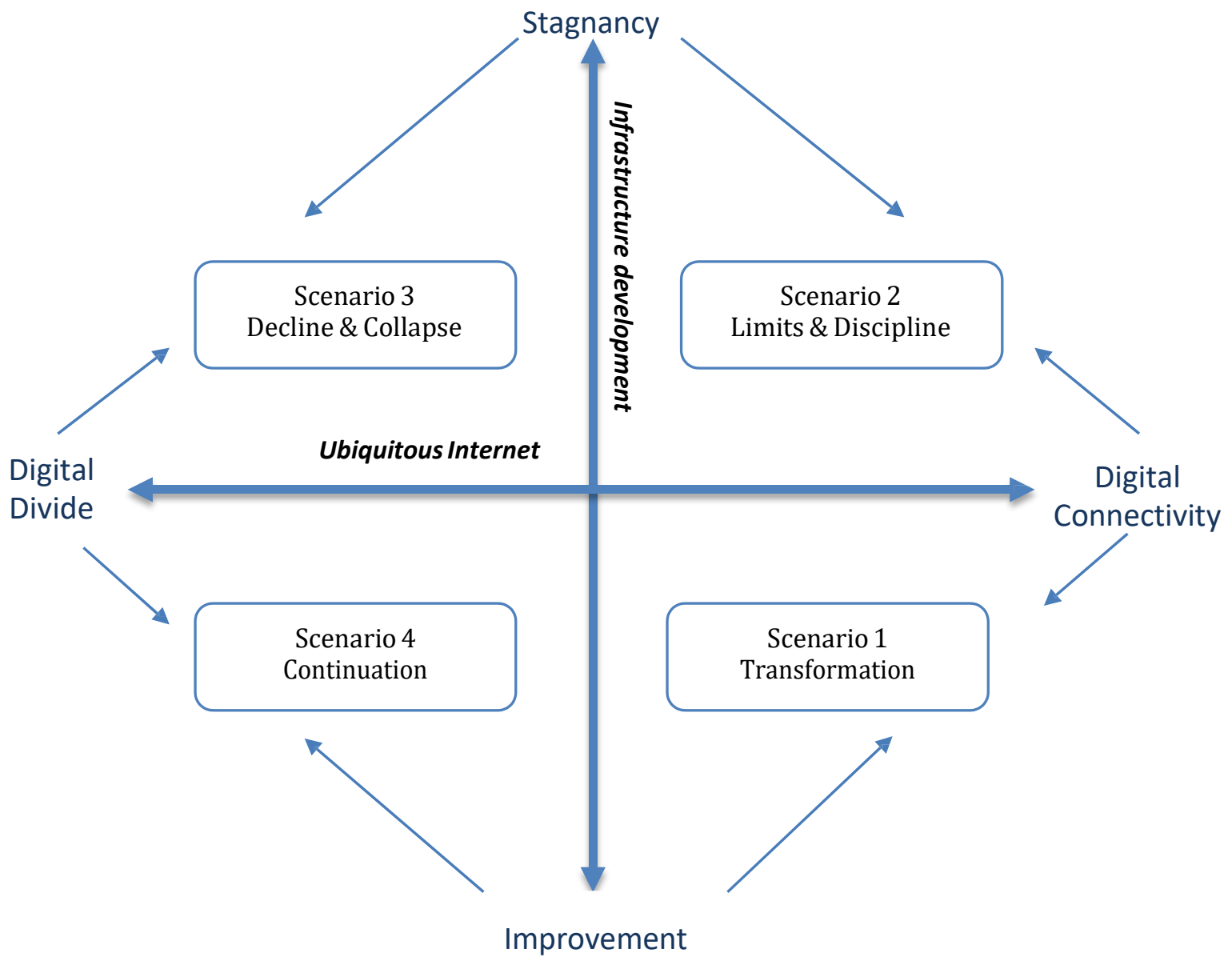

As seen in Figure 3.3, each scenario will depict a different future outcome on how the sharing economy in accommodation in Bali by 2030 could look, and will be discussed in more detail in Chapter 5. In portraying each scenario in the initial four-quadrant scenario matrix, the researcher adopted the Generic Alternative Scenarios developed by Dator (2009). This approach believes that all possible futures in the world, in every case and circumstance, can be grouped into four alternative futures, namely continuation, limits and discipline, decline and collapse, and transformation.

\subsubsection{Visioning}

\subsubsection{The Fourth Round of Delphi (Second panel interview)}

This phase aims to refine and extend the initial four-quadrant scenario matrix by inviting all panelists to evaluate the scenarios based on their logic and creativity, and also to provide the strategic implications for each scenario. First, the researcher 
prepared an online presentation outlining the process of scenario construction as well as a sketch of each scenario with its specific features. A blank space was prepared after each slide to accommodate feedback and recommendations from panelists. Similar to the first interview, all panelists resident in Jakarta and Bali were interviewed face-toface, while overseas panelists were contacted through online chat platforms. Second, the researcher displayed and verbally delivered each slide of presentation and feedback pages from previous panelists, so the current interviewee could review both scenarios and ideas from other interviewees, but also to think about possible key strategies that can be offered in response to the possible future circumstances represented by such scenarios. All the interviews were once again recorded and transcribed.

\subsection{Limitations of the methodology}

It was mentioned earlier that one of the fundamental limitations in this research is to find panelists with expertise in the sharing economy in Indonesia, particularly because it is a relatively novel issue. In some interviews, the researcher has to spend some time to briefly re-introduce the panelist into the general concept of the sharing economy. This might limit the insights needed to formulate the future of the sharing economy in accommodation in Bali. In fact, the selection of suitable panelists is not an easy task to fulfill. Some of the well-known prospective panelists with expertise on the sharing economy in accommodation, who at first were expected to give valuable inputs relating to the latest issues in this topic, were unable to participate due to tight schedules.

In relation to that, as recognized by academics and existing literature, the practice of scenario planning itself is very time-consuming (Mietzner \& Reger, 2005), not to mention the integration of the Delphi method, which conflicted with the time constraints of this study. Eventually some steps of the scenario building process did not allocate sufficient time to panelists to respond with the tasks given because the researcher also requires enough time to prepare for the following phases of scenario construction. One of the most noticeable examples was the low response rate of returned questionnaires in the third round of Delphi despite the relatively small number of respondents. Further, to make sense of the drivers of change obtained in the second round of Delphi, a wealth of data and information from different sources needed to be collected and interpreted which makes the scenario-building process even more timeconsuming. 


\subsection{Conclusion}

Chapter 3 began with an introduction to the paradigm of research as it is of paramount importance to clarify the position of the researcher on the topic researched. Owing to one of the distinct paradigms in the future study, this section thus elucidated a linear choice of ontology, epistemology, and methodology in order to properly answer the research question. To obtain the objective of this research, the main section has been partitioned into two main parts. The first part introduced the reader to scenario planning, the Delphi method, and Delphi-based scenario planning as these research methods are often unfamiliar to many readers. Furthermore, the first part of this chapter also outlined the generic scenario planning step as well as the general function of the Delphi method. The way in which academics have combined both into an integrated approach were also discussed.

The second part of the chapter was devoted to the discussion of the research methodology. It introduced the modification of Delphi-based scenario planning used in this research, and illustrated each round of Delphi, leading to the development of drivers of change and the ultimate selection of the two most important drivers of change according to highest importance and highest likelihood to occur. These two key drivers were used to construct the initial four-quadrant scenario planning which will be discussed in depth in chapter 5. Lastly, another interaction with each panelist was conducted in order to refine the initial four-quadrant scenario planning as well as developing strategic decisions. The very end of this chapter points out this research's methodological limitations. 


\section{Chapter 4}

\section{The Drivers of Change}

\subsection{Introduction}

The first sub question, proposed to answer the research question, is "what are the drivers of change that will shape the future of the sharing economy in accommodation in Bali?". Defined as factors occurring in society that may both cause the norm to change and shape the outcome of the scenarios (Yeoman, 2013; Van der Heijden, 2002), the drivers of change are pivotal piece of the puzzle in scenario construction. Chapter 3 has outlined the systematic processes of generating the drivers of change, beginning with summarizing interview transcripts, identifying a longlist of drivers, clustering similar drivers, and then giving a representative key headline to explain what the driver involves. To help the reader in making sense of each driver, evidence from existing literature and industry reports are further supplemented in this chapter.

This chapter presents the second step of Bishop et al.'s (2007) approach: the scanning which delivers a broad overview of the 14 drivers of change by connecting all related resources in a comprehensive structure. To that end, each driver will be discussed in the following order:

- Literature review relating to the driver, revolving around discussion of the relevant literature from academic researches, statistics, and industry reports that underpin the emergence of the driver

- Key quotes emphasizing the driver, including related quotations from panellists taken during the first round of Delphi (the first panel interview)

- The future of the driver, debating relevant literature that demonstrates the probable future state of the driver by 2030

To conclude this chapter, a critical reflection considers how each driver can be related to the sharing economy in accommodation in Bali as well as the probable consequences on the future of this sector by linking every element discussed earlier. 


\subsection{Driver 1: Ubiquitous Internet}

This driver is related to the importance of the Internet to facilitate sharing, to enhance connectivity among humans, and to facilitate the rise of the sharing economy in accommodation platforms such as Airbnb.

\subsubsection{Literature review relating to ubiquitous Internet}

As technology continues to advance at an unprecedented rate, the Internet takes a very important place among the human world.' The Internet of things' is a term used to describe the networked interconnection of everyday objects - in the near future the term might even be applicable to cars and clothing, as technology develops (Yeoman, 2012). The Internet of things also makes it possible to collect and analyze larger data sets, and to provide real-time insight into the digital and physical world that enables real-time decision-making (De Filippi, 2015). With regard to global Internet users, Internetlivestats (2016) point out that around $40 \%$ of the world population (more than 3 billion people) had an Internet connection in 2016, a 'quantum leap' compared to less than $1 \%$ in 1995 (see figure 4.1). As one of the world's most populous countries, Indonesia shows a prolific increase of Internet users with around 34\% of population using Internet at home and via mobile connections. Most are active social media and ecommerce users (internetlivestats, 2016; Balea, 2016).

Figure 4.1: Global Internet users

Source: internetlivestats.com, 2016

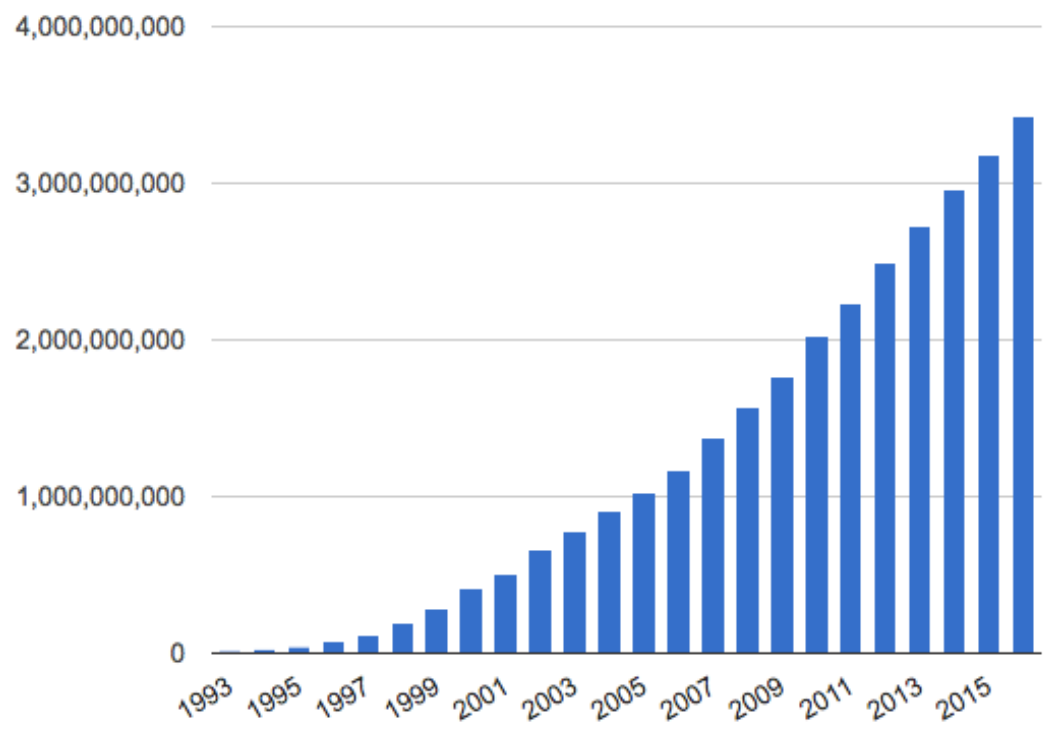


The pervasive development of Internet, particularly peer-to-peer social networks and real-time technologies, are key factors that have driven the sharing economy to emerge (Botsman, 2010). Peer-to-peer social networks are not only able to aggregate supply and demand at a high speed and scale, but also help people build trust with strangers (Finley, 2013; Botsman, 2010). Via the Internet, sharing platforms can "deliver highly targeted, very personal goods and services at the right time and location" (Gansky, 2010:3). To date, there are enormous business models that apply peer-to-peer social network technology, enabling sharing activity involving a range of goods and services such as cars, bikes, equipment, tools, lands, working spaces, money, skill and expertise (Botsman, 2010; Botsman and Rodgers, 2011).

\subsubsection{Key quotes emphasizing the driver}

Some of the key quotes stating the importance of ubiquitous Internet to facilitate the interconnectedness and also the sharing economy in accommodation include:

"Today everything is connected via the internet. Whatever I need, there is always someone that offers it online. In the past, if I happened to need something, I would have to post an advertisement in the newspapers or such. Through Google now you can ask anything and get an instant answer. So everyone is basically meeting on the same platform facilitated by the Internet technology and that what causes the change. There is no borders or gender discrimination, everyone can get on board anytime."

[Interview Panelist \#3]

"You had the people renting the apartments and houses before but without the Internet that has not reach the level of growth and exposure that sharing economy platform has now. So that is only possible thanks to the underlying Internet technology."

[Interview Panelist \#8]

\subsubsection{The future of ubiquitous Internet}

Gartner (2014) predicted Internet of Things (IoT)'s products and services to generate incremental revenues exceeding US\$263 billion in 2020. By 2030 this figure is expected to increase due to the rising popularity and perfection of the IoT mechanism in the form of applications such as smart homes, wearable devices, smart cities, smart grids, connected cars, and connected health (Vermesan \& Friess, 2014). Vermesan and Friess (2014) also predicted that IoT, by 2030, will see an extension of people connected to their objects through Internet. In such a future, objects [are] connected to other objects through Internet, accurately analyzing the needs of a human user and 
communicating to other objects to meet those needs. The so-called preordained analytics example would be when a refrigerator inventory system detected the number of eggs remaining were low and placed an order to an IoT-installed grocery store for restocking.

Also, by 2030, the pervasiveness of the Fifth-generation $(5 \mathrm{G})$ network that allows the exponential growth in the speed and size of big data transfers would further advance the entire ICT ecosystem. The real-time technology that is the pivotal factor of the sharing economy could exist even more ubiquitously by means of the Fifth generation network (Vermesan \& Friess, 2016).

\subsection{Driver 2: Indonesia as a developing economv}

This driver is related to the progress of development in Indonesia that leads to the increase of average income and the availability of disposable income for travel.

\subsubsection{Literature review relating to Indonesia as a developing economy}

The Indonesian economy has recorded strong economic growth and resilience over the years, particularly after overcoming the Asian financial crisis in 1997-1998 (World Bank, 2016). Indonesia reached its highest total GDP in 2012 with $\$ 917.87$ billion, and despite the slight downturn in total GDP since 2013, today Indonesia remains the world's $10^{\text {th }}$ largest economy in terms of purchasing power parity (World Bank, 2016). Yeoman (2010) stresses the overall increase in GDP and household income has resulted in changes in living standards and the desire for improvements in the quality of life with tourism at the center of that change.

Table 4.1: Indonesia's domestic travels and spending Source: Ministry of Tourism, Republic of Indonesia

\begin{tabular}{|c|c|c|}
\hline Years & $\begin{array}{c}\text { Number of } \\
\text { Domestic travels }\end{array}$ & $\begin{array}{c}\text { Total Spending } \\
\text { (Billion Rupiahs) }\end{array}$ \\
\hline 2010 & $234,377,000$ & 150,410 \\
\hline 2011 & $236,752,000$ & 160,890 \\
\hline 2012 & $245,290,000$ & 172,850 \\
\hline 2013 & $250,036,000$ & 177,840 \\
\hline 2014 & $251,200,000$ & 213,900 \\
\hline
\end{tabular}


The relatively constant increase in national GDP is an impetus for Indonesians to travel far away from their hometowns, to worldwide popular destinations, as well as local destinations. In fact, numbers of domestic tourists are far greater that foreign ones and, aligned with the growth in GDP, increase continuously over the years (see table 4.1).

\subsubsection{Key quotes emphasizing the driver}

This subsection offers some quotes that punctuate the developing economy of Indonesia and how it strengthens the propensity to spend on travel costs.

"Still the first factor is the development of the economy, staging of development and the improvement of social structure in Indonesia. So "why did the Indonesians mindsets change?' is always correlated with the betterment of economy setting. People are more educated. Social security was influencing new necessities. Why did that happen? It is all the consequences of economy growth that influence behavioral changes, life style, and access to technology.

\section{[Interview Panelist \#7]}

"The overall income of Indonesians increase. The improving economy state is what really determines the propensity to consume, that more people are able to travel and spend money for travel. The future of Indonesia economy is optimistic due to its stable growth with projected gross domestic product (GDP) to exceed US\$3.7 trillion by 2030."

[Interview Panelist \#4]

\subsubsection{The future of Indonesia as a developing economy}

Indonesia has the potential to become the seventh biggest economy in the world by 2030, overtaking Germany and the United Kingdom (McKinsey, 2012). As seen in figure 4.2, an additional 90 million Indonesians could join the ranks of the consuming class, which would then total 135 million if GDP growth were around 5 to $6 \%$ per annum. The total would be even bigger if GDP was to reach 7\% per annum.

The consuming class itself is defined as consumers with enough income to purchase not only basic needs such as food and clothing but, as seen in figure 4.2, also to spend on investment and discretionary services including travel/leisure. In fact, by 2030 McKinsey (2012) foresees Indonesians' yearly travel spending as their third priority, behind saving and investment and food and beverages, but far above the 'traditional' basic needs such as education, transportation, housing and health care. McKinsey also foresees that such additions will be fueled with the continued growth of Indonesia's 
young population and the rise of urbanization enhancing the number of consumers with considerable budgets to spend.

Figure 4.2: Estimated addition to the Indonesia's consuming class by 2030 Source: McKinsey, 2016

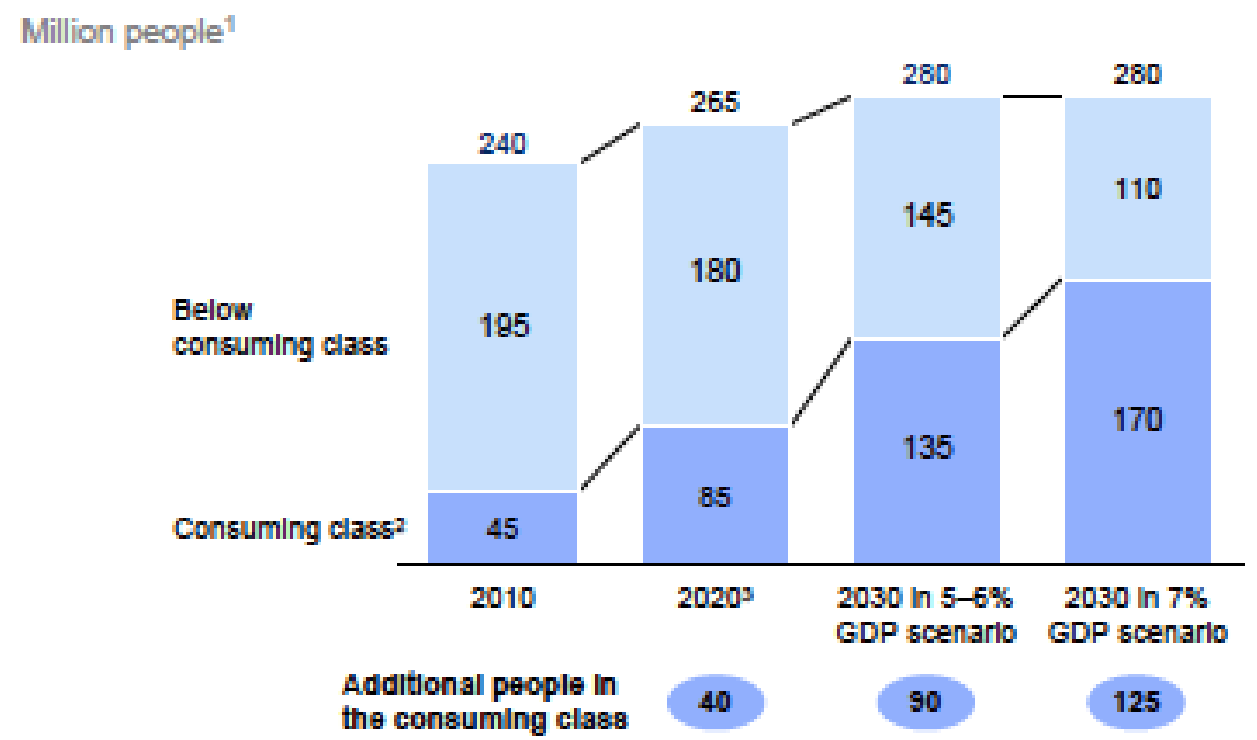

\subsection{Driver 3: Smart technologies domination}

This driver is closely linked to the above discussed driver of ubiquitous Internet, nonetheless this driver focuses on the increasing sophistication of smartphones and smart technologies which support the sharing economy activities.

\subsubsection{Literature review relating to smart technologies domination}

eMarketer (2014) estimated global smartphone users reached 1.9 billion people in 2015 and expects the number to continue growing over the years. In 2015, more than onequarter of the global population is predicted to use smartphones, and by 2018 over one third of the global population will use the device. In the same year, the figure of smartphone users will reach $51.7 \%$, which means feature phones will eventually become a minority in the telecommunication world (see figure 4.3). Indonesia will surpass 100 million smartphone users by 2018 and become the fourth largest country with regard to smartphone users, just below China, India, and the US (eMarketer, 2014).

Smartphones play a significant role, given both the main essence of the sharing economy is to connect people and that most information conducted over mobile phones 
(Lunny, 2015). Parallel with the tremendous growth of smartphone users, mobile broadband continues to provide a gateway to powerful and easy-to-use applications that display multiple sharing options (Fairview, 2015), as, for example, the development of big data analytics and cloud computing. According to Fairview (2015), the low-cost of cloud computing makes it possible to create fully functioning sharing applications, which manage inventories, collect usage data, and facilitate transactions. Other smart technology advancement includes cashless payment systems which have subsequently made the process of the sharing economy more faultless (Finley, 2013).

Figure 4.3: Smartphone users and penetration worldwide, 2013-2018

Source: eMarketer, 2014

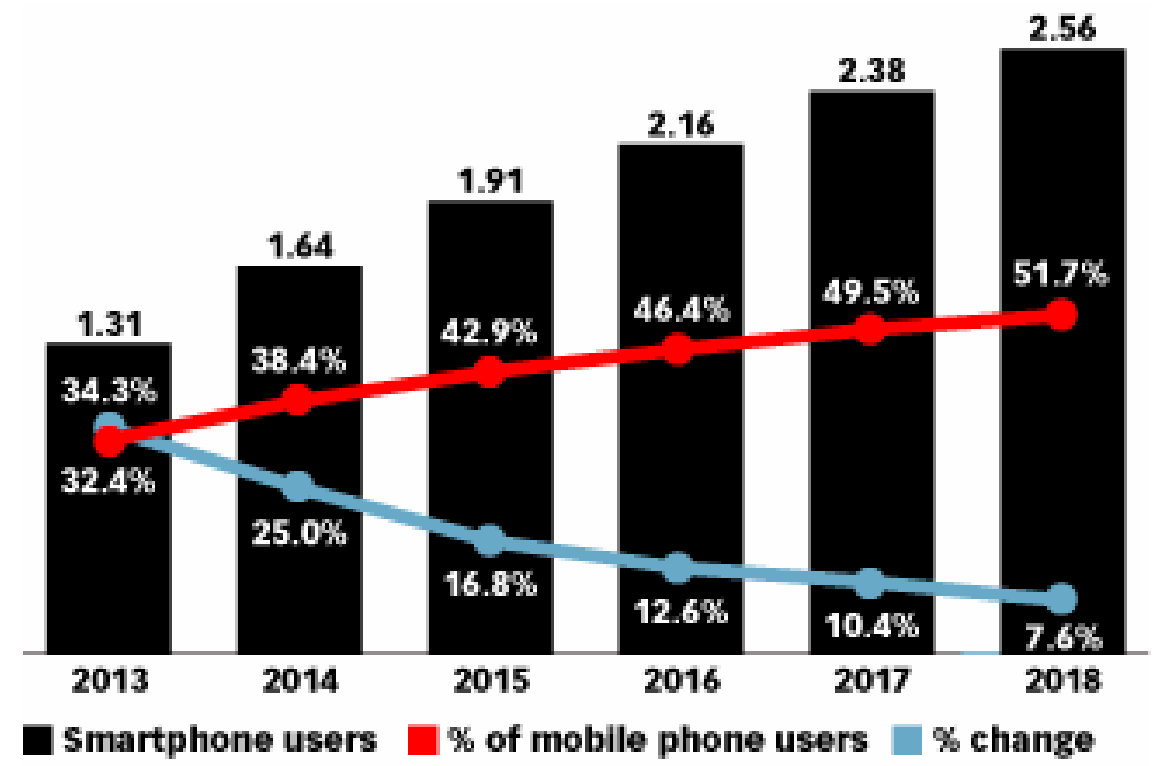

\subsubsection{Key quotes emphasizing the driver}

Evidence from the interviews emerged with some of the key quotes including:

"The development of smart technologies and smartphones are to enable the interconnected environment. They are here to facilitate. Take for example myself. I am usually just too lazy to eat out, now I can order in from the 'Gojek' application using my smartphone. It is so addictive!"

[Interview Panelist \#4]

\subsubsection{The future of smart technologies}

By 2030, the number of Indonesia's mobile Internet subscribers will be nearly 500 million or approximately 4 times bigger than in 2015 owing in part to the growing middle class (Euromonitor, 2016). On a different note, Islam and Want (2014) predict 
some big trends in the future of the smartphone: 1) by means of system-on-chip design, smartphones will take over the role of personal computing including computation, storage, and network hub; 2) smartphones will be the central controller of the Internet of Things (IoT); 3) smartphones will be foldable, conforming to the human body, or integrated into human clothing; 4) context awareness in mobile phones, which is often associated with artificial intelligence, will help users by giving suggestions and directions based on users' locations, patterns, and characteristics.

\subsection{Driver 4: Political decision on the sharing economv}

This driver portrays the positions of various different governments on whether or not to support the sharing economy in accommodation through various regulations.

\subsubsection{Literature review relating to political decision on the sharing economy}

The substantial growth of the sharing economy in accommodation is threatened by some concerns that are rooted in the difficulty of imposing existing regulations (Oskam \& Boswijk, 2016). Taxation and housing laws are at the forefront of regulatory and legal issues, along with competition with existing industry and issues on consumer protection (Kaplan \& Nadler, 2015; Guttentag, 2015). As evidenced in many municipalities, the widespread expansion yet unregulated sharing properties invites prohibition and quite often causes tension among stakeholders. However, regulations have been made to counter these concerns and to integrate the sharing economy into the formal economy. Guttentag (2015), Psarros (2015), and Hotrec (2015) exemplify such regulations toward Airbnb in table 4.2.

On the other hand, Airbnb has begun to address these regulatory challenges. According to Kaplan and Nadler (2015), as the first step, Airbnb has ensured their hosts be aware of the regulatory and legal regimes in which they operate by emphasizing a clause in Airbnb's Terms of Service. Also, Airbnb has further informed hosts that there may be applicable taxes which they are obliged to pay. In addition, in January 2016, Airbnb has made a plea to hundreds of American mayors confirming that they are ready to pay taxes or help their hosts pay the appropriate taxes owed to the local city, county, and state governments (Ting, 2016). 
Table 4.2: Regulations on Airbnb in different municipalities

Source: Psarros, 2015 and Hotrec, 2015

\begin{tabular}{|cl|}
\hline Municipalities & \multicolumn{1}{c|}{ Regulations } \\
\hline San Francisco & Under the current law San Francisco residents are allowed to \\
& rent out their homes for a maximum of 90 days per year if they \\
are not present and unlimited amount if they are. & Short-term renters have to register with the city through the San \\
& Francisco Treasurer \& Tax Collector. \\
& A $14 \%$ Transient Occupancy Tax (TOT) is applied on \\
& reservations of fewer than 30 nights \\
\hline New York City & Last regulation maintains a maximum 30 days per year for host- \\
& absent rentals \\
\hline Paris & Airbnb guests are obliged to pay taxes that collected through Airbnb \\
& site \\
\hline Amsterdam & Individual property may be rented out under several conditions: \\
& - Subject to prior registration to the municipal authority \\
& - Subject to payment of the city tourism tax \\
& - For a maximum of 60 days in the year \\
\hline & To a maximum of 4 persons at a time \\
\hline
\end{tabular}

\subsubsection{Key quotes emphasizing the driver}

The political decision on the sharing economy is an important discussion point in many interviews. Some of the key quotes underlining these issues are:

"In China, the prime minister has come out and said that the sharing economy is going to be a major driver of Chinese economic growth over the next five years. And by 2020, the sharing economy will represent 10\% of their GDP. When you have the political leader that said the kind of bold vision like that, it has people understand that this is the priority; it has them to work on achieving certain goals."

[Interview Panelist \#6]

"We have not seen protest from hotels industry on Airbnb at the Ministry of Tourism.

But it's a matter of time. Yesterday there was a protest made by the taxi drivers towards Uber and we (Ministry of Communication and Information) have issued a policy on this ride-hailing application's drivers to have their vehicle inspected and maintained, also to regularly pay the tax. We can expect similar demonstration to the Airbnb at the Ministry of Tourism."

[Interview Panelist \#3]

\subsubsection{The future of the political decision in Indonesia}

Indonesia remains in the infancy stage of the transition to democracy that began in 1998 and still has a long way to go in terms of the procedural consolidation of democracy (Mishra, 2015). However, Indonesia shows positive progress in terms of its democracy 
ranking, a model which, according to Campbell (2008) refers to a neutral line between equality, freedom, and the performance of good governance. In the period 2013-2014 Indonesia ranked $63^{\text {rd }}$ out of 113 surveyed countries, with a total score of 55.6, slightly better than the previous survey period in 2010-2011 where the country was ranked $67^{\text {th }}$ with 54.3 points (Global Democracy Ranking, 2016). Under the political rights and civil liberties dimension of the democracy ranking model, there are two highly relevant aspects in particular in respect of the sharing economy in accommodation: first, for civilians to enjoy social and economic freedoms, including equal access to economic opportunities; and second, for civilians to have access to an established system of rule of law (Freedom House, 2016).

\subsection{Driver 5: Domination of Generation Y/Millennial Generation}

This driver concerns the potential domination of global travel by Generation Y/Millennial Generation, a generation which, with its global mindset and technological aptitude, could lead the massive sharing economy movement.

\subsubsection{Literature review relating to the domination of Generation Y/Millennial Generation}

Schroer (2016) defines the Generation Y or Millennial as the cohort born from 1977 to 1994. This is the largest cohort since the Baby Boomers and is characterized as incredibly sophisticated in terms of technology, because they grew up in an increasingly online and socially networked world, and ethnically diverse so they tend to be more tolerant of differences (Botsman and Rodgers, 2012). According to Nielsen (2014), the Millennial segment are the largest group likely to participate in sharing communities, compared with other generation groups such as Generation Z (ages under 20 in 2014), Generation X (35-49), Baby Boomers (50-64), and Silent Generation (65+). Another commonality of this generation is its courage to change and challenge social norms by creating sophisticated inventions with sharing principals such as Kickstarter (a crowdfunding model for creative projects) or Meetup (an online platform that allow anyone with same interest to organize local face-to-face groups). 
Figure 4.4: Declining of the Millennial Ownership

Source: Hynek, 2016
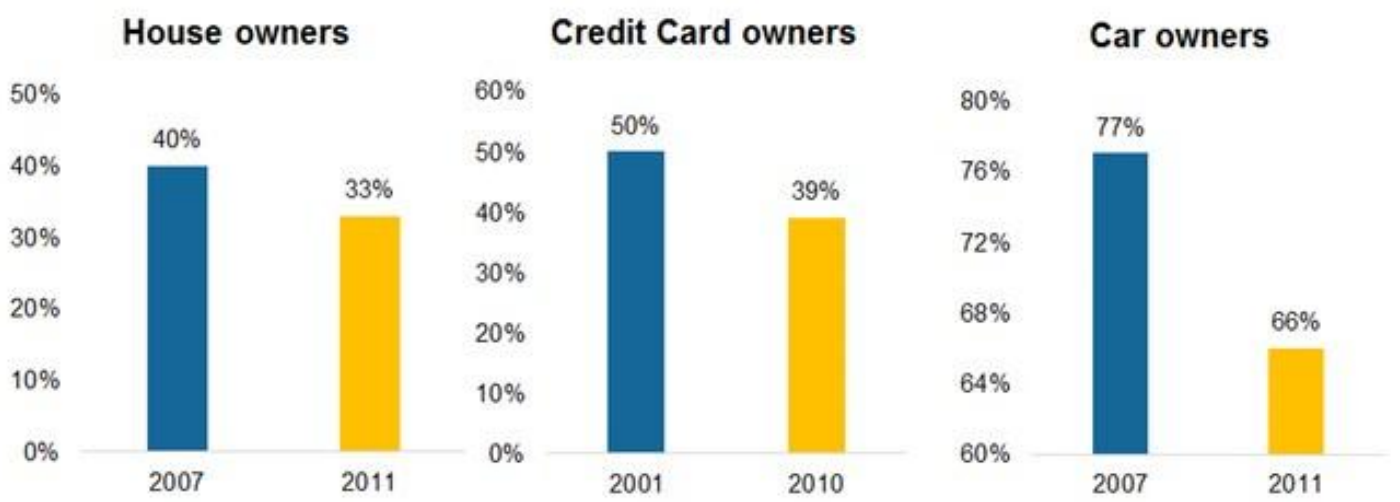

As seen in figure 4.4, they also show a different attitude to ownership, opting to enjoy asset-light consumption and the benefit of sharing (Hynek, 2016). Psarros (2015) predicts the Millennials to outnumber the Baby Boomers by 22 million in 2030. By that time, the cohort is deemed to become the fastest growing consumer segment in the hospitality industry and dominate numbers of global travelers.

\subsubsection{Key quotes emphasizing the driver}

Panelists commented on the domination of Generation Y/Millennial Generation by stating that:

"If you look at what is going to happen in the next five, ten, or twenty years, you are going to see that the older generation will going to stop travelling. They will die off. And the millennial generation is going to make a substantial portion of the global travelers. So by 2020, 75\% of all travelers will be today's millennial. Means that sharing economy in the hospitality sector has to response the changes of consumer preferences. And be able to provide the authentic, local experiences that the millennial are looking for."

[Interview Panelist \#6]

\subsubsection{The future of Generation Y/Millennial Generation}

There is a lack of data foreseeing the future of international tourist arrivals to Indonesia and Bali, let alone the segmentation based on range of age. However figure 4.5 demonstrates that the general number of international tourist arrivals to Bali increased over the past seven years. In 2015, the number of international tourists visiting Bali alone represents $38 \%$ of total international arrivals to Indonesia. That is the highest contributor in comparison to the capital Jakarta and Batam (Euromonitor, 2016). When the total number of Indonesia's inbound arrivals is predicted to achieve 14,907,000 in 
2020, an increase of about 30\% from 10,406,759 in 2015, and assuming other things hold constant, the same percentage of increase could also be expected for the number of Bali's visitors. By 2030, when South-East Asia is expected to become the fourth most visited sub-region in the world with 187 million arrivals as the result of a $6 \%$ growth a year, Indonesia and Bali are also expected to continue growing in terms of international arrivals and tourism expenditure.

Figure 4.5: International tourist arrival to Bali

Source: Statistic Indonesia, 2016

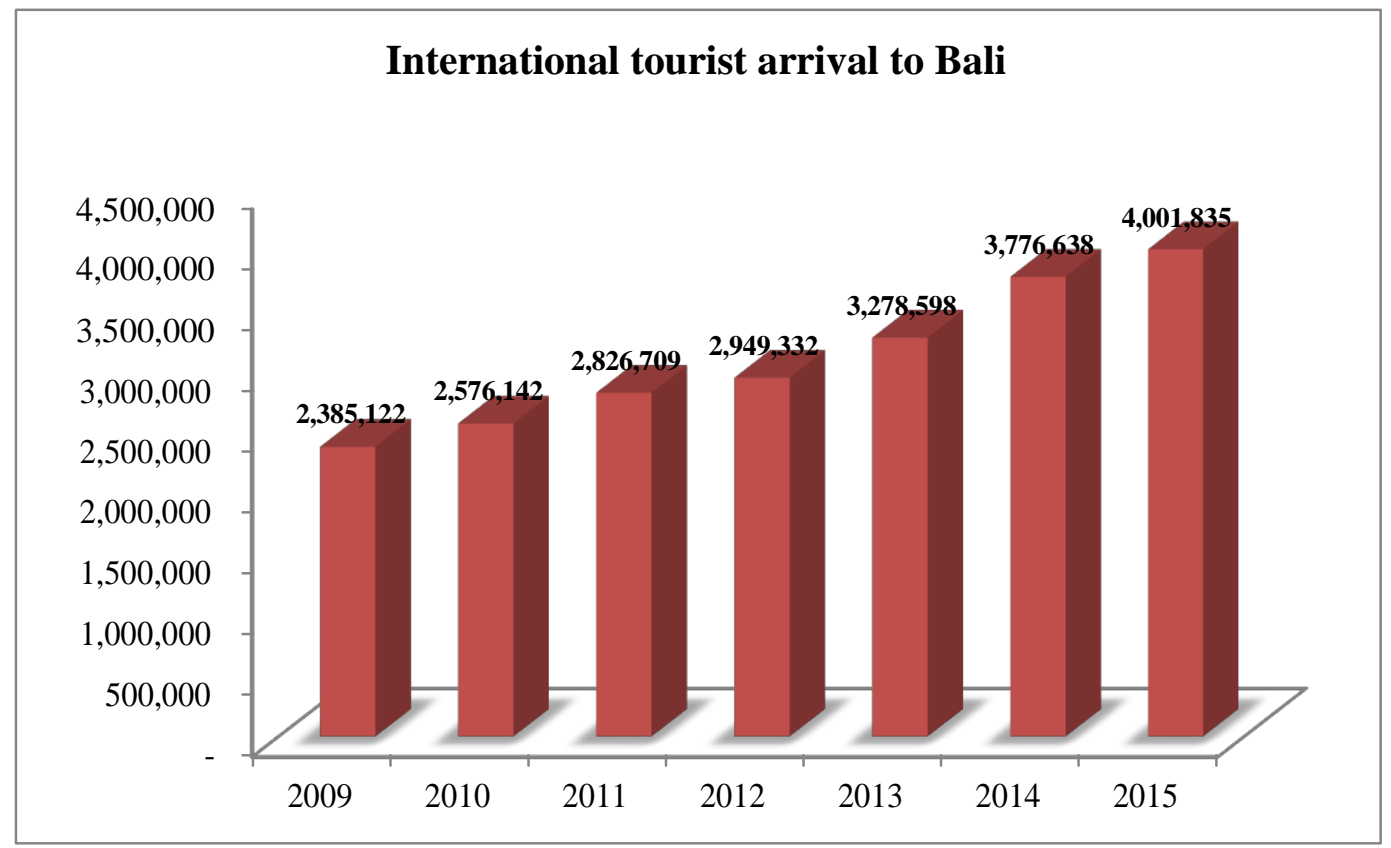

According to WTTC (2015), the total spending by international tourists in Indonesia by 2025 is expected to reach 390,824 billion Rupiahs, an increase of 5.5\% per annum since 2015. Singapore, Malaysia, and China are expected to provide the highest numbers of millennial travelers to Indonesia (Euromonitor, 2016) thanks to the character of Asian Millennial travelers to largely travel to destinations that are less than four hours away (Singapore Tourism Board, 2015). Take China as an example. Out of 220 million projected outbound tourists in 2025 , over 70 percent are Millennials who graduated from universities; they are well-informed and do not consider language barriers to be prohibitive, and opt to travel to destinations of the closest proximity such as Hong Kong, Macau, and ASEAN countries (Goldman Sachs, 2015). 


\subsection{Driver 6: Infrastructure development}

This is a core driver that emerged during the interview; it includes discussion about the Indonesian government's initiatives to develop both hard infrastructure and soft infrastructure to attract more tourists to Bali.

\subsubsection{Literature review relating to infrastructure development}

The worldwide popularity of Bali as a tourism destination is a result of continuous support and involvement from many parts. As for example, the expansion of Bali's Ngurah Rai International Airport, worked on by multiple actors in order to be ready to host the 2013 APEC Summit. The project not only involved the airport's state enterprise, Angkasa Pura, responsible for airport facilities' expansion, but also other national enterprises such as Jasamarga, Indonesia Tourism Development Corporation (ITDC), and Pelindo, responsible for providing access and the Bali toll road into the airport (Putra, 2015). When the whole work is completed in 2025, Ngurah Rai will be able to accommodate 25 million passengers per annum. The development is followed by new flight services to Bali, namely AirAsia with its long-haul low fare from Melbourne, Emirates Airlines with its non-stop daily flight from Dubai (HVS, 2015), and Qantas with a seasonal route from Sydney to Denpasar from December to January 2016 (Horwarth, 2015).

However, interviews indicated an urgent need for improvements, in particular to ease the uneven development in the northern, eastern and western parts of Bali. The crowded and congested destination of south Bali is the consequence of large-scale urbanization and uncontrolled development. In her work, Cole (2012) explains how massive exploration in Bali has driven unsustainable development with no regard for water resources. If continued, Bali will have a serious water crisis by 2025. Bali is also heading for an electricity crisis due to the delay in new power plant projects that may put the tourism industry, and Bali residents, in a rolling blackout (Cahyafitri, 2014).

\subsubsection{Key quotes emphasizing the driver}

In terms of the topic about infrastructure development in Bali, these key quotes summarize what panelists have in mind: 
"The building of the new airport has proven to reduce overcrowding on holiday seasons. However the government still has to encourage tourist to visit other places of

Bali aside from Kuta and Sanur. New roads or even highways are needed. They should also facilitate people that live in certain areas of the paddy fields to be able to make online transactions easier by providing a land line, Internet connection for communication, and sufficient electricity."

[Interview Panelist \#12]

"Bali is relatively poor in waste management. There are also lacks of consistency in spatial and drainage management. Clean water remains a problem for years, as we still don't have excellent water distribution system for hotels and local community.

[Interview Panelist \#11]

\subsubsection{The future of infrastructure development in Bali}

In accordance with the Law No. 9/2009 concerning tourism, the National Tourism Development Master Plan from 2011 to 2025 was drawn up as national tourism development guidance. In the master plan, Bali as the National Tourism Destination (Destinasi Pariwisata Nasional/DPN) has 11 strategic tourism regions with thematic development throughout Bali (see Figure 4.6 circled in red).

Figure 4.6: Bali National Tourism Destination development plan Source: Indonesia National Tourism Development Master Plan, 2011

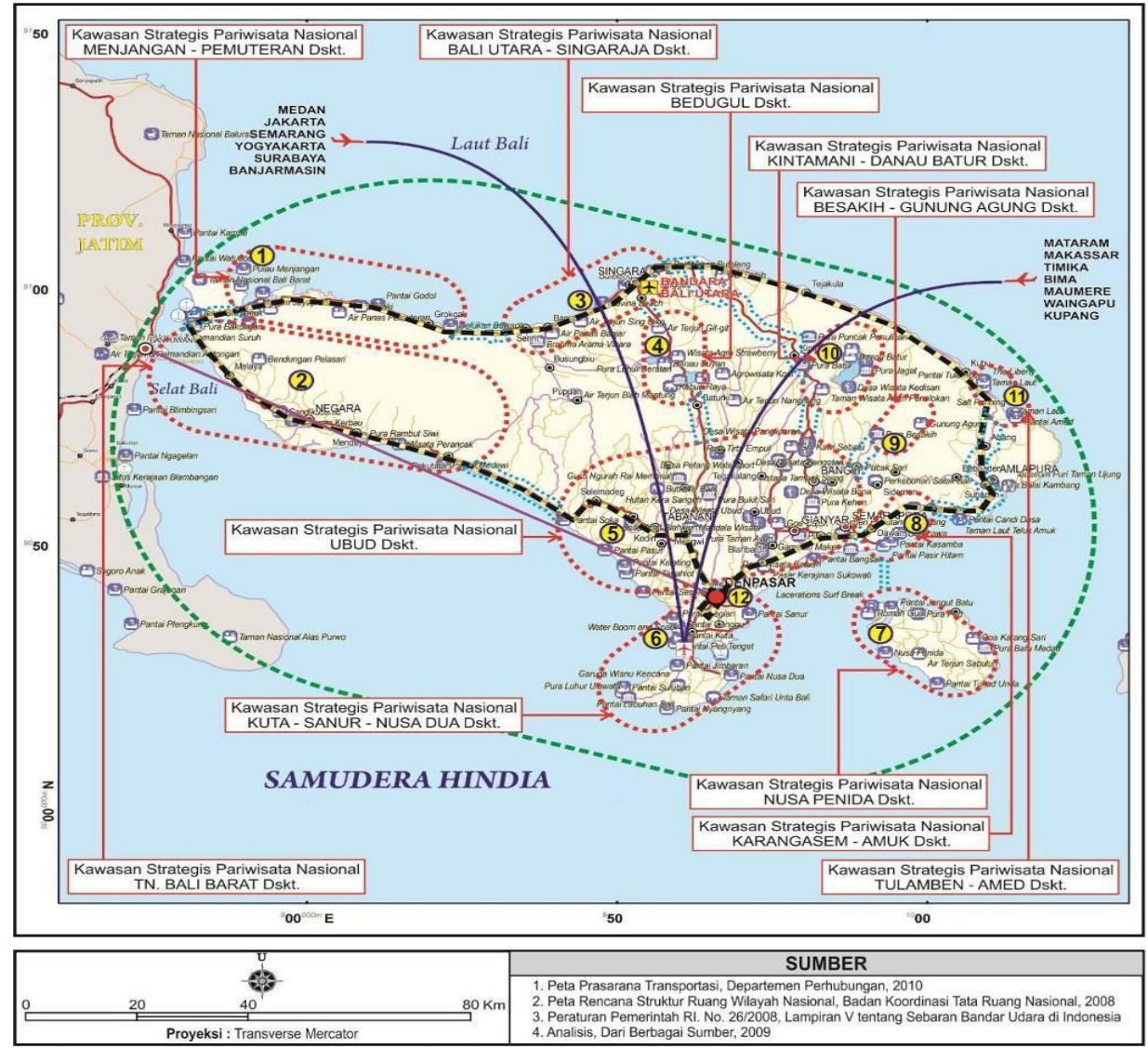


If the plan was accomplished according to the lifespan, by 2030 Bali will have a new airport in the northern part, a railway track circling the island, and new high roads or highways connecting each strategic tourism region, as well as plenty of ports to accommodate visitors traveling by cruise ships or yachts.

Additionally, despite contestation over the project, if the revitalization and reclamation of Benoa Bay in southern Bali was to apply, a series of artificial islands to cater worldclass tourist accommodations, golf courses, shopping malls, offices, and other commercial ventures will be ready by 2030 (see figure 4.7). On a different note, as emerged in many of the interviews and highlighted by panelists 11 and 12, future infrastructure in Bali is expected to manage with the shortage of power plants, water supplies including the seawater purifying technology, and recycling disposal management.

Figure 4.7: Benoa Bay reclamation project

Source: Nusa Benoa, 2016

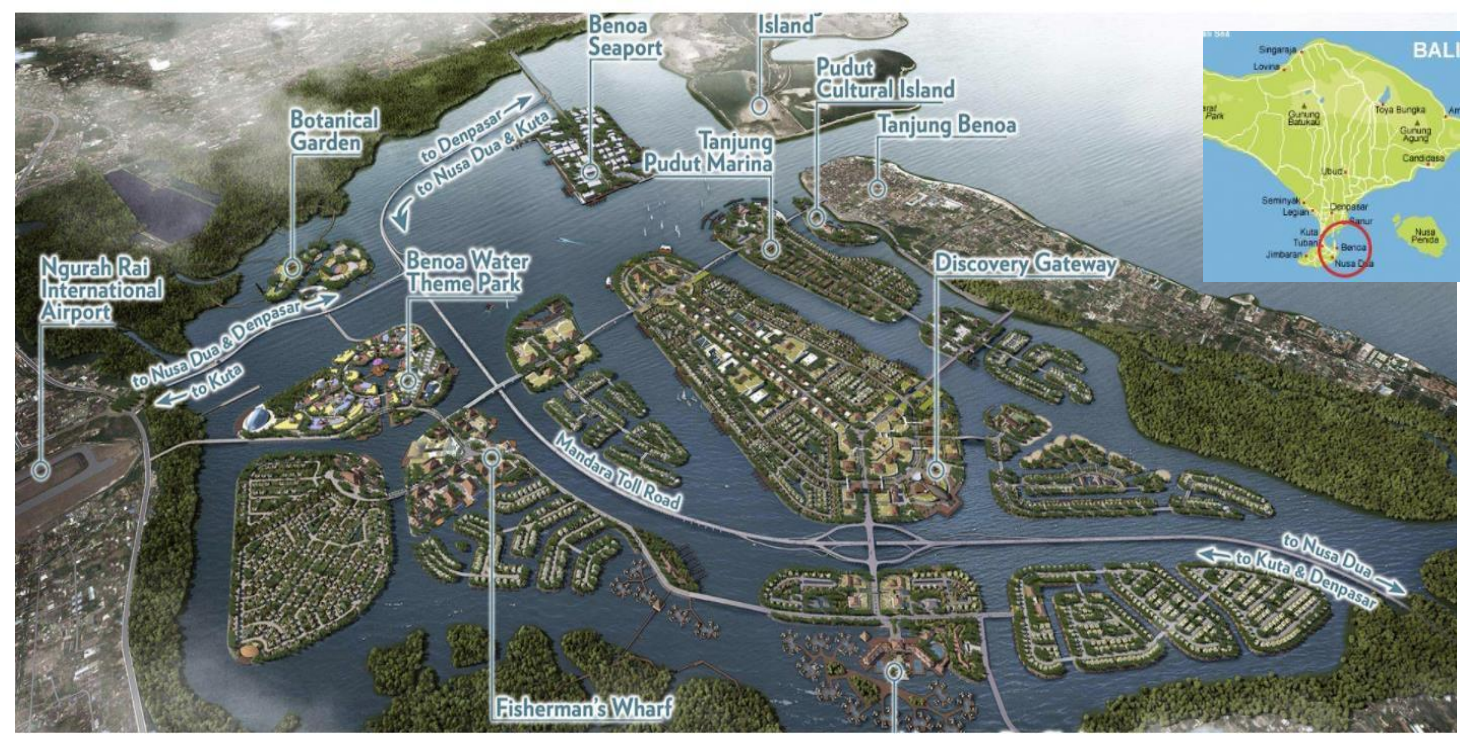

\subsection{Driver 7: 'Living like a local' tourists}

This driver is linked with the prevalent rise in demand for authentic experiences while traveling.

\subsubsection{Literature review relating to 'Living like a local' tourists}

Many believe in the initial assumption that the sharing economy is an appealing alternative for those in need of low cost accommodation, as it saves significant expenses 
in overall travel budgets. After the global economic crisis, it makes sense to many to take trips without involving costly agency arrangements and hotel accommodation (Zekanovic-Korona \& Grzunov, 2014). However, recent studies reveal how use of the sharing economy accommodation is not always driven by economic benefit but also by the social motivation to interact and connect with local communities in a more meaningful way, to experience the authenticity of tourism destinations, to live like and contribute to the local community, or put simply, to live like a local (Tussyadiah \& Pesonen, 2016). Staying in sharing economy accommodation is believed by many to offer authentic experiences, as visitors enter the 'back regions' of a destination without its beautification (Hamari et al., 2015; Guttentag, 2015). This authentic experience itself is broadly defined as the strong desire to indulge in the unspoiled environment and to have real human contact in order to avoid the disturbances of high-density tourist districts (Yeoman, 2008).

\subsubsection{Key quotes emphasizing the driver}

Panelists commented on this driver by stating that:

"There is a change in the people interest. They tend to be more looking for a 'backdoor' environment. When someone are staying in your home, you welcome them, you offer them drinks, show them the room, explain a little bit and have a little bit of chit-chat, and quite often at the end of their couple of days stay, when they leave, frequently, I naturally hug those person. It is like you treat the family member

as oppose to the hotel environment that might seems a little bit stalled, cold, unfriendly, and same across the board anywhere you go. Living like a local means you are more likely to have the local knowledge, about the little room on the corner that no one knows because you cannot see it from the main street. If one of our guests wants to have the Babi Guling (suckling pig), I would recommend the little local warung (stall) that we go to, then they experience a little more localized foods, products, opportunity, and walks to see what is not on the maps. All of that comes down to the information. Information is king. You got power through the information."

[Interview Panelist \#13]

\subsubsection{The future of 'Living like a local'}

Tourists will still seek the 'living like a local' experience, closely related to the demand for authentic experience, in the years ahead. Yeoman (2008) asserts that as long as technology and virtual life continue to be produced as in the present, and people become more cynical about falseness and fake promises, future tourists will still long for sharing the local lifestyle, engaging in human contact, traditional activities, and seeking out the 
authentic experience while traveling far from the commodification of manufactured experiences produced by theme parks and resorts.

\subsection{Driver 8: Innovation of the sharing economy in accommodation platform}

Due to limited research unpacking thoroughly the online platform of the sharing economy in accommodation - including the interface, algorithms, structures, and regulations - except for Airbnb, this driver will focus on discussing sustainable transformation and innovation by Airbnb, which simplify hosting and booking procedures, provide wider exposure, and comply with the user's needs.

\subsubsection{Literature review relating to innovation of the sharing economy in accommodation platform}

An exploratory study by Finley (2013) is a stepping-stone to conceptualize the mechanism of Airbnb as a platform facilitating the sharing economy. In her research, Finley assesses Airbnb website from different angles to develop contextual insight on how trust is developed among the users of Airbnb. First, the presence of both listing and host profile photos. In Airbnb the hosts' photos are presented next to the photos of their rented out properties in order to emphasize the sense of personal contact (Tussyadiah \& Pesonen, 2015). For this aspect, Airbnb provides free professional photography for eligible hosts to capture high-resolution, wide-angle photos of properties in the hope that these can reassure potential guests about the details of the properties (Airbnb, 2016c). Second, the profile verification process in order to guarantee the safety of both guests and hosts. Airbnb requires anyone partaking in the 'sharing' process to complete essential identification including uploading a profile picture, photo of government-issued ID such as passport or driver license, or take a selfie/live photo of one self if needed (Airbnb, 2016d). Alternatively, Airbnb offers options to connect another online accounts such as Facebook, Google, or LinkedIn to verify one's identity. Third, the availability of worldwide customer support teams with the Instant Chat option by which every complaint is handled and solved, including extensive refunds and booking of alternative accommodation for those not satisfied with the property upon arrival. 
Fourth, the professional, aesthetic and attractive appearance of website interface as seen in figure 4.8 and 4.9. The website also offers easy-to-use mechanisms from searching the properties to payment (figure 4.10). Furthermore, Airbnb has developed other innovations over the years. The guidebook (see figure 4.11) is a collection of written tips by local hosts suggesting local well-known spots such as restaurants, parks, shopping centers, arts and culture galleries, and tourism attractions that can be added whenever potential guests select the property (Airbnb, 2016e). The neighborhood is a feature with a unique algorithm based on the personal inclinations of Airbnb users that introduces and matches them to more areas/neighborhoods with particular traits that might not have been originally considered (Airbnb, 2016f). The wish list is an individual list of properties that users might like, whereas the instant book listing allows guests to choose the travel dates and book instantly without preliminary approval from the hosts (Airbnb, 2016g). To appreciate the achievement of hosts, Airbnb awards the superhost to whomever hosts at least 10 trips in a year, maintains a $90 \%$ response rate, receives a 5-star review for at least $80 \%$ of total reviews, and completes each of the confirmed reservations without cancelling (Airbnb, 2016h). Being a superhost, the hosts will be given a badge in their account as a recognition of their impeccable standards.

Airbnb has attempted to widen the exposure of its corporate brand through various channels such as Airbnb blogs, the annual festival Airbnb Open, and the referral program that allows registered Airbnb users to earn a maximum of \$5,000 USD travel credits upon referring relatives to create a valid Airbnb account and become either a legitimate guest or a host (Airbnb, 2016i). 
Figure 4.8: The interface of Airbnb

Source: Airbnb, 2016

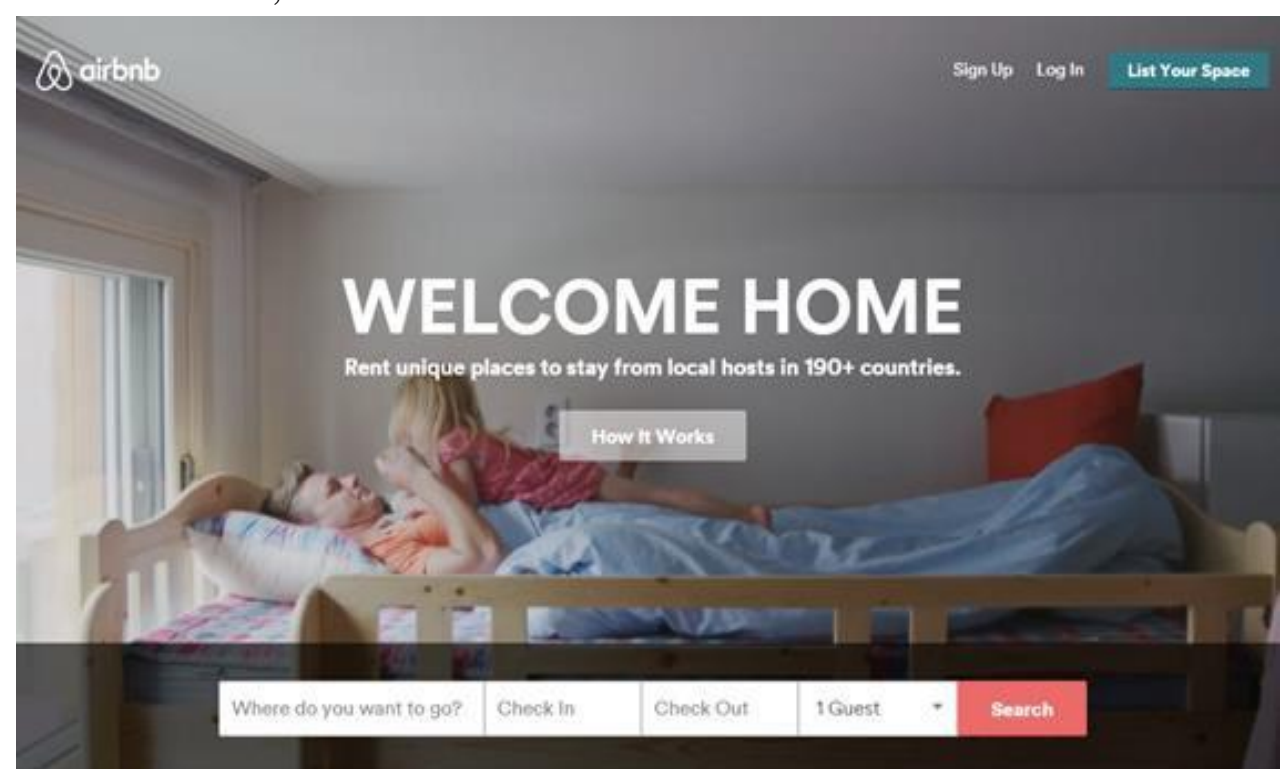

Figure 4.9: The interface of Airbnb

Source: Airbnb, 2016

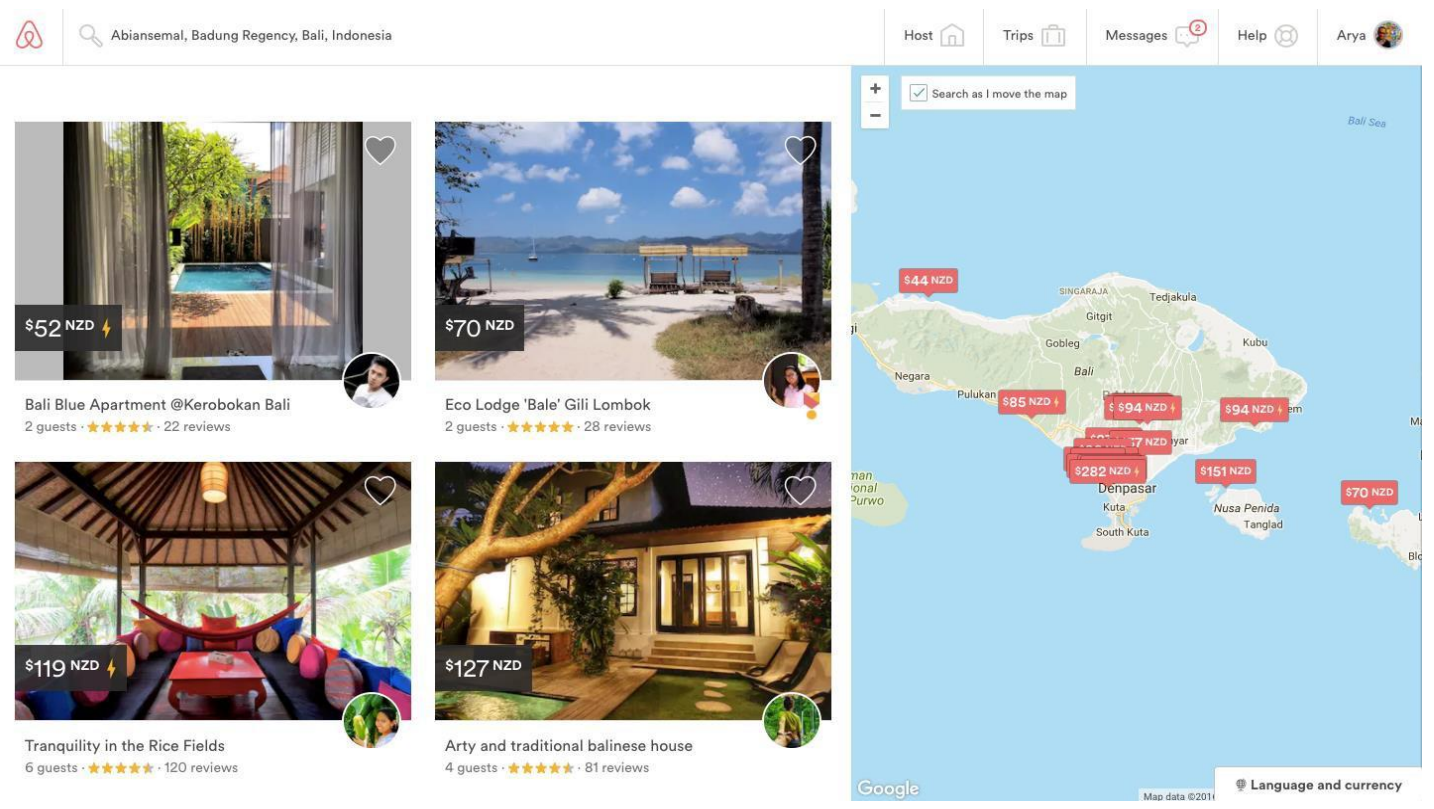


Figure 4.10: The searching and payment process in Airbnb Source: Airbnb, 2016

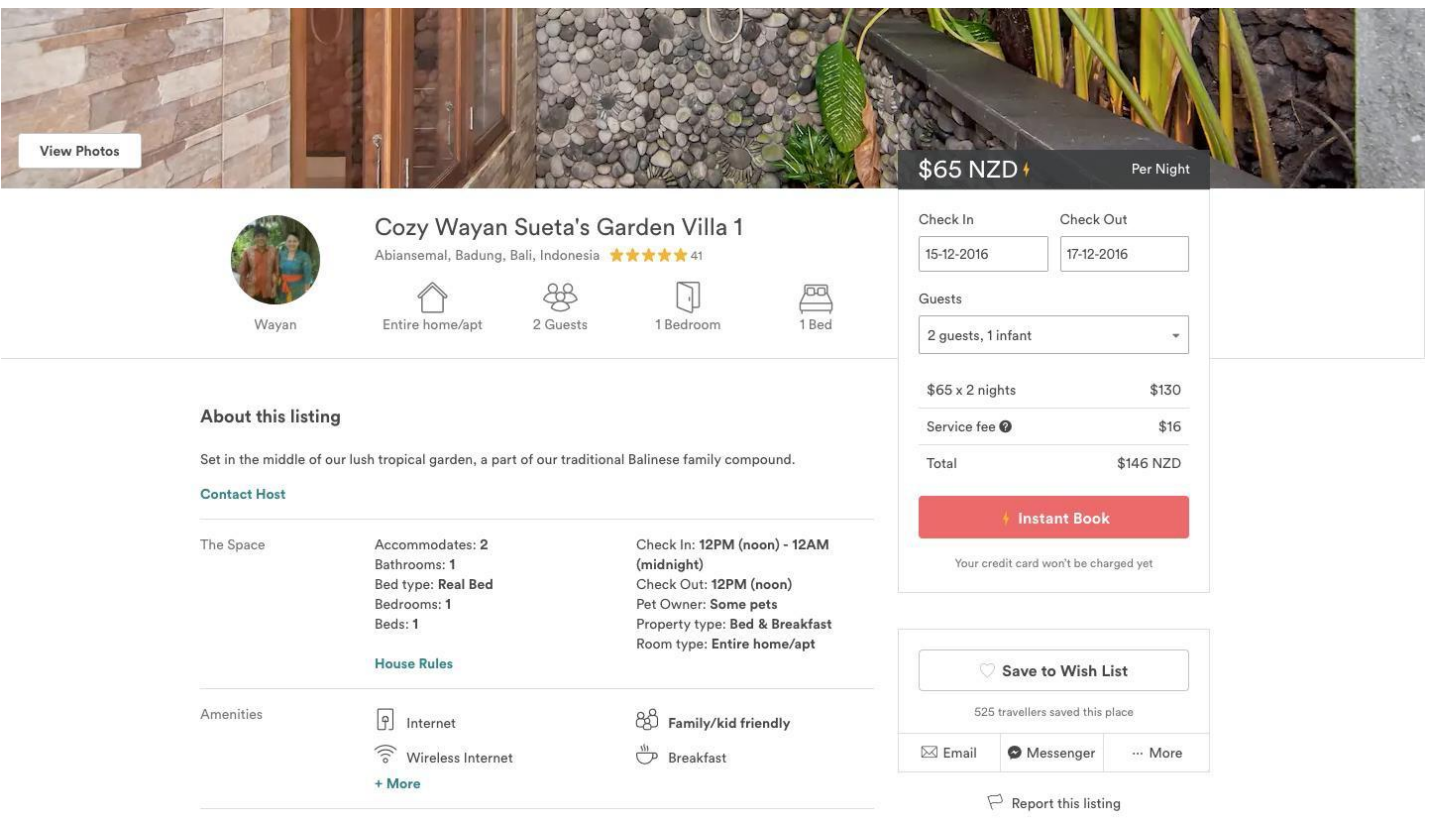

Figure 4.11: The guidebook of Airbnb

Source: Airbnb, 2016

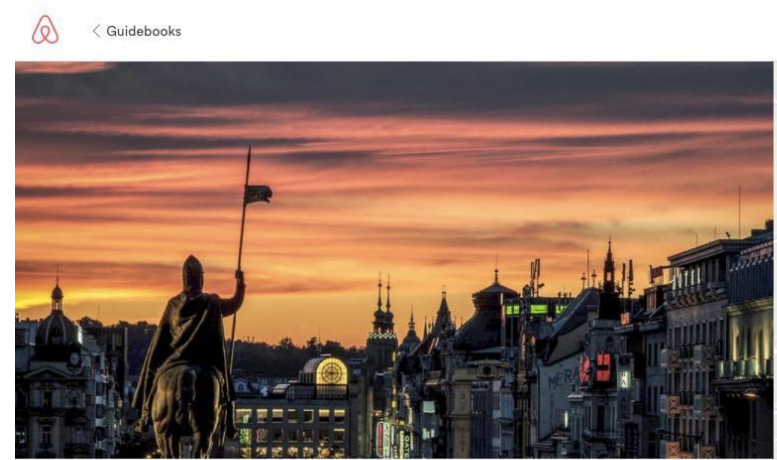

\section{Things to do in Prague}

Here's your key to the city. A definitive guide of the best local spots, as told by local Airbnb hosts
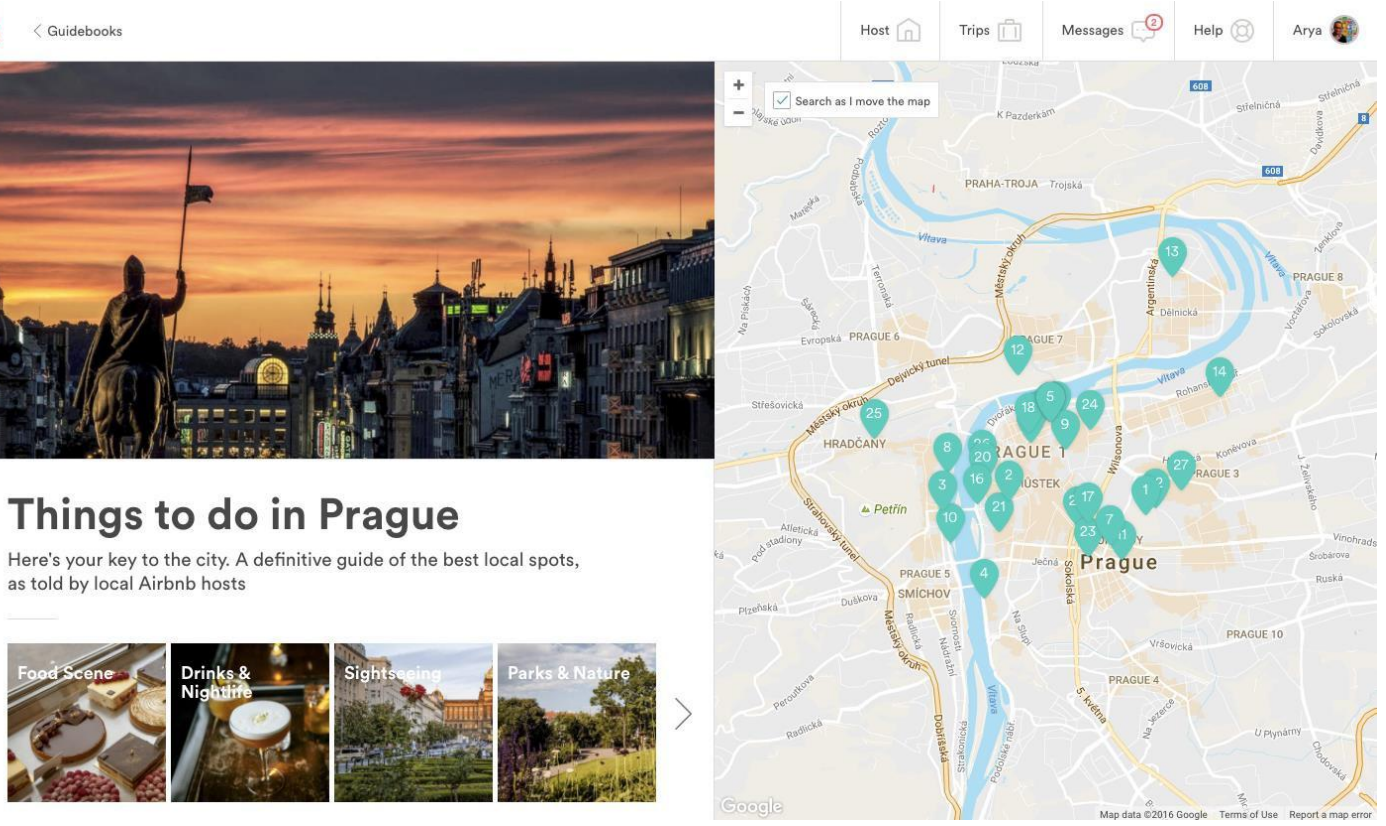


\subsubsection{Key quotes emphasizing the driver}

These key quotes summarize what panelists had to say about innovations in the sharing economy platform:

"Airbnb got a very slick, sophisticated, smart system. Airbnb is developing yet more sophisticated infrastructure within the IT system for the better. They always very innovative of what they offerings are, for instance by adding on "the wishlist", or by organizing annual events called "Airbnb open" where a lot of Airbnb hosts are going to discuss products, enhancements, changes, problems, and the people. When you have 20 people in the room and 10 of them say "we do not like this or that", I got a very strong impression that they will listen, and if they can, they adapt to the system to favor these people who do not like things. They are always making changes; they open enough to receive comments. Every now and then, the screen on Airbnb is always changing, with all that boxes but maybe a few months later, it will not be there anymore because most people do not like the user interface or just do not work well."

[Interview Panelist \#13]

\subsubsection{The future of innovation of sharing economy platform}

As the sharing economy in accommodation platforms continue to improve their consumer enhancement features, future evolution might ensure the fulfillment of fundamental principles in the sharing economy. First, such features guarantee supply and demand are evenly dispersed without allowing the top listings to dominate. That being said, the promise of creating micro-preneurs with income streams would be successfully accomplished. For that purpose, platforms in the future would able to match-make personalities and hosting styles to particular guests, which helps promote those hosts that have not got any inquiries, yet are qualified to deliver excellent hospitality (Porges, 2015). Second, the platforms would extend their services to go beyond providing spare rooms into finding a guided-tour, booking a restaurant, and allowing local services and products such as welcome kits, private chefs, and laundry services to sell on the platform (Fix, 2016). Third, platforms may facilitate cultural translation by providing features to helps hosts understand the cultural backgrounds of their guests and vice versa (Porges, 2015), ranging from types of breakfast to Islamic philosophy-compliant facilities needed by guests from particular countries. Fourth, platforms may be allow more inclusive lodging providers to different market segments that have not been captured previously. Porges (2015) mentions the potential to serve business travel, romantic trips or honeymooners, and babymooners. 


\subsection{Driver 9: Variety of low cost carriers}

This driver is linked with the growing number of various low cost airplanes to travel into and within Indonesia.

\subsubsection{Literature review relating to variety of low cost airplanes}

Some low cost carriers (LCCs) in Asia have expanded their domestic routes services into larger market shares by servicing long-haul international routes within Asia. Airlines include Tiger Airways, AirAsia, and Jetstar (Chung \& Whang, 2011). Tiger Airways and Jetstar, the subsidiary of Australian flag carrier, Qantas Airways, have operated long-haul routes into bordering countries. Indonesia's homegrown airline corporation, Lion Air, has been scaling up their coverage on international routes and also carrying Indonesian pilgrimage travelers to Saudi Arabia (Lion Air, 2016).

In terms of intra-Indonesia routes, OECD (2014) points out that, after the liberalization of the air transportation industry was put into practice in 1999, the number of airline companies increased to 27 in 2004 from only 7 in 1999. Among them, 17 airlines serve domestic routes, dominated by LCCs. The liberalization is an important step taken by the Indonesian government because air transportation plays a big role in the archipelagic country. In fact, over the years Indonesia's largest airline groups like Lion Air and Garuda Indonesia have been taking action to expand their domestic networks and to provide more services from regional hubs to second or third tier destinations through LCCs or subsidiary airlines (Airline Leader, 2016). These dominate major domestic routes with Lion Air (see Figure 4.12). As a result Indonesia's domestic passenger numbers doubled in four years from 2008 to 2012, exceeding 70 million and making Indonesia the world's fifth largest domestic market (Airline Leader, 2016). However, the expansion of smaller Indonesian LCC corporations will increase as they seem slow to expand in the international market and inclined to focus on servicing domestic routes; this trend is also triggered by government incentives for LCC companies who serve pioneer routes, i.e. to locations in isolated and underdeveloped areas, and unprofitable to run (OECD, 2014; Airline Leader, 2016). 
Figure 4.12: Domestic routes served by Lion Air

Source: Lion Air, 2016

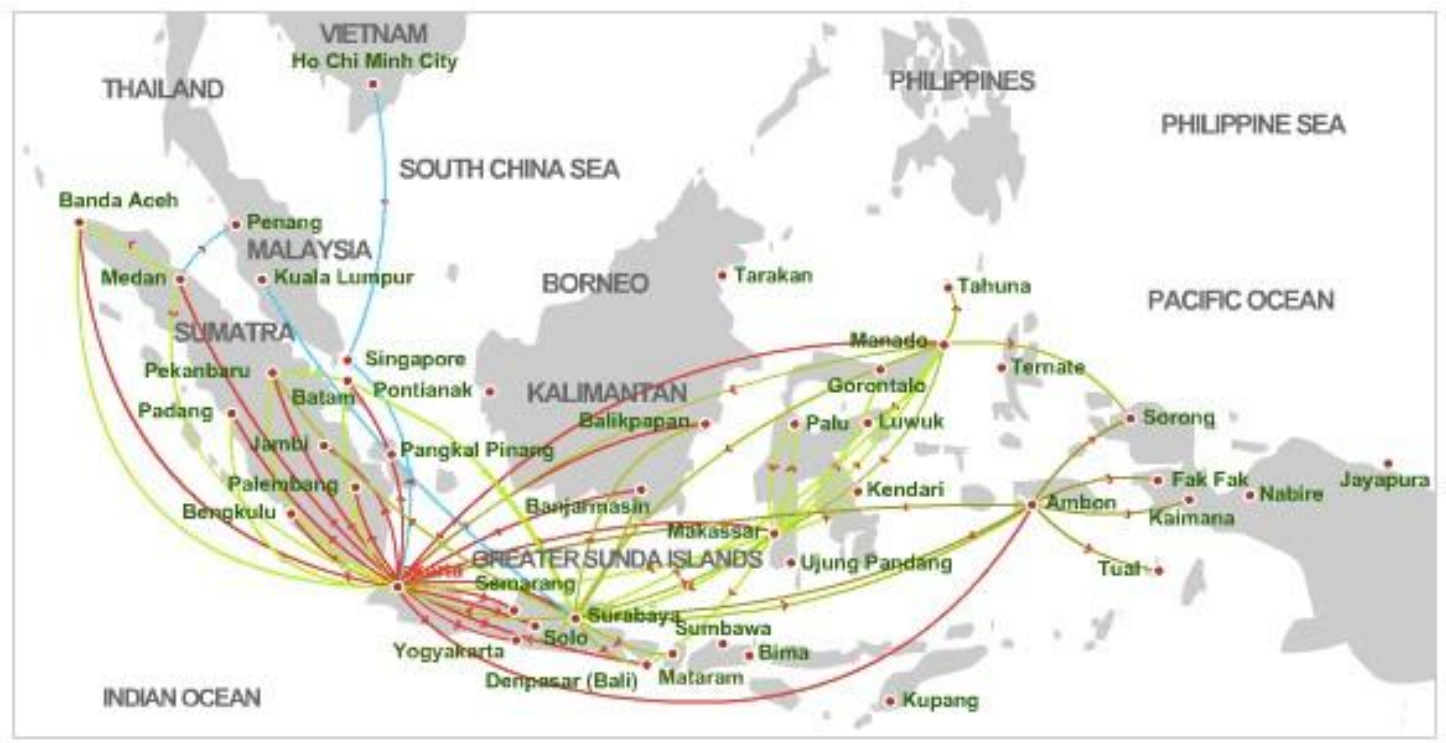

\subsubsection{Key quotes emphasizing the driver}

This is what panelists embraced about the variety of low cost carriers:

"The driver could be the cheap travel. The increase of city-focused tourism that has been made possible, thanks to cheap flights. So low cost travel is also the important driver that has boosted the city tourism, and supports the popularity of sharing economy in accommodation platform. The cheap travel has created the conditions and created the demand that once did not exist."

[Interview Panelist \#8]

\subsubsection{The future of the low cost carriers}

Figure 4.13 forecasts that numbers of Asia passenger will grow at an average rate of over 6.0 percent per year from 2016 until 2036. The Asia region is also predicted to experience a robust growth rate in terms of airlines and airport capacity in the next 20 years driven by the region's strong economic development and increasing aircraft infrastructures (Boeing, 2016).

As the passenger traffic throughout Asia will constitute 48.7 percent of global passenger traffic by 2035 due to the growing middle class, LCCs will shift their attention to capture the potential demand. Boeing (2016) forecast the LCC model, which was initially designed to supply short-haul travel at the lowest fares, will slowly shift into tapping corporate/business travel with a premium cabin in the new long and 
medium-haul routes.

Figure 4.13: World passenger's traffics

Source: Boeing, 2016

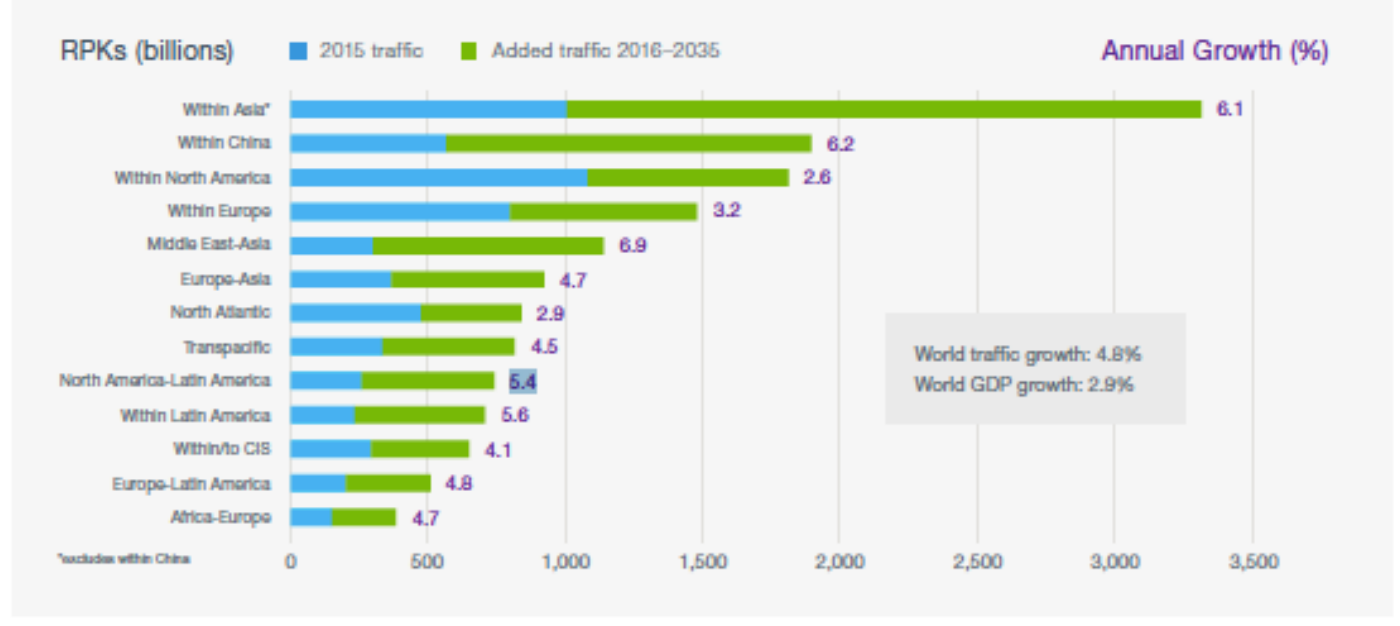

\subsection{Driver 10: Cultural tradition of Bali}

This driver involves the ability of Bali and Balinese to preserve their unique rituals and cultural values of their daily activities, as the primary attraction of Bali.

\subsubsection{Literature review relating to cultural tradition of Bali}

For decades, Balinese culture has been the main feature of Bali tourism and has been praised for its dynamic resilience, while the Balinese have also been praised by many for the ability to take advantage of their appealing culture as the pull factor in inviting tourists without sacrificing their own values as a purely mercantile commodity (Picard, 2008). Amid the continuous debates about how tourism at some points had 'polluted' Balinese culture, many admit the opposite: that tourism and Balinese culture rather developed symbiotically. Tourism has been contributing towards cultural preservation and cultural creativity, and also towards turning Balinese culture into a source of both profit and prestige for Balinese (Picard, 2008). Along with the flood of tourists, Bali's picturesque cultural traditions have also invited many European artists and scholars who have lived among local communities, thus enhancing the richness of indigenous traditions (Romanos \& Jenkins, 2013). 
Over the years, joint attempts have been made by Balinese stakeholders and Indonesian central government to maintain the desired harmony between tourism growth and cultural resilience. Some of the most important are: First, issuing revised regulations about cultural tourism in 1991, which was intended to develop Balinese culture to attract tourists while the revenue generated from tourism was used to foster the culture (Picard, 1990). Second, the campaign of 'Ajeg Bali' (Bali erect) which not only aimed to preserve Balinese culture by not losing its Balinese, but also act as a safeguard for the island especially after the bombings on October 2002 (Picard, 2008). Lastly, the annual Bali Arts Festival, which serves as a local celebration to encourage the dynamic development of Balinese arts and culture, and provides a sense of pride in local culture (Hitchcock \& Darma Putra, 2007). These endeavors, together with the vibrant cultural expression, and the embedded unique traditions of the Balinese that are displayed in the form of artifacts (painting, wood and stone sculpture, furniture, masks and costumes, and temple offerings) as well as performances and ceremonies (dancing, music, cremations), are the key factors for the renaissance of Balinese culture as the backbone of Bali tourism.

\subsubsection{Key quotes emphasizing the driver}

Below is what one panelist embraced about the cultural tradition of Bali:

"Tourists come to Bali for the culture. As Balinese, we never created such attraction.

Our culture is inherited. It is also an obligation. For example after we cook and before we eat, we thanks God. Our life philosophy is Tri Hita Karana, which means we have to possess a great relationship with God, the people and the environment. We are also required to respect each other. We have a ceremony once in every 6 months for plants and for the environment. We give thanks because we feel we have benefited a lot from the earth and its environment."

[Interview Panelist \#9]

\subsubsection{The future of cultural tradition of Bali}

Many believe the underlying factors that naturally maintain the culture is the system that orders the civil aspect of the community, the Banjar and its unique dual currency system (Lietaer \& DeMeulenaere, 2003). Banjar usually comprising between 75 and 1200 members, is an ancient civil unit structure that holds together the Balinese in democratic and mutual cooperation, and in which a dual currency system is operated. Two different kind of currencies are used: the Rupiah, which is the national currency of Indonesia, and the Nayahan Banjar, which constitutes time service currency or 
"work for the common good". Both currencies work simultaneously in the sense that financial and physical contributions can be mobilized in order to put into practice what the Banjar decides is important. For participating members, the Banjar's large-scale religious and cultural projects for example, require the involvement of Rupiah money, but more importantly Navahan Banjar, the 'Time money'. Performing a great Kecak dance at a Balinese temple, regularly working three hours in the morning, afternoon, and evening, requires a lot of Time money. The complementary currencies help to generate social capital which result in cultural resilience (Lietaer \& DeMeulenaere, 2003). Considering how these principle and currency systems are embedded in all 3000 Banjar operational in Bali (Lietaer, 2003), and how this practice have been faultlessly applied over the decades, the future of Bali's cultural tradition will remain sustainable and resistant to foreign influences. In the future, we might be able to witness the existence of the Balinese sacred dances to God and an abundance of ceremonies throughout the years as the result of the "strong community fabric" driven by the solid traditional organizational structure and its unique currency system.

\subsection{Driver 11: Oversupplv of hotel rooms in Bali}

This driver addresses the continuous expansion of new hotels in Bali leading to the oversupply of hotel rooms that implicate environmental concerns and tariff wars among lodging suppliers.

\subsubsection{Literature review relating to oversupply of hotel rooms in Bali}

In 2015 Bali has 2.079 hotels from different classifications, a slight increase from 2.050 hotels a year before but significant upsurge from 1.691 hotels in 2010 (Statistic Bali, 2016). According to the report issued by HVS (2015), the hotel supply in Bali will continue to flourish ranging from budget to upper luxury. The uninterrupted hotel developments and surplus of rooms in Bali have raised concern about, firstly, the general decline in occupancy rates, and secondly, the impact on the environment. Table 4.3 shows a definite decline during 2012 to 2015 with a slight improvement in 2015. However, by and large, the hotel occupancy rate in Bali sits below 60\% from 2009 . Despite the continual increase in numbers of tourist arrivals, the industry needs to be cognizant of the repercussions of supply growth outpacing demand. A study conducted by the Ministry of Tourism and Udayana University confirmed Bali was suffering from 
oversupply of hotel rooms with more than 9,800 rooms, after which the Governor of Bali declared a moratorium on the development of new hotels on 2011 (Walhi, 2014). However, evidence suggests that the moratorium is far from being fully implemented (Nengah 2013; Colliers, 2015). According to Walhi (2014), permissions were given secretly so that some new exclusive hotels were built during the prohibition.

Table 4.3: Occupancy rate in Bali

Source: Statistic Indonesia, 2015

\begin{tabular}{|c|cccccc|}
\hline $\mathbf{2 0 1 5}$ & $\mathbf{2 0 1 4}$ & $\mathbf{2 0 1 3}$ & $\mathbf{2 0 1 2}$ & $\mathbf{2 0 1 1}$ & $\mathbf{2 0 1 0}$ & $\mathbf{2 0 0 9}$ \\
\hline 51,60 & 51,28 & 54,35 & 55,43 & 55,38 & 55,28 & 53,05 \\
\hline
\end{tabular}

In some parts of the island with high touristic activity, land availability, particularly the beachfront area, becomes scarcer (HVS, 2015). The wave of new hotel expansion implicates water shortages, as experienced in Kuta regency when water sources dropped from 20 to 25\% against normal (Horwarth, 2015; Nengah, 2013; Walhi, 2007). Also, the substantial increase of energy consumption every year without adequate supply, impels Bali to "import" some supplies from Java Island. Many believe that Bali will suffer an electricity crisis in 2017-2018, if proper management is not achieved or with a failure to provide supplementary energy resources (Himawan \& Hapsari, 2016; Walhi, 2007).

\subsubsection{Key quotes emphasizing the driver}

The evidence of this key driver is summed up in the following quotation:

"I think there are too much hotels in Bali. It is true that Bali local government has applied the regulation about minimum standard of room size at $4 \times 8$ meters and minimum square yards in area but many investors can still afford and find the required land for it. As the consequence, the room rate goes very cheap at \$18-23 a night with only $60 \%$ on occupancy rate. This is worrying!"

[Interview Panelist \#12]

\subsubsection{The future of oversupply of hotel rooms in Bali}

Future outlook for the total hotel numbers in Bali is currently unavailable. Nonetheless Colliers's (2015) prediction on the cumulative supply of star hotel projects in Bali from 2010 to 2019 (see figure 4.14) shows a constant increase. 
Figure 4.14: Cumulative supply of star rating hotel projects Source: Colliers, 2015

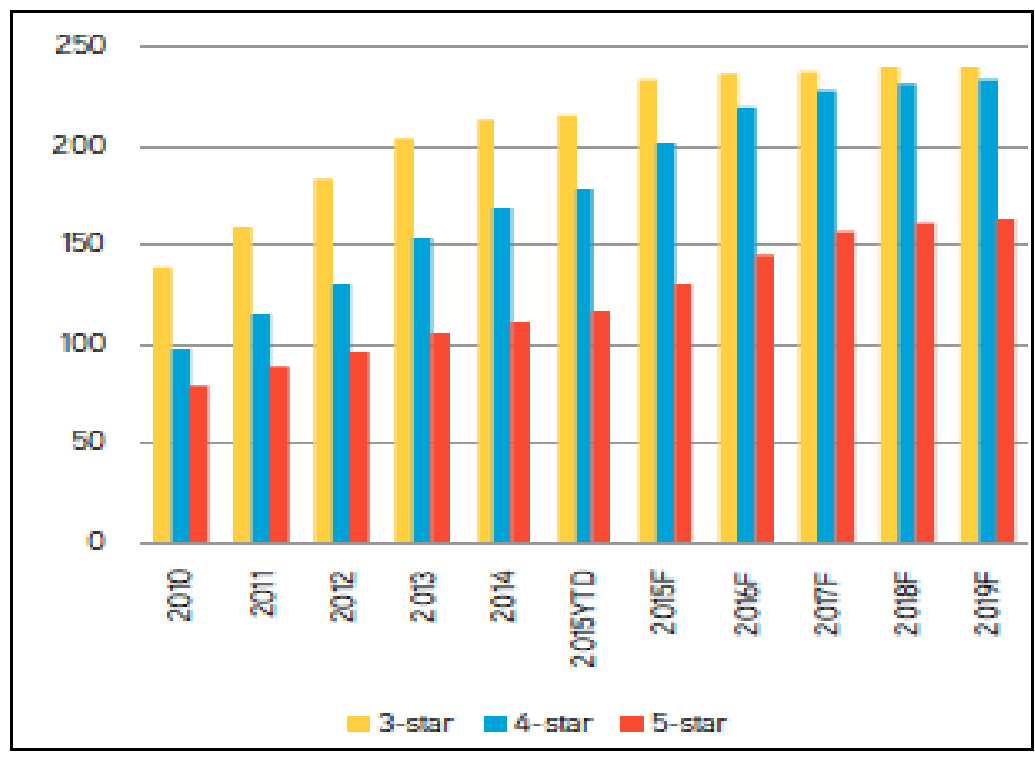

However, considering the persistent decrease in occupancy levels and the damaging impact on the environment, the government will likely force a moratorium on the new hotels at any risk in order to remedy industry performance and to reduce critical land area. As a result, the growth of new hotels in 2030 will remain stagnant, as it is expected to be in the early 2020s, with only small additions in permissions, and then owing to their contribution to help revitalize the environment and to ease the 'tourist bubble' at the same time. See, for example, the Benoa Bay project mentioned in driver 6: infrastructure development.

\subsection{Driver 12: Abundance of idling capacity in Bali}

This driver discusses the phenomena of idling capacity and the underutilized assets in Bali in the form of spare houses, which enlarge the potential of the sharing economy in accommodation.

\subsubsection{Literature review relating to abundance of idling capacity}

Botsman and Rodgers (2010) point out that $80 \%$ of belongings in the United States are used less than once a month. Some of those are cars that are left unemployed in parking lots or garages, the spare bedroom that is rarely used, or the office space and its equipment that are used for less than 12 hours. The unused potential of those when they are not in use is what Botsman and Rodgers (2010) referred to "the idling capacity". 
For the case of accommodation in Bali, one of the most explicit examples of the idling capacity is the growing of second homes, defined as non-mobile privately owned dwellings for recreational residences and secondary use (Hiltunen, 2007). For foreigners to own land and property in Indonesia is strictly prohibited by Indonesian law, however, the newly-elected president, Joko Widodo, recently signed a government regulation allowing foreigners to buy a landed house or apartment under the 'right-ofuse' category, weaker than the 'right-for-ownership', for a period of up to 80 years (Indonesia-investments.com, 2016). Nevertheless, the media claims that although there are no statistics available on the actual figures, around 40 percent of properties in Bali are owned by foreigners (The Jakarta Post, 2015), with buyers from Australia, France, United Kingdom, Singapore, and Hong Kong purchasing their second homes or property investments there (Hodal, 2013). The vacant status of second homes primarily visited only on holiday, and the fact that many second homes are very well equipped, increase the percentage of idling capacity.

\subsubsection{Key quotes emphasizing the driver}

Key quotes highlighting the expanding of second homes in Bali include:

"I know a residential area located on top of the hill in Bali where houses are rented out. In the different case, an entrepreneur leases civil servant's second home for 5 to 10 years, then the house is rented out to foreign tourists for profits. This practice is really common in Bali."

[Interview Panelist \#2]

\subsubsection{The future of idling capacity in Bali}

When predicting the future of second homes in Finland, Pitkanen and Vepsalainen (2008) have mentioned possible alternative forms including commercial second homes and urban second homes. Pitkanen and Vepsalainen have also predicted the possibility of regional differentiation, where clusters of second homes are built in some areas only accessible to the wealthier, contributing to the creation of an elite landscape. Aligned with that prediction, the Prime International Residential Index (PIRI) shows Bali as the leading Asian second-home market with the highest value of residential luxury in 2014 (Knight Frank, 2015). As seen in table 4.4, values in Bali reached an annual increase of $15 \%$ in comparison to the previous year, making this island among the world's most luxurious second home destinations amid the domination of the US and Middle East. 
Table 4.4: Top 10 of luxury property and second home locations Source: Knight Frank, 2015

\begin{tabular}{|cllc|}
\hline Rank & \multicolumn{1}{c}{ Location } & \multicolumn{1}{c|}{ World region } & Annual change (\%) \\
\hline 1 & New York & North America & 18.8 \\
\hline 2 & Aspen & North America & 16.0 \\
\hline $3=$ & Bali & Asia & 15.0 \\
\hline $3=$ & Istanbul & Middle East & 15.0 \\
\hline 5 & Abu Dhabi & Middle East & 14.7 \\
\hline 6 & San Francisco & North America & 14.3 \\
\hline 7 & Dublin & Europe & 13.4 \\
\hline $8=$ & Cape Town & Africa & 13.2 \\
\hline $8=$ & Muscat & Middle East & 13.2 \\
\hline 10 & Los Angeles & North America & 13.0 \\
\hline
\end{tabular}

Considering the looser regulations issued by Indonesia's new president for foreign ownership of houses, and the rising land price in Bali, the idling capacity of second homes in Bali will inevitably face increasing regional differentiation, with the crowding of certain areas including urban regions, contributing to the creation of elite landscape.

\subsection{Driver 13: The disruptive innovation of the sharing economy in} accommodation

This driver is about the disruptive effect of the sharing economy in accommodation on the incumbent tourism-related industry.

\subsubsection{Literature reviews relating to the disruptive innovation of the sharing economy in accommodation}

Christensen and Raynor (2003) describe disruptive innovation as “... products and services that are not as good as currently available products... but offer other benefits - typically, they are simpler, more convenient, and less expensive products that appeal to new or less-demanding customers". At the early stage of its appearance, disruptive innovation will capture only new or low-end markets with small margins, so it is unappealing to companies with a focus on sustaining innovation. Nonetheless, over time the previously inferior products and services eventually improve to intersect with the needs and preferences of more demanding consumers. By the time bigger companies are attracted by its market potential, disruptive innovation has been firmly established, leaving incumbents struggling to compete. Christensen and Raynor supplement the theory with case studies in the economic sector. For example, 
Bloomberg began by providing financial data, analysis, and financial business news, substantially disrupting bigger players such as Dow Jones and Reuters. The tourism sector is epitomized by the rise of Online Travel Agencies (OTA), which offer convenience and cost saving, despite the absence of personalized services that traditional bricks-and-mortar travel agencies usually offer (Guttentag, 2015).

Evidence suggests the sharing economy in accommodation is consistent with disruptive innovation theory. The sharing economy platform in accommodation like Airbnb is noticeably lacking in hospitality attributes that are the main considerations for common consumers in selecting accommodation, such as service professionalism/quality, staff friendliness, brand reputation, and security (Dolnicar \& Otter, 2003). Nevertheless they offer these attractive attributes:

a. A relatively cheaper price

Morgan Stanley, quoted in Bird (2015), specify cheaper price to be the most important factor in leading tourists to stay in Airbnb listings, indicating the popularity of this benefit among global travelers.

b. Consumers and user friendly

Unlike the traditional bed and breakfasts (B\&BS) that commonly struggle to make their products known to potential consumers, sharing economy platforms like Airbnb have made it simple for consumers to access descriptions and photographs of accommodation, as well as to attain fairer rates without obligation to compensate the middle man.

c. The 'back regions' experience

This attribute is related to authentic experiences and the intimacy of the relationship with local residents, which has been discussed earlier (refer to the 'Living like a local' tourist driver).

As shown in table 4.5, the valuation of Airbnb, which achieved \$25.5 Billion in 2015, is higher than Marriot International or Hilton Worldwide but with smaller margins than both (Skift, 2016). The statistics and trends determine a pattern of disruptive innovation in the sharing economy platform in accommodation. Airbnb's small revenue margin is consistent with disruptive innovation signposts, as many other examples of disruptive innovation begin with capturing low-end markets with small margins (Christensen and Raynor, 2003). 
Table 4.5: Valuation and revenue comparison of accommodation providers in 2015 Source: Skift, 2016

\begin{tabular}{|lcc|}
\multicolumn{1}{c}{ Company } & Valuation/Market Cap & Revenue \\
\hline Marriott International & $\$ 18.59 \mathrm{~B}$ & $\$ 3.6 \mathrm{~B}$ \\
\hline Hilton Worldwide & $\$ 23.2 \mathrm{~B}$ & $\$ 2.9 \mathrm{~B}$ \\
\hline Accor Hotels & $\$ 10.2 \mathrm{~B}$ & $\$ 1.58 \mathrm{~B}$ \\
\hline Wyndham & $\$ 8.9 \mathrm{~B}$ & $\$ 1.56 \mathrm{~B}$ \\
\hline Starwood Hotels & $\$ 12.4 \mathrm{~B}$ & $\$ 1.4 \mathrm{~B}$ \\
\hline Hyatt Hotels & $\$ 6.9 \mathrm{~B}$ & $\$ 1 \mathrm{~B}$ \\
\hline Airbnb & $\$ 25.5 \mathrm{~B}$ & $\$ 340 \mathrm{M}$ \\
\hline Choice Hotels & $\$ 2.9 \mathrm{~B}$ & $\$ 241.5 \mathrm{M}$ \\
\hline
\end{tabular}

\subsubsection{Key quotes emphasizing the driver}

This is what panelists embraced about the topic of disruptive innovation of the sharing economy in accommodation:

"The phenomena of people renting out the room is not new but the distribution attached to Airbnb or similar platform is new. So the fact that these communication channels reach the consumer is new and disruptive."

[Interview Panelist \#8]

"What we see today is a creative disruption towards established ecosystem. Uber shows us how it disrupts taxi industry and we (government) haven't have regulation to control that disruption."

[Interview Panelist \#3]

\subsubsection{The future of disruptive innovation of the sharing economy in accommodation}

Despite relatively little clear evidence clarifying the disruption of the sharing economy in accommodation, current literature identifies the extent to which disruption signposts are still limited to the lodging provider industry. In the future, the sharing platforms would be expected to threaten various tourism-related actors. First, the OTAs as sharing platforms offer a much more cost-effective opportunity for small and independent hotels (Citi GPS, 2015). While OTAs normally charge the hotels up to $25 \%$ of the room revenues, and given the costs of daily operation, sharing platforms like Airbnb charge only $9-15 \%$ on room revenues. As shown by figure 4.15, by 2020 Airbnb would challenge Expedia, the world's largest OTA, in terms of the number of accommodation bookings, which might also involve medium scale hotels who find Airbnb the more economical distribution channel. 
Figure 4.15: Hotel booking comparison: in 2014 (left) and booking scenario in 2020 (right)

Source: Citi Gps, 2015
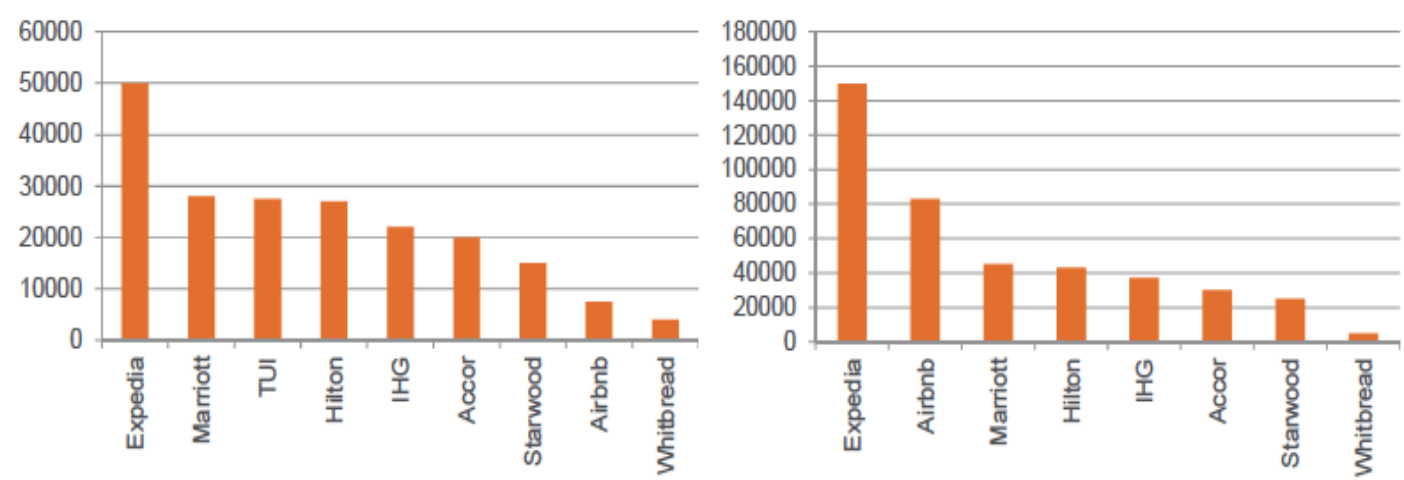

Second, the sharing platforms might become the entry points to the restaurant industry as some of the shared houses' hosts might cook local food and traditional recipes, and, through the platforms, invite tourists into intimate, friendly dinner environments (Ferenstein, 2014). If continued, there might be homes turned into regularly visited restaurants while the hosts themselves would become breakout chefs famous for their home-style cooking. Lastly, as foreseen by Oskam and Zandberg (2016), similar business concepts and local pop-up concepts that challenge the sustainability of mature sharing platforms in accommodation like Airbnb and HomeAway could be expected.

\subsection{Driver 14: Popularity of reputation and rating system}

This driver concerns the increasing popularity of digital reputations and rating systems to mediate trust between strangers in the sharing economy in accommodation platforms like Airbnb.

\subsubsection{Literature review relating to popularity of reputation and rating system}

By their own nature, the cornerstone of sharing economy models rely on social connection and interaction between strangers - such connections are built upon trust (Piscicelli et al., 2015; Finley, 2013; Botsman, 2012). Given the importance of trust to successful sharing economies, reputation systems are introduced to mediate trust between strangers. Finley (2013) holds that this is exemplified by the Airbnb reputation system (see figure 4.16), in which guests and hosts can rate and leave comments about each other in order to exchange experiences during their stays and to postulate feedback for the host. 
Figure 4.16: Example of rating and review in Airbnb Source: Airbnb, 2016

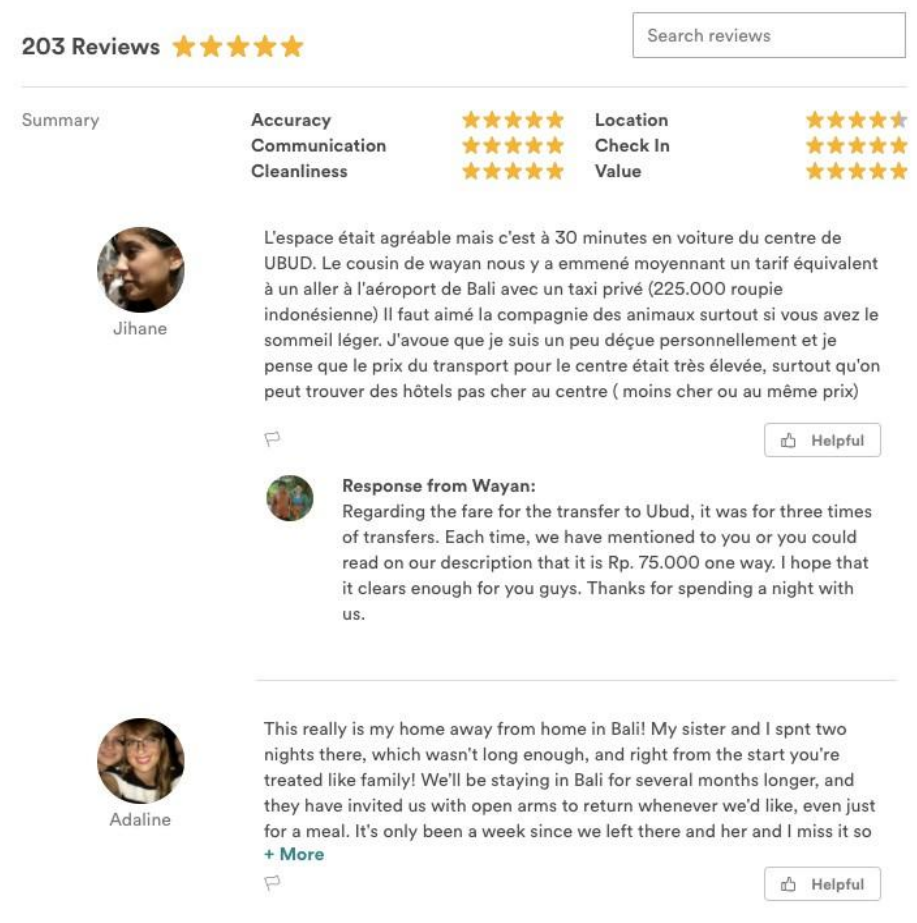

\subsubsection{Key quotes emphasizing the driver}

Panelist 6 commented on this key driver by stating that:

"So online trust that lead to offline security. What I mean by that, if you were interacting with somebody online, the old joke on the Internet is "everybody is a dog". You do not know who is the other person on the other end of the Internet. Whereas now, there are so much kind of identity that can create trust and safety mechanisms to verify if somebody is in fact real. Those things develop very recently." [Interview Panelist \#6]

\subsubsection{The future of reputation and rating system}

Considering the impact of accommodation providers on the tourists' experiences, and driven by the rise of online guest feedback, a number of initiatives to incorporate travelers' online ratings and feedback (such as Tripadvisor) into conventional accommodation classification systems have been applied. Abu Dhabi was the first tourism destination to put this into practice (Hensens, 2015). As sharing properties continue to establish themselves as a sign of trustworthy lodging providers, we can expect government involvement to integrate sharing platforms' reputation systems into conventional classification systems in the future. Therefore, the guest review is an integral part of the classification process. Having implemented the system, when accumulated online reviews of a shared property fell below a predefined threshold, 
hosts were notified that the property fell short. Failure to resolve the issue within a certain timeframe, saw the conventional rating downgraded.

\section{$\underline{4.15}$ Conclusion}

The previous sections present the discussion of the drivers of change that emerged during the first interviews in light of existing literature and empirical evidence. A total of 14 drivers of change are used for this study. Each driver of change has a different level of influence; some of the key drivers have been categorized as having a high level of importance and a high likelihood to occur, while others are only deemed to have both a low level of importance and a low likelihood to occur (see chapter 3 on methodology). The infrastructure development and ubiquitous Internet are deemed as the primary drivers whereas the rest are considered secondary drivers.

The discussion about how each driver impacts the future of the sharing economy in accommodation in Bali by 2030 is provided in table 4.6 by critically linking together the literature review, key quotes, and the future state of each driver. The list of impacts of the drivers offer a significant guide to the future pathway of the sharing economy in accommodation in Bali, and all will be used as a guide for the development and structure of Chapter 5 in which the four scenarios are presented and discussed. 
Table 4.6: Critical reflection of how the driver of change impacts the future of the sharing economy in accommodation in Bali

\begin{tabular}{|c|c|c|}
\hline Driver of change & Key highlights & $\begin{array}{l}\text { Impacts on the sharing economy } \\
\text { in accommodation in Bali by } \\
2030\end{array}$ \\
\hline Ubiquitous Internet & $\begin{array}{l}\text { Considerable tendency of } \\
\text { global Internet users and } \\
\text { infrastructures to keep } \\
\text { increasing. } \\
\text { The ubiquity of Internet of } \\
\text { Things (IoT) and new } \\
\text { generation of network (i.e. } 5 \mathrm{G} \\
\text { network). } \\
\text { The pervasiveness of } \\
\text { preordained analytics where } \\
\text { objects are connected to other } \\
\text { objects through Internet. }\end{array}$ & $\begin{array}{l}\text { The use of intelligent/smart house } \\
\text { with all-connected house } \\
\text { appliances to indulge visitors. } \\
\text { The use of preordained analytics } \\
\text { to comprehend guests' past } \\
\text { behaviour in order to offer more } \\
\text { personalized services. }\end{array}$ \\
\hline $\begin{array}{c}\text { Indonesia as a } \\
\text { developing economy }\end{array}$ & $\begin{array}{l}\text { About } 90 \text { to } 135 \text { million } \\
\text { Indonesians will join the consuming } \\
\text { class with sufficient income to } \\
\text { spend on investment and } \\
\text { travel/leisure as the result of GDP } \\
\text { increase. }\end{array}$ & $\begin{array}{l}\text { Bali would expect a substantial } \\
\text { upsurge in the number of domestic } \\
\text { tourists, which affect the demand } \\
\text { on accommodation. } \\
\text { More starting from scratch } \\
\text { entrepreneurs in temporary lodging } \\
\text { service due to sufficient demand. } \\
\text { Starting from scratch } \\
\text { entrepreneurs defined as ordinary } \\
\text { residents who identify } \\
\text { opportunities of visitor necessities } \\
\text { then launch their own enterprise to } \\
\text { fill the needs (Koh and Hatten, } \\
\text { 2002). }\end{array}$ \\
\hline $\begin{array}{c}\text { Smart technologies } \\
\text { domination }\end{array}$ & $\begin{array}{l}\text { - Increasing numbers of } \\
\text { smartphone users and mobile } \\
\text { Internet subscribers. } \\
\text { Multiple modifications of } \\
\text { smartphone and progressive } \\
\text { improvement of smart } \\
\text { technologies. }\end{array}$ & $\begin{array}{l}\text { Further amalgamation of smartphones } \\
\text { and smart technologies that enable } \\
\text { innovations such as real-time video talk } \\
\text { on smartphones between prospective } \\
\text { guests and hosts prior to the 'deals' so } \\
\text { the host could inspect the properties in } \\
\text { their real time condition. }\end{array}$ \\
\hline $\begin{array}{l}\text { Political decision on } \\
\text { the sharing economy }\end{array}$ & $\begin{array}{l}\text { Indonesia shows positive progress } \\
\text { in the global democracy ranking } \\
\left(63^{\text {rd }} \text { out of } 113 \text { countries) in } 2013 \text { - }\right. \\
2014 \text {. }\end{array}$ & $\begin{array}{l}\text { The democratic state would put it in } \\
\text { place supportive regulations to ensure } \\
\text { equal access to economic opportunities, } \\
\text { including sharing one's spare room in } \\
\text { exchange for extra income. }\end{array}$ \\
\hline $\begin{array}{l}\text { Domination of } \\
\text { Generation } \\
\text { Y/Millennial } \\
\text { Generation }\end{array}$ & $\begin{array}{l}\text { The constant increase of Bali } \\
\text { inbounds arrivals and tourism } \\
\text { expenditures. } \\
\text { Three biggest international } \\
\text { tourist segments are to be } \\
\text { millennial travellers from Asia } \\
\text { region: Singapore, Malaysia, } \\
\text { and China. }\end{array}$ & $\begin{array}{l}\text { More opportunities for sharing } \\
\text { economy in accommodation in Bali as } \\
\text { Millennial travelers prefer to stay at } \\
\text { locals' houses and to interact with } \\
\text { native residents. }\end{array}$ \\
\hline
\end{tabular}




\begin{tabular}{|c|c|c|}
\hline $\begin{array}{l}\text { Infrastructure } \\
\text { development }\end{array}$ & $\begin{array}{l}\text { New infrastructures built to } \\
\text { accommodate more tourists and to } \\
\text { connect different strategic tourism } \\
\text { regions. }\end{array}$ & $\begin{array}{l}\text { Equal tourist distribution to previously } \\
\text { less visited areas therefore the demand } \\
\text { for the sharing economy in } \\
\text { accommodation was adequately } \\
\text { dispersed in every corner of Bali. }\end{array}$ \\
\hline $\begin{array}{l}\text { 'Living like a local' } \\
\text { tourists }\end{array}$ & $\begin{array}{l}\text { The desire to engage in local } \\
\text { lifestyle and human contact, and to } \\
\text { seek authenticity remains } \\
\text { sustainable in the world full of } \\
\text { falseness. }\end{array}$ & $\begin{array}{l}\text { Sustainability of the sharing economy in } \\
\text { accommodation in Bali as long as it } \\
\text { benefits both sides with cultural } \\
\text { exchange and understanding of different } \\
\text { culture. }\end{array}$ \\
\hline $\begin{array}{l}\text { Innovation of the } \\
\text { sharing economy } \\
\text { platform }\end{array}$ & $\begin{array}{l}\text { The continuous modification of } \\
\text { sharing platforms features }\end{array}$ & $\begin{array}{l}\text { Further increase of engagement between } \\
\text { hosts and guests, from which trust and } \\
\text { credibility of sharing platform were } \\
\text { built, but most importantly the } \\
\text { modification would attract more users } \\
\text { and maintain their loyalties }\end{array}$ \\
\hline $\begin{array}{l}\text { Variety of low cost } \\
\text { carriers }\end{array}$ & $\begin{array}{l}\text { The 'within Asia' passengers } \\
\text { would be the world's largest } \\
\text { passenger traffic markets in } \\
2035 \\
\text { - LCC would have new markets } \\
\text { and new business models by } \\
\text { tapping corporate/business } \\
\text { travel in the new long and } \\
\text { medium-haul routes }\end{array}$ & $\begin{array}{l}\text { - The affordable transportation link } \\
\text { for different market segments would } \\
\text { alter 'seasonal habits' and allow } \\
\text { tourists, particularly foreigners to } \\
\text { undertake vacations or any kind of } \\
\text { travel to Bali almost every time } \\
\text { More stable tourist arrivals to Bali } \\
\text { throughout the year }\end{array}$ \\
\hline $\begin{array}{l}\text { Cultural tradition of } \\
\text { Bali }\end{array}$ & $\begin{array}{l}\text { The sustainability of a system that } \\
\text { orders the civils aspect of the } \\
\text { community, the Banjar and its dual } \\
\text { currencies would hold the } \\
\text { sustainability of Bali's overall } \\
\text { cultural traditions. }\end{array}$ & $\begin{array}{l}\text { Bali's cultural tradition would accept } \\
\text { greater acknowledgment as a tourist } \\
\text { attraction and as a motivation to stay in } \\
\text { the shared houses. The local system, } \\
\text { Hinduism philosophy, and Balinese } \\
\text { wellness are some of cultural traditions } \\
\text { that attract global attention. }\end{array}$ \\
\hline $\begin{array}{l}\text { Oversupply of hotel } \\
\text { rooms }\end{array}$ & $\begin{array}{l}\text { A constant increase of new } \\
\text { hotel projects in Bali until } \\
2019 . \\
\text { Considering the occupancy and } \\
\text { environment issues, from } 2019 \\
\text { onward, there was a strong } \\
\text { possibility of forcing the } \\
\text { moratorium of new hotel. }\end{array}$ & $\begin{array}{l}\text { Sharing properties could absorb the } \\
\text { latent demand during a moratorium or } \\
\text { become a long-term alternative due to } \\
\text { its greater sensitivity to the } \\
\text { environmental damage (Tussyadiah, } \\
\text { 2015; Airbnb, } 2015 \text {. }\end{array}$ \\
\hline $\begin{array}{l}\text { Abundance of idling } \\
\text { capacity }\end{array}$ & $\begin{array}{l}\text { - The second homes are the most } \\
\text { explicit example of idling } \\
\text { capacity in Bali. } \\
\text { Bali is announced as one of the } \\
\text { most luxury second home } \\
\text { destinations. }\end{array}$ & $\begin{array}{l}\text { The increase of 'regional } \\
\text { differentiation' where clusters of second } \\
\text { homes were built in selected areas and } \\
\text { only accessible for high-income bracket } \\
\text { markets but could create gentrification } \\
\text { of native residential areas. }\end{array}$ \\
\hline $\begin{array}{l}\text { Disruptive innovation } \\
\text { of sharing economy in } \\
\text { accommodation }\end{array}$ & $\begin{array}{l}\text { - Further disruption of restaurant } \\
\text { and Online Travel Agent } \\
\text { (OTA). } \\
\text { Local platforms would } \\
\text { challenge mature sharing } \\
\text { platforms. }\end{array}$ & $\begin{array}{l}\text { Hotels might lose market access and } \\
\text { marketing power, while restaurants lose } \\
\text { seat turnover. Local sharing platform } \\
\text { might exceed worldwide-known sharing } \\
\text { platform users. }\end{array}$ \\
\hline
\end{tabular}


Popularity of reputation and rating system
- Online reputation and rating system are used to mediate trust and security between strangers.

- The integration of sharing platforms' reputation and rating systems into conventional accommodation classification systems.
More legislative control to ensure guest' safety and confidence to stay in shared houses particularly through standardized facilities. 


\section{Chapter 5}

Scenarios

\subsection{Introduction}

Chapter 4 discussed each of the key drivers supported by industry reports and existing literature emphasized by evidence from interview panelists and also critical thinking in relation to the sharing economy in accommodation in Bali. On the other hand, chapter 3 revealed how the top two drivers of change were selected; they are infrastructure development and ubiquitous Internet. The chapter explains how they comprise a fourquadrant scenario-planning matrix, each of which is represented in very distinct storylines. In addition, as discussed in chapter 3, Dator's (2009) General Alternative Scenarios are adopted to describe the environment of each scenario.

This chapter represents the third step of Bishop et al.'s (2007) approach, that is the forecasting whose outcome is to create alternative future scenarios by integrating drivers of change, future thinking and creative imagination. This chapter also provides an answer to the second sub research question "What are the possible scenarios for the future of the sharing economy in accommodation sector in Bali in 2030?"

Figure 5.1 re-visualizes the previously developed four-quadrant scenario-planning matrix (as seen in Chapter 3), but here each scenario is already appended with scenario title; they are: from local to global, the joint first prize, the volte-face, and what's yours is mine. For this study, the scenarios are presented as the storylines since human brain can more easily relate to stories and process heavy information if narrative thinking is used (Yeoman, 2012). The storylines are written from the perspective of future scenes capturing all key variable attributes. Then, fictitious, specific, and concrete illustrations of four different individuals are created and described in narrative form, in such a way that they present four different writings about each individual's travel memoir to Bali in diverse mediums, ranging from personal blog entries, reviews on online travel websites, to social media status/captions. Each storyline differs in their depiction of the future condition of Bali as a tourism destination, and in light of the ubiquity of the Internet, and the sharing economy in accommodation, because each scenario is shaped by a different matrix of primary drivers and a mixture of secondary drivers. 
The aim of creating multiple storylines is not simply to describe different possible futures; even further it is created to stimulate the reader's creative thinking and to reflect upon potential future development. The following sections in this chapter explain the four different storylines.

Figure 5.1: the four-quadrant scenario-planning matrix

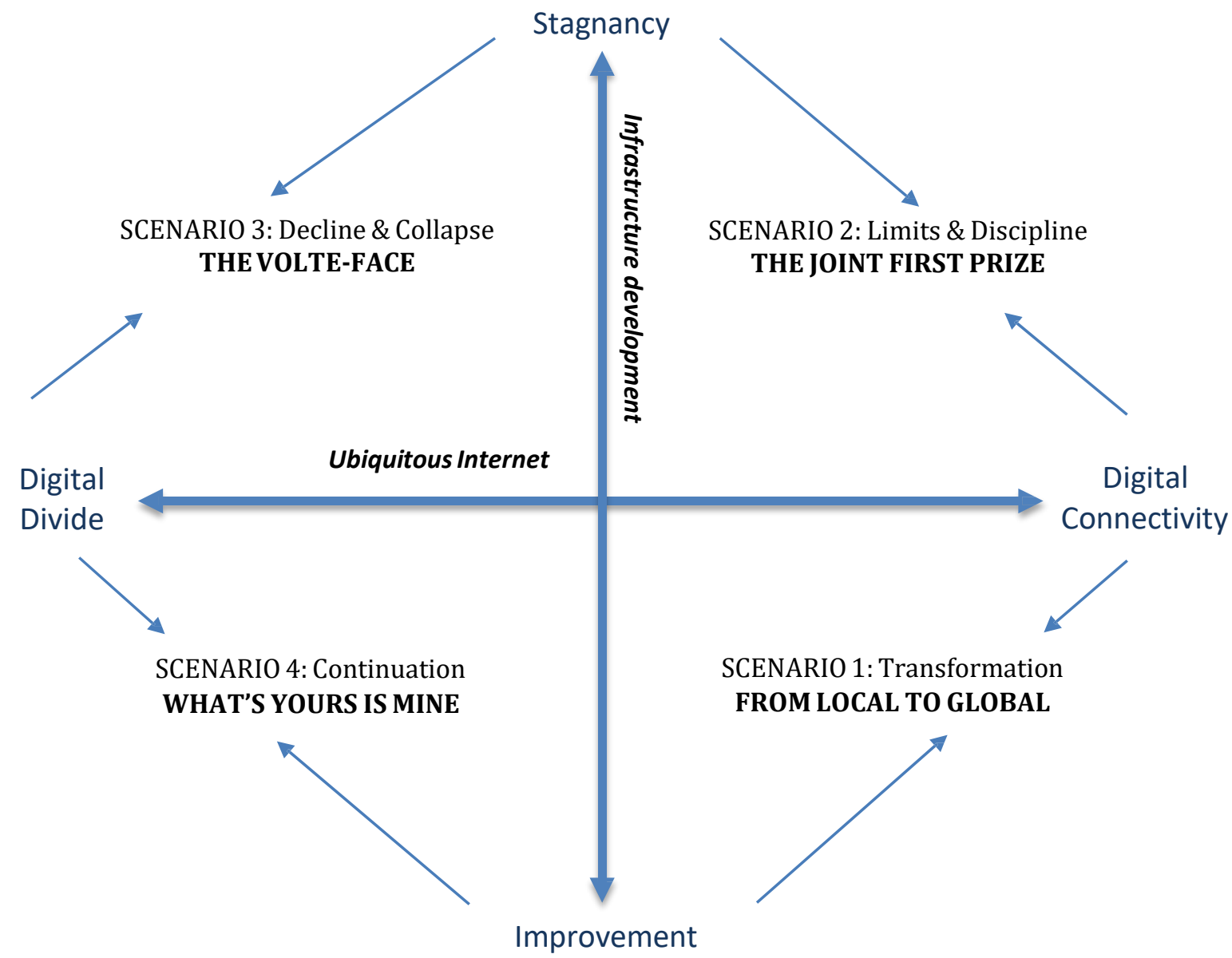




\subsection{Scenario 1: From local to global}

Scenario 1 implements Dator's (2009) transformation alternative that focuses on the powerful transition to an innovation-technological regime, introducing a whole new way of living heavily reliant on technological advancements. In that sense, this scenario foresees the transformation of Bali, previously known as 'the island of God', into a mega structure tourism destination where large-scale investment projects have taken over this relatively small island.

Figure 5.2: The essence of from local to global scenario and the influencing drivers

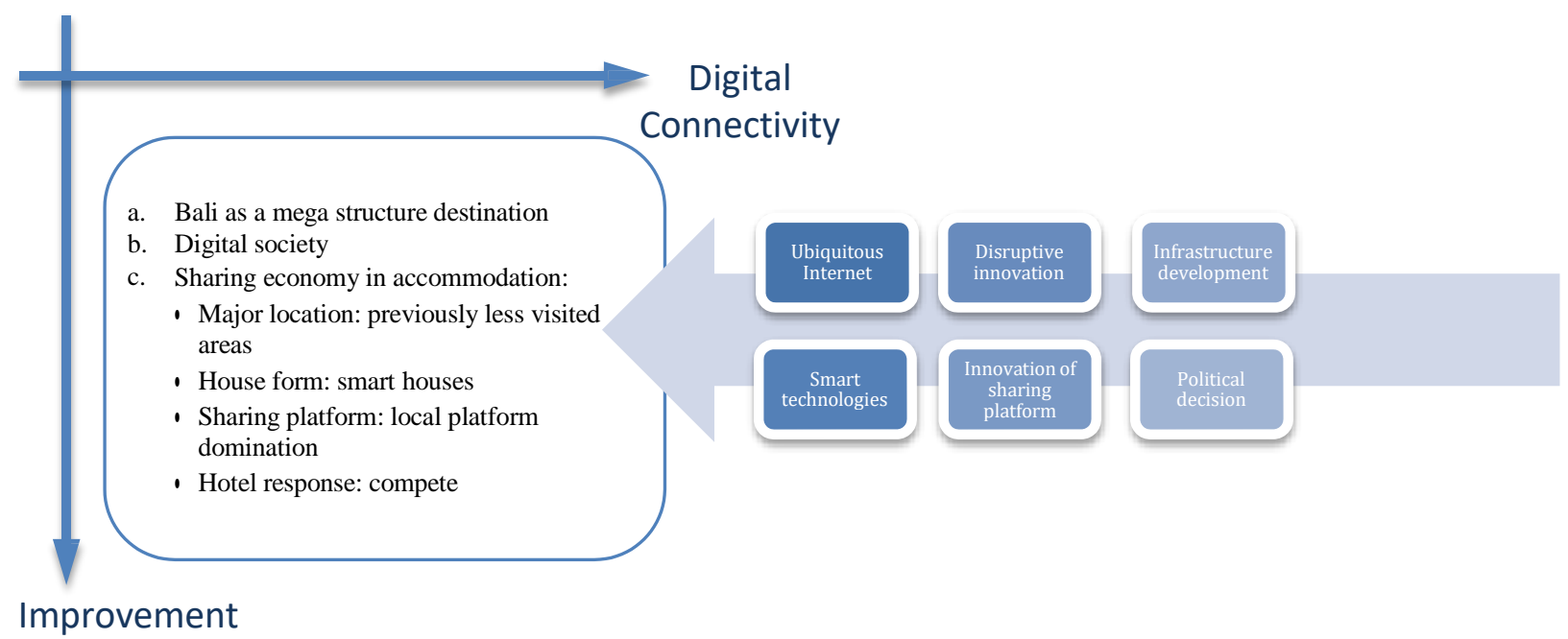

On a different note, mature information technology infrastructure including affordable ultra-high Internet connection are also in place, and have enabled the Balinese to transform into a modern digital society who have embraced the full potential of the mobile Internet to get daily tasks done. With regard to the sharing economy in accommodation in Bali, some key occurrences that might happen in this scenario:

- The majority of shared properties would be located in previously less visited areas.

- The houses that share accommodation would be mainly smart homes fitted with national standard facilities.

- The rise of local versions of the sharing economy in the accommodation platform would see, after a long and intensive competition with similar platforms, the remaining local platforms sustain and eventually hold solid market share and penetration to equal the worldwide platforms Airbnb and Homestay. 
- The big players in the hotel industry opted to compete with shared properties by adopting the distinctive characteristics of the sharing economy in their new properties.

This scenario is shaped by the combination of infrastructure improvement and digital connectivity. It also includes evidence from key drivers such as ubiquitous Internet, smart technologies domination, the disruptive innovation of sharing economy, innovation of sharing economy platform, political decision on the sharing economy, and infrastructure development.

\subsubsection{The storyline}

Ben Sanders was a father of three and a grandfather of one. He would be 58 years old by 2030 making him a part of the Generation X. He worked at one of the most reputable local carrier companies in Sydney, Australia as the concept development manager. In the middle of his peak earning years, he traveled for the second time with his wife to Bali in their New Year break. Upon his travel, he narrated the rapid transformation of Bali and their experience of staying in a modern local house in his high-ranked personal blog.

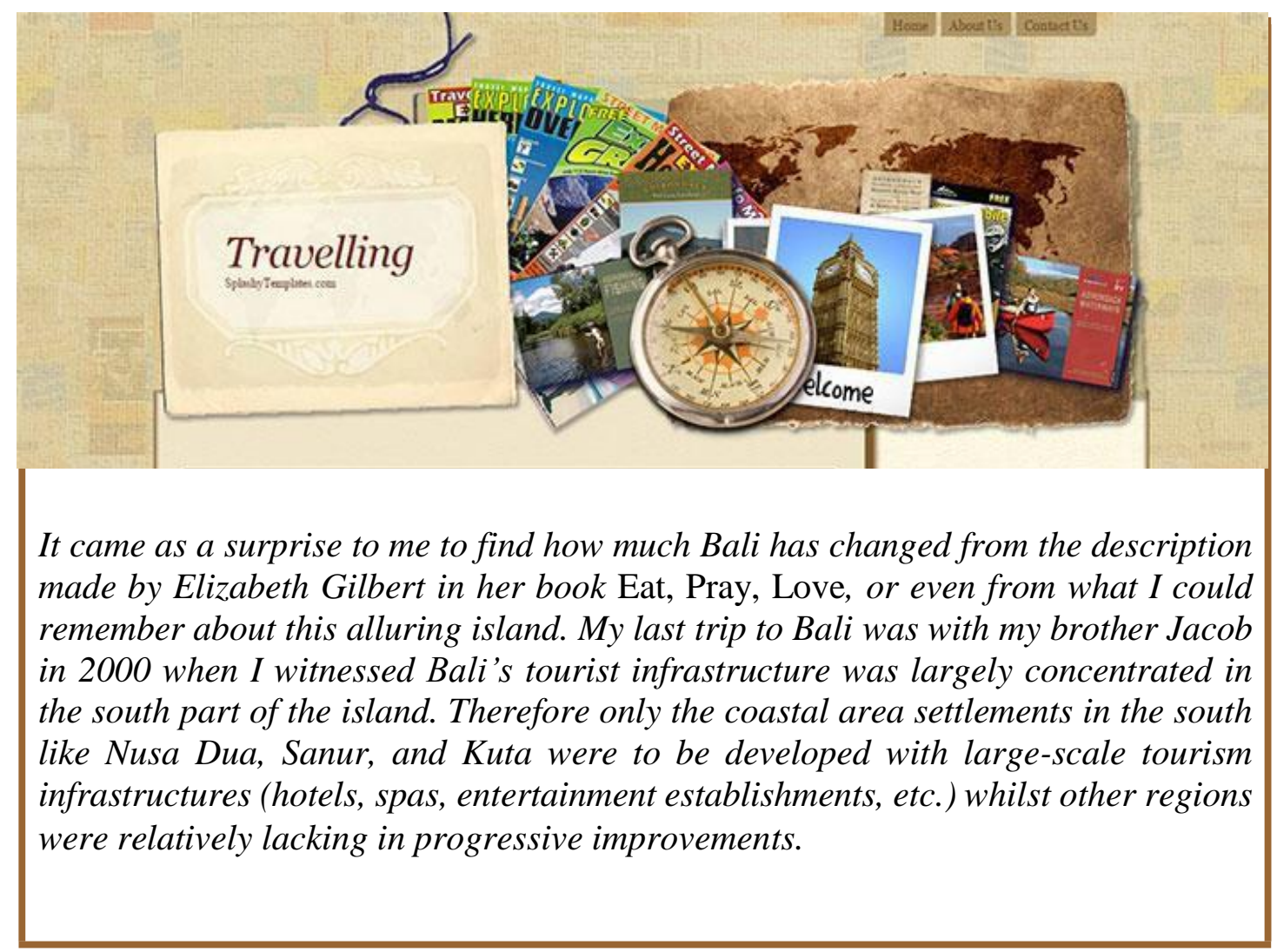




\section{Bali tourism destination}

Thirty years later (it is indeed quite a long time), Bali has changed to the new Dubai or Singapore in terms of modernity! My trip to Bali two weeks ago with Carolyn was a complete journey through the global city with impressive luxuries, and the new entertainment capital of the South East Asia. The transformation of busy, metropolitan Bali encompass the rapid improvement of infrastructure through the establishment of new international airports in the northern Bali, man-made islands, land reclamations on which commercial buildings and resorts were built, high quality roads and highways connecting every corner and the very remote part of the island, renewable energy sources, sustainable clean water system, and atop of that, equal level of development between the southern part of Bali and the rest of the island. White sand beaches and rolling waves for surfing can still be found in southern Bali, Bali Disneyland and other modern theme parks are to be enjoyed with family in Buleleng, northern Bali near the new airport or in Klungkung, further east from the cultural center Ubud. Almost all beaches in Bali have modern waterfront precincts with premium shopping malls adjacent to them. For those who are shopping junkies, you will not miss Bali's largest mall "The Bali Mall" located in the capital with free fantastic attractions such as the water fountains and giant aquariums. Here is a bird's eye view of the new, highly developed city of Buleleng:

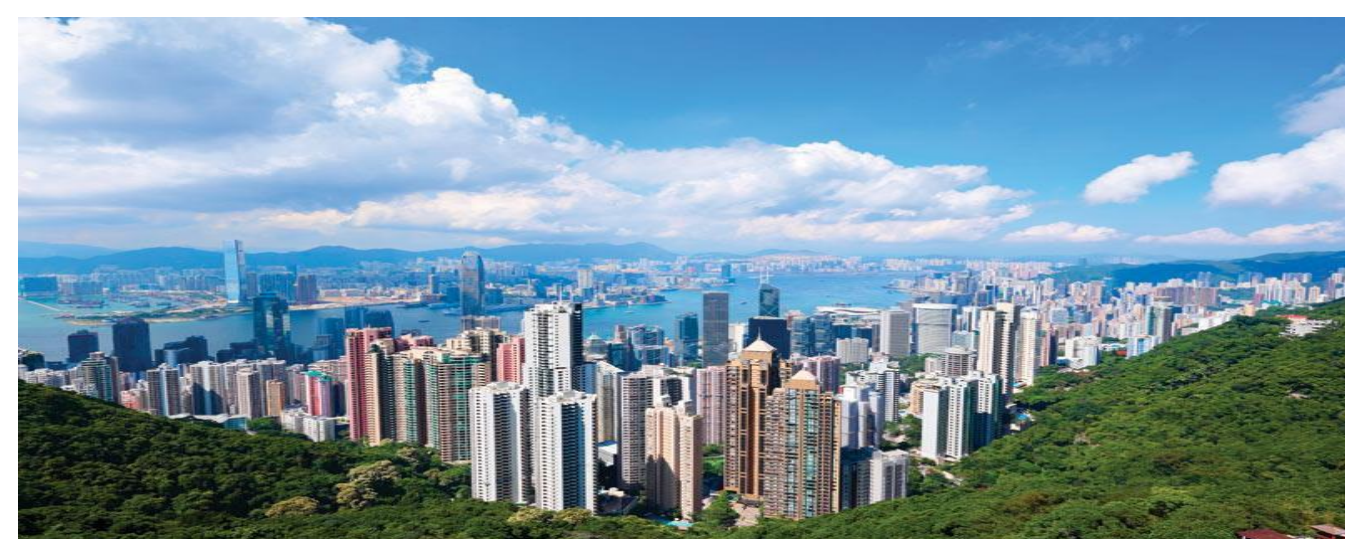

\section{Internet Ubiquity}

The Internet connection in Bali is super affordable and easily accessible through multiple devices, but what really fascinates me is the fact that Balinese have been optimizing the full potential of mobile Internet. I talked to many locals and realized that they now rely heavily on mobile devices and their applications to do almost anything! They use their smartphones to purchase daily needs and make any kind of payment, to monitor their health and their kid's movements, also to control their self-driving cars and home equipment.

\section{Sharing economy in accommodation}

With the outstanding infrastructures and attractions, today's Bali is not only a "suit for all" tourist destination but also "opportunities for all" owing to a wider community in different locations that benefit from tourism. For this trip, we have decided to stay in the local house in Buleleng. This city might not really have been popular for tourists in the past but it has transformed into one of the best spots with so much to do over the last few years. Besides the tourist attractions, I think there are tons of local houses in and around town where tourists can stay in for a fee 
through sharing platforms, giving more positivity to everyone's travel experience! At first it might be confusing because many new small hotels offer similar "localness" but dare I say staying in local houses might come with surprises you might never anticipate, in a good way.

When looking up Bali's local houses (or Indonesia's in general), be sure to try Bumi.com. This local home sharing platform exceeds the popularity of Airbnb or HomeAway in Indonesia because unlike its counterparts, Bumi has the cultural translator feature that helps the hosts to understand the cultural backgrounds of their guests. It was Big Data that plays an important role in supplying such past behavior information so our host, Ketut knew even before our arrival that Carolyn loves to have the crunchy macadamia and meat pie for her breakfast, which he served nicely every morning. Ketut also shared to us that Bumi also capable on projecting his revenue, scheduling the cleanings and linen service, and also providing professional concierge, all are done by the third party. Another feature that makes Bumi unique is the algorithm to automatically match-make personalities of guests with hosting styles, thanks again to Big Data, so there are no top hosts really dominant in the market. As per us, because we were after something more modern, luxurious, and unique with a taste of home accommodation, something we described as a $21^{\text {st }}$ century homestay, Bumi has matched us with Ketut's house which was a beautiful house in a lush tropical garden with a large lounge area and full kitchen.

Like the majority of shared houses in Bali, ours was a smart house where lighting air conditioning, ventilation, and home appliances such as fridge and washing machines can be controlled remotely by our smartphones. Interestingly, the toilet was able to analyze waste for medical problems and report it to the nearest medical center for assistance if necessary. This technology, where objects are connected to other objects through Internet left us in amazement. Safety and security were not such concerns because, in accordance with national regulations, all the local houses have to install security systems including CCTV and panic button. By staying at Ketut's home, we were shown a great mixture of modern metropolitan Bali with a hospitable human touch because Ketut was so helpful, caring, and very knowledgeable of the hidden gems around the neighborhood. We would definitely love to go back.

This story reflects and presents a number of key issues and trends that could shape the sharing economy in accommodation in Bali which include:

- Massive development of superlative infrastructures and modern man-made tourist attractions funded by foreign and local investment that enable an evenly dispersed tourist flow in Bali and greater opportunities for local residences to become 'from scratch tourism entrepreneurs'.

- Increased Internet ubiquity and metamorphosis of Balinese into a society heavily reliant on smartphones and smart technologies. 
- The local versions of the sharing economy in accommodation platforms are growing as the result of the pervasiveness of the micro-preneurial spirit among the younger generation.

- The platforms have sophisticated features to fulfil the promise of creating more micro-preneurs with income streams, to mediate cultural understanding, and to deliver personalized services.

- The platforms provide property management software to gain analytical insight into booking history in order to maximize the revenue; and hotel-associated function such as responding to inquiries, scheduling and coordinating cleanings, and providing concierge services or any professional services in the case of emergency.

- The smart technologies were adopted and installed inside residential and shared houses.

- The national authorities regulate the sharing economy in accommodation, which make this sector a national concern. All sharing activities are monitored and controlled to guarantee the safety of both hosts and guests.

- To compete with the expansion of the sharing economy in accommodation, new small-size hotels were built by incumbent providers positioned to serve as a basecamp from which visitors can explore the surrounding local richness of music, food, arts, and other cultural programs, both on-property and offsite. 


\subsection{Scenario 2: The joint first prize}

Scenario 2, applies Dator's (2009) limits and discipline alternative that emphasizes the focus on fair distribution and preserving nature and cultural aspects. It is about getting back to human roots. For that reason, this scenario portrays the endeavor of Balinese stakeholders to revive their precious cultural traditions, art, and history, at any cost, and after the rapid exploitation of the tourism business over previous decades. Technically speaking, the down zoning process is applied, by which a high-density area of land is rezoned to usage that is less dense and less developed than its previous usage to limit the overgrowth of an area (Kuhn, 2011). As a result, the originality of Bali was restored, in a way that has tourists indulging in strong 'living like a local' experiences. In contrast, mature information technologies including affordable ultra-high Internet connection, were put in place and continuously reinforced. Consequently Balinese residents transformed into a modern digital society whereby tourists were facilitated to engage with the interconnected digital environment.

Figure 5.3: The essence of the joint first prize scenario and the influencing drivers

\section{Stagnancy}

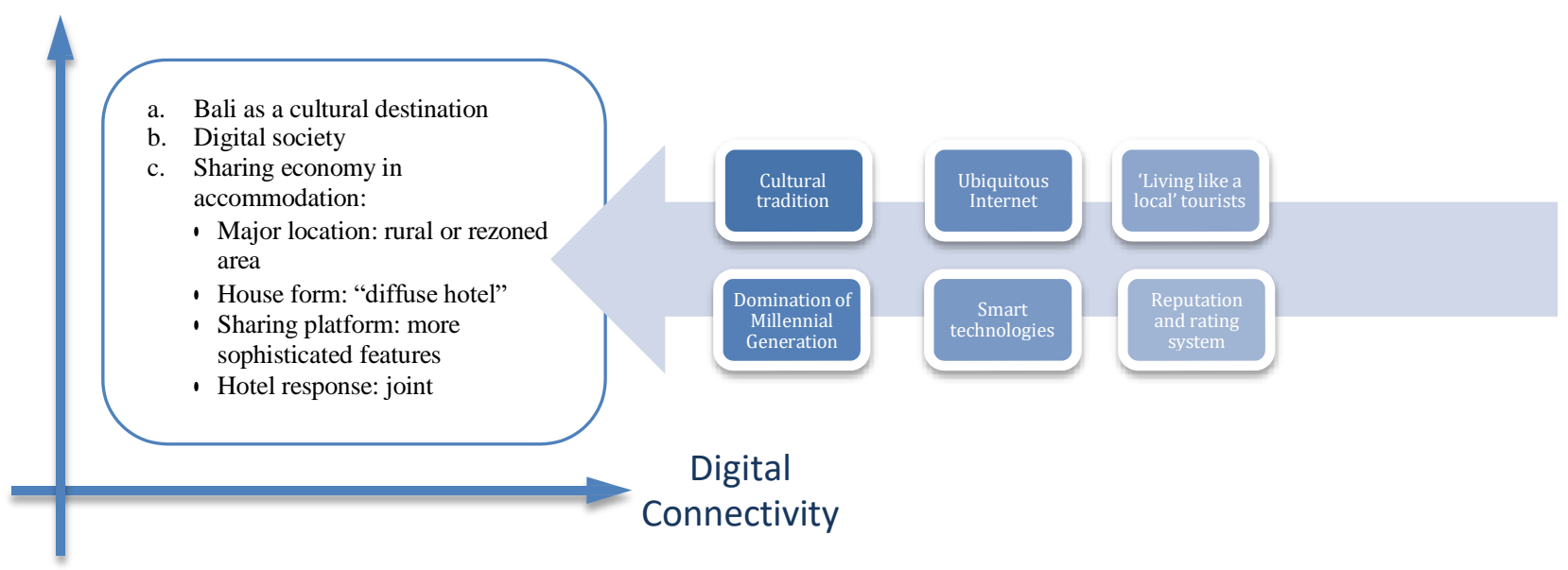

With regard to the sharing economy in accommodation in Bali, some occurrences that might happen include:

- The majority of shared properties would be located in the rural or rezoned area.

- There would be partnership between hotels and traditional villages comprised of locally owned houses in order to develop a similar accommodation concept to the Diffuse Hotel in Italia. Gilli and Ferrari (2016) define the diffuse hotel (also known as a 'spread hotel') as a hotel composed 
of dispersed rooms or suites, yet providing standard services to all the guests.

- In short, the incumbent Sharing platforms would offer more sophisticated features including metasearch, matchmaking and real-time video talk.

- Authorized institution would apply the integrative rating system to stratify the shared properties, incorporating travellers' online ratings, feedback, and a conventional accommodation classification system.

This scenario is shaped by the combination of infrastructure stagnancy and digital connectivity. It also includes evidence from key drivers such as cultural tradition, domination of Generation Y/Millennial Generation, ubiquitous Internet, 'Living like a local' tourists, popularity of reputation and rating system and smart technologies domination.

\subsubsection{The storyline}

Emilie Chang was a mother of one residing in the Tianjin, China. She worked as an independent architect and would be 38 years old by 2030, making her a part of Generation Y. She has travelled to many popular tourist destinations all over the world, some of which with her daughter. In her case, Emilie has actively recounted her firsthand travelling experiences in an online travel review. As she finished her visit to Bali with her daughter at the end of September 2030, she decided to share her experience and reflection as an entry in the collaborative blog on TripAdvisor.com, with the aim of depicting the actual situation in Bali from her point of view. 


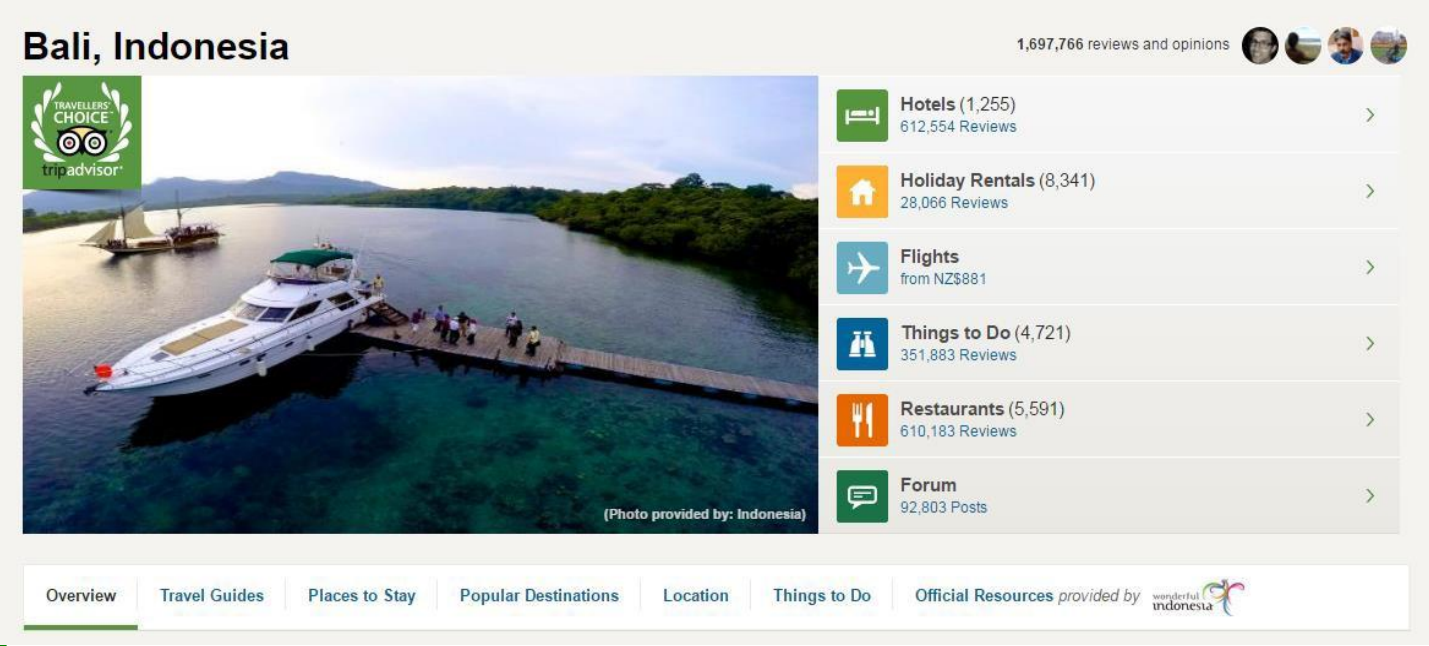

Bali has always been on my bucket list and I think it is wise to save the best for the last. In the past 15 years I have been reading blogs and travel reviews, all describe how this alluring island entices visitors with its ecological beauty and thriving natural scenes, as well as its depth of ceremony with sacred temples, traditional villages, local arts and humble people for decades, far from gleaming skyscrapers and extravagant luxury.

\section{Bali tourism destination}

After long and tiring travel around Australia, finally I fulfilled my wish list by spending a wonderful three weeks in Bali. Indonesia was then the $53^{\text {rd }}$ country I have ever visited! Prior to this trip I spent hours looking up historical progress, by which I discovered an agreement signed by local government and Balinese communities in 2020 to revive the authentic Balinese culture and atmosphere. The agreement was followed by compelling regulation and a moratorium on the new hotel, man-made attractions, even banning typical visitors with their potentially destructive effect on Balinese culture, while on the other hand, pushing the sharing of traditional houses as the forefront of lodging providers. The results of such efforts are extraordinarily amazing. From the first time I arrived at the airport, I could savor the ancient Balinese ambiance where the serene, peaceful, harmonious, and somewhat mystic environment captivated me, in the form of architectural Balinese design and aromatic scent, like nothing has changed from the 1960s! All of those left me with a renewed and pure feeling. Even better, ancient villages, houses, the Banjar and its dual currency, rice terraces, rituals and traditions are preserved in such a respectful manner.

\section{Internet ubiquity}

Despite the return to ancient Bali in terms of nature, ceremony and tradition, the Balinese as a whole have transformed into a modern, progressive society in terms of mobility and interconnectedness. Excellent Internet connection and mobile device reliance has changed Balinese society into an 'onliner' one, particularly in the way people socialize, co-create government regulation, shop, work, research and purchase goods, and travel. It is indeed a $3 A$ (anytime, anywhere, any device) society. 


\section{Sharing economy in accommodation}

To live the way locals live is something I always look for in my travel. For this trip I spent some time comparing shared houses in Airbnb. The matchmaking feature of Airbnb is very handy in simplifying guests' decision-making, but I prefer to use the metasearch feature from my smartphone to compare multiple listings because it also allows me to communicate through my smartphone using the real-time video talk with the potential hosts. The integrative rating system is also of help because the classification of shared houses is based on the first-hand experiences of the previous users. The system is an essential formal source of information as it boosts one's confidence if the potential shared house received more positive comments, or to the contrary. Happy to say I was able to get only the excellent.

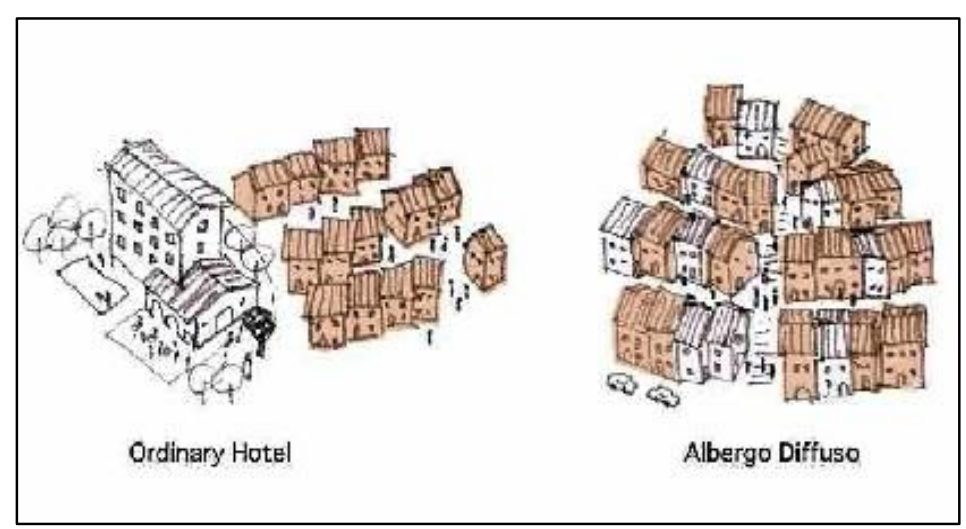

An interesting common practice I found is the partnership between big hotel corporations and traditional villages, knowing that investing in new hotels is not reasonable due to the agreement. The dwellings are original houses in a traditional village converted for tourism use, retaining the spatial organization and functions of a local resident's house. In this way, residents remain living in their own compounds and manage the cleanliness and basic necessities for staying guests, under the coordination and supervision of hotel management, which is responsible for online marketing activities, providing logistics and hospitality guidelines. This concept is similar with the Diffuse Hotel (Albergo Diffuso) in Italia. Too bad I cannot share the house and the village photos we stayed in but hopefully that little illustration above helps you to comprehend.

Eventually, my daughter and I ended up picking a house in Sebatu village managed by Aston Group. Sebatu is a wonderful spiritual village to visit with temples in which statues and ponds are well preserved, as a result of rezoning procedures. I notice that a house situated in the middle of this village is designed to function as a restaurant and entertainment stage, where all staying guests enjoy dinner and a glass of wine. We were mesmerized during our stay with the house and the entire construction of the village, thus we were able to make some unforgettable memories. 
This story reflects and presents a number of key issues and trends that could shape the sharing economy in accommodation in Bali which include:

- The new generation of travellers from close geographical proximity would be the biggest international tourist segment for Bali.

- The desire for authenticity and connection with something real will continue to exist across different generation of travellers.

- The sustainability of the Banjar and its dual currency system, along with strong collective awareness are the critical factors to revive Bali's indigenous culture and atmosphere.

- The urgency of compelling the moratorium on new hotels to reduce destructive impacts on environment in parallel with executing the down zoning procedures to revive Bali's natural resources.

- Increased Internet ubiquity and metamorphosis of the Balinese into a society heavily reliant on smartphones and smart technologies. Balinese has a 3A (anytime, anywhere, any device) attitude but with strong traditional values.

- National and international hotel groups would start to partner with sharing participants by putting into practice the diffuse hotel's model. In a nutshell, it was the practice of corporate investment on individual assets.

- Integration of online ratings and user feedback into a system by which the stratification of the accommodation providers, especially the shared houses can be ranked.

- The sharing economy in accommodation platforms would have sophisticated features to enhance trust among hosts and guests with the provision of real-time video talk. 


\subsection{Scenario 3: The volte-face}

Scenario 3 implements Dator's (2009) decline and collapse alternative that visualizes the future to be degraded into a lower stage of development, caused by the failure of critical systems, social and environmental collapse, or catastrophic incidents whether to natural or human-made disasters. In that sense, this scenario foresees the drastic decline of Bali's popularity as a tourism destination mainly due to severe friction between migrant domestic workers and native Balinese battling for entrepreneurship and employment opportunities, frequent terrorist attacks, and misuse of digital private data and transaction. The tourism industry collapsed with many international hotel chains and other accommodation providers deciding to close down their operations. In terms of digital connectivity, local government applied strong Internet censorship to protect national security from digital terrorism and cybercrime. This was an era of digital divide where the gap of accessing digital connectivity became even wider as Internet access was exclusive for the big corporations and selected government offices; therefore the digital skills and knowledge of residents, especially in rural areas, were extremely inadequate. Given that situation, the sharing economy in accommodation in Bali has no space to flourish and the only lodging providers are traditional accommodation with offline management system.

Figure 5.4: The essence of the volte-face scenario and the influencing drivers

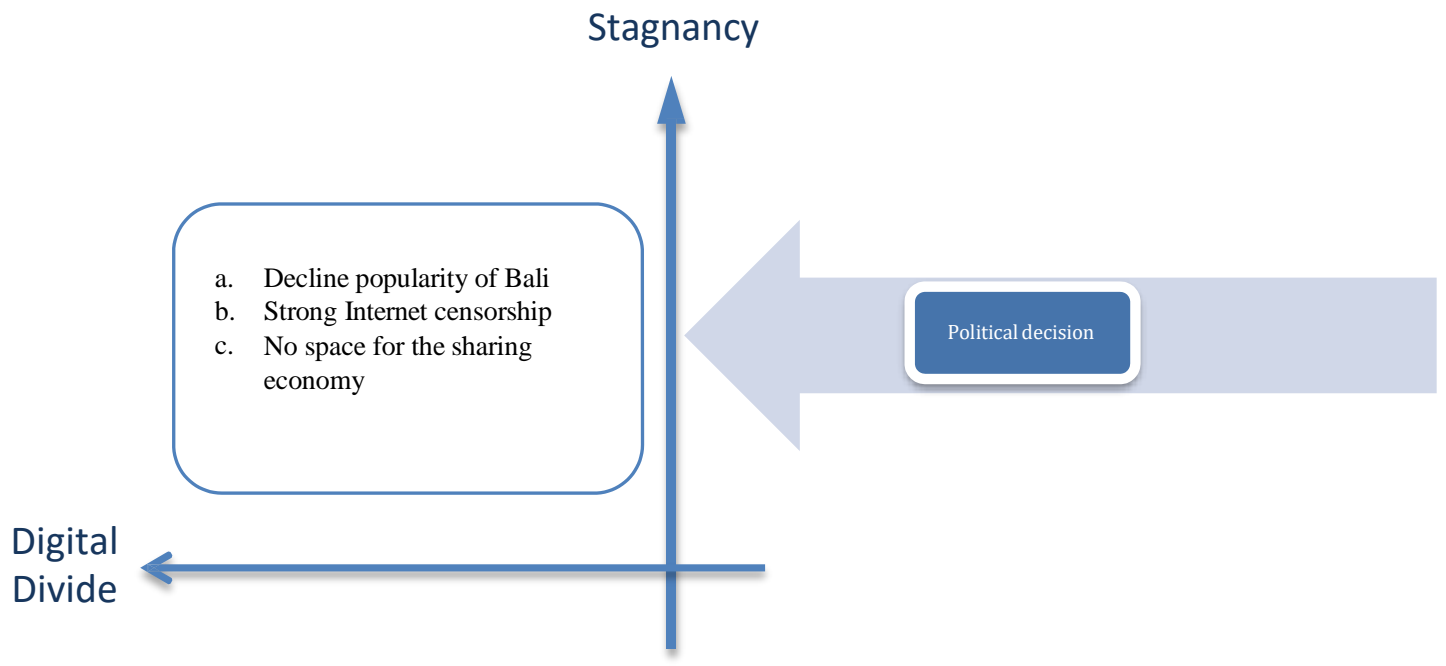

This scenario is shaped by the combination of infrastructure stagnancy and digital divide. It also includes evidence from key drivers such as political decision related to the sharing economy. 


\subsubsection{The storyline}

Sally Thompson was a UK travel columnist for one of the highest viewed online news portals based in Singapore. Sally has been assigned to thoroughly report the effect of first and second Bali bombings in early 2000. In 2030, she once again visited Bali to investigate the notorious circumstances called by many the 'dark age of Bali'. Aside from the appointment, her personal interest was to explore the dramatic decrease of the sharing economy in accommodation, which in previous years had achieved its utmost popularity. The on-field findings and opinions were covered in her blog and were linked to her Facebook account, which invited the attention of many readers.

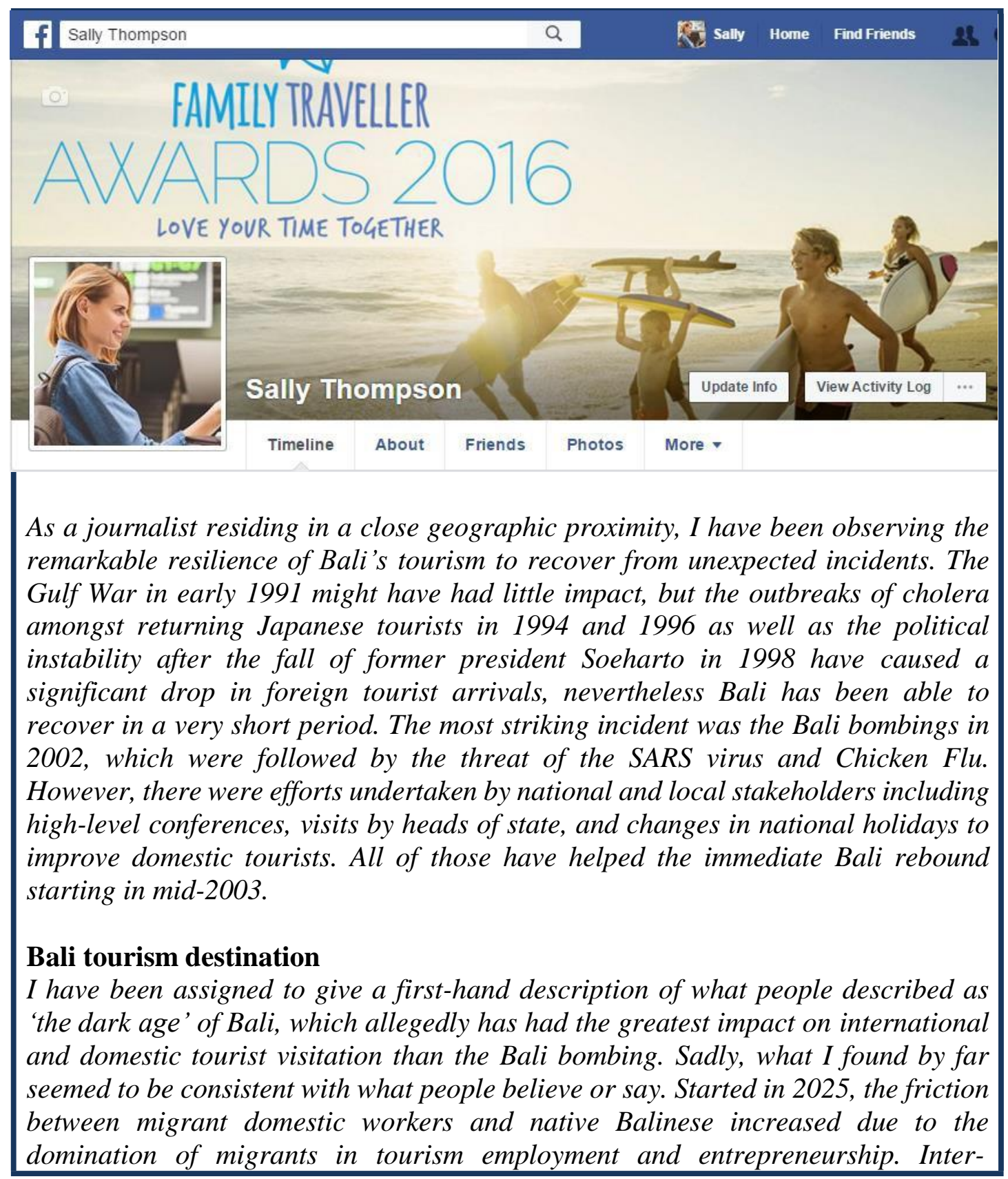


religious strife was also in place caused by severe provocation to persecute Bali's minorities, notably Muslims. It was worsened by several suicide bomb attacks in public places and misuse of digital private data and transactions by Bali-based syndicates. As a result of the huge drop in tourist arrivals, I found many hotels have been put up for sale. Restaurants, shops and other tourist amenities were also placed on the market. Tourism related businesses have to lay off employees, forcing them to return to traditional farming or any job to secure the roof and food for the family. From different sources I found that stakeholders have made many attempts to recuperate from the crisis but, unlike any previous mitigation, appeared to be unsuccessful.

\section{Internet ubiquity}

To more complicate the unstable situation, Bali has controversially strong Internet censorship due to frequent cases of cybercrime and digital terrorism. Affordable access to Internet is exclusive for selected people, government agencies and corporations. Other than that, an outstandingly expensive rate applies. Transnational Internet corporations such as Google, Facebook, and YouTube are also subjected to censorship regulation. Like the Golden Shield Project of China, which is initiated and operated by local government, has widened the digital skill gap especially for rural inhabitants.

\section{Sharing economy in accommodation}

While staying in a stranger's house, booked through online platforms like Airbnb and HomeAway, have become globally common, Bali leaves no room for this practice owing to Internet censorship, but there are still traditional hotels to stay in. Staying in a hotel is the best option for travelers despite the fact that many hotels have had to close down their operations and have had to establish offline reservation systems.

This story reflects and presents a number of key issues and trends that could shape the sharing economy in accommodation in Bali including:

- Failure to maintain fair job distribution for local migrants and native Balinese, congregational conflicts, terrorist attacks, and cybercrime will cause chaos in Bali tourism.

- The authoritarian power can employ the Internet censorship to avoid the risk of new cybercrime and cyber-attacks which disadvantage the sharing economy in accommodation. 


\subsection{Scenario 4: What's yours is mine}

Scenario 4 applies Dator's (2009) continuation alternative that accentuates the continuous growth of the current economic situation and human civilization. Applying that alternative, this scenario depicts a pathway that presents a strong awareness that rejuvenating the quality of nature in rural area is equally important to centralizing the enhancement of new infrastructure in the city area. Technically speaking, the transfer of development right (TDR) is operated. According to Walls (2007) the TDR is a zoning mechanism used to preserve natural and cultural resources in the protection zone and redirecting development that should originally occur in these resource lands (sending zones) to another location where development is encouraged (receiving zones). Having local wisdom and the latest technology, the city region of Bali was transformed into the world's largest hub to study yoga, Balinese wellness, and Hinduism philosophy, which invite interest from global students. However, Internet coverage was also limited for city residents and students in the city region with strong controls from the government, leaving rural inhabitants with a complete lack of digital skills.

Figure 5.5: The essence of what's yours is mine scenario and the influencing drivers

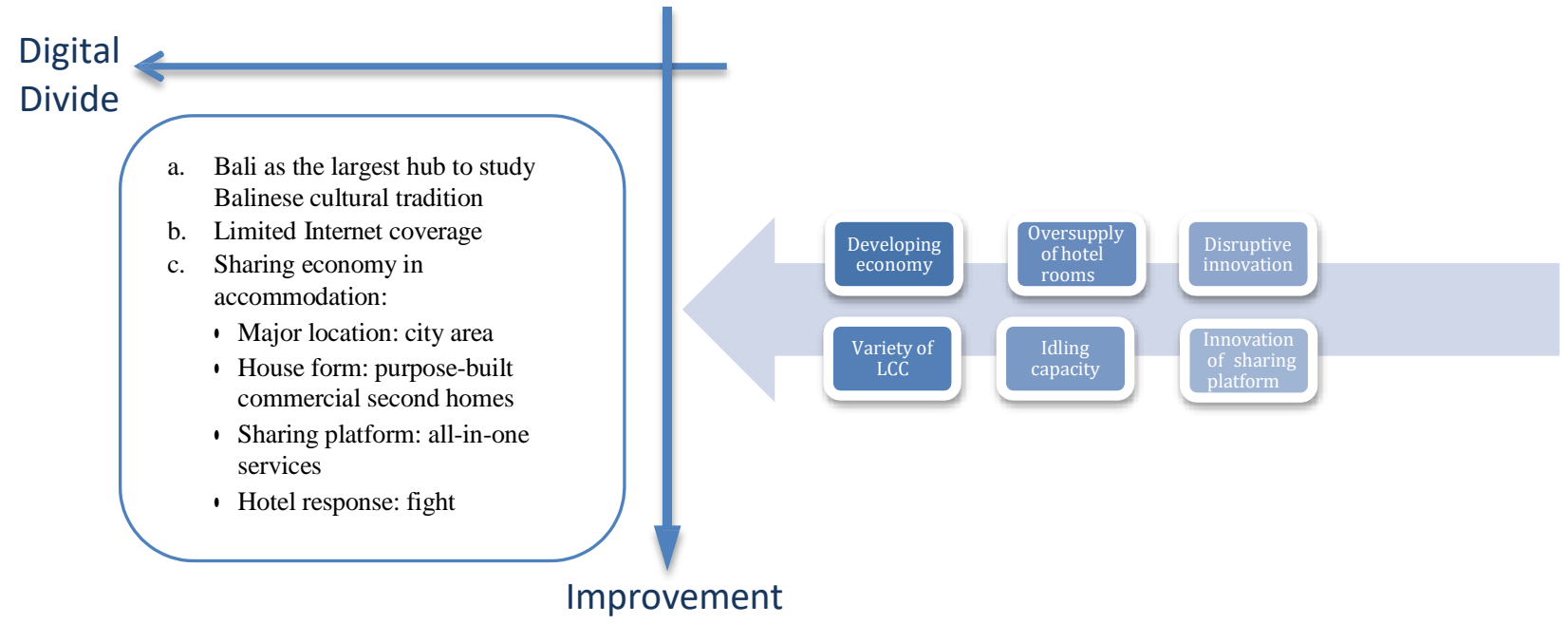

In this scenario, some of the occurrences that might happen with respect to the sharing economy in accommodation in Bali would be:

- The majority of shared properties would be located in city regions.

- The houses that share accommodation would be mainly purpose-built second homes with exclusive facilities and personalized services tucked away in secluded areas. 
- The sharing economy in accommodation platforms would offer multiple tourism services far beyond the accommodation sector, enabling users to book shared dinner or guided-tours.

- The hotel industry would team up with other disrupted tourism enterprises in Bali for a direct confrontation with actors in the sharing economy in accommodation.

This scenario is shaped by the combination of infrastructure improvement and digital divide. It also includes evidence from key drivers such as Indonesia as a developing economy, variety of low cost carriers, popularity of reputation and rating system and oversupply of hotel rooms, disruptive innovation of sharing economy in accommodation, and abundance of idling capacity

\subsubsection{The storyline}

Being labeled as the 'entrepreneurial generation', generation $\mathrm{Z}$ has a strong affection for establishing their own startups; given that they really like the idea of working for themselves, the majority are risk-averse, practical, and pragmatic. Among them, Edward Hagi was a digital nomad who owned a crowdfunding startup for tree planting based in Jakarta, Indonesia. His main reason to visit Bali in 2030 was to partake in an international Balinese yoga class as he felt it important to always learn new knowledge and keep improving, while he also managed to control his business over his laptop. He regularly posted his activities and opinions about Bali in his Instagram account as follows: 

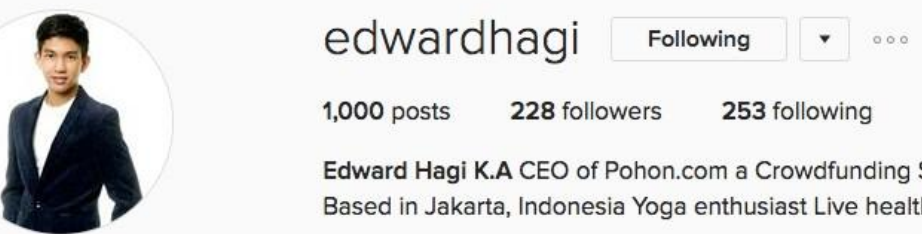

Edward Hagi K.A CEO of Pohon.com a Crowdfunding Startup for Tree Planting Based in Jakarta, Indonesia Yoga enthusiast Live healthy

Bali is simply wonderful. It is the home of relaxation yet offers the workplace to always keep up with my business at the same time. Oozing with the perfect mixture of a peaceful environment and modern facilities, Bali continuously becomes the abode of the wellness seeker to pursue pure balance, which is the very base of a fulfilled life. I notice constant progress from fifteen or even twenty years ago when Bali was a relatively new tourist destination for medical purposes but already it has risen to prominence in the wellness and spa segment.

\section{Bali tourism destination}

I rate today's Bali as more advanced than previously. Stakeholders have been working really hard to implement rigorous zoning regulations, which limit the development in rural regions and centralizes the enhancement of new, high-tech infrastructures in the city regions in the hope that the quality of the natural environment in rural regions is rejuvenated from overdevelopment. The city region, however, expands and transforms into the world's largest hub to study or indulge in Balinese yoga and practice wellness philosophy. Large modern multipurpose halls are built for spa and yoga studios to cater to people from all over the world, myself included, and who come to this island again and again to seek the abounding health in body and mind. For this visit, I have booked a two week yoga retreat in Vinyasa hall that has a natural jungle vista and rice paddies planted inside the building. The other hall, Asana, that has a river stream and artificial Hindu temple, offers a longer session on how to become a well-rounded yoga teacher. Another good thing about going to Bali is the prevalence of premium cabins in the national low cost aircraft, which make the journey from all over Indonesia even more enjoyable.

\section{Internet ubiquity}

I have no particular concern regarding the Internet connection. The connection also works perfectly for my wearable devices (I use a smart watch and smart glasses as replacements for the mobile phone). Sadly, city residents or tourists and wellness seekers who stay in the city domain can only experience this interconnectedness. A strong control from the local government is applied in rural regions causing a lack of digital skills for inhabitants.

\section{Sharing economy in accommodation}

I traced the reputation and rating of multiple areas in Bali but it seems like there is no possibility to stay in rural areas, since residents do not have adequate access to Internet. So, staying in an urban backdrop it is. Nowadays I cannot really tell the difference between staying in hotels or modern homestays, especially in Bali, as high-end properties with personalized facilities are everywhere and can be easily 
found on sharing platforms such as Airbnb, of course with different peer ratings and reviews.

Interestingly I found out that many new sharing houses in Bali are second homes, modified from their original functions or built purposively to accommodate exclusivity and convenience. They even get clustered which makes them accessible only for those who can afford the fee. I have heard such mixed things about the home ownership model from reports and news I read, but it seems like such residences are mostly owned by foreigners. Yes, the non-Indonesians who buy investment properties since investing in luxury property in Bali are always fascinating and profitable. They own it although they might not visit it regularly in part of the year due to commercial reason.

Luckily, I can book a cool elegant house in one of such clusters in the heart of Denpasar city from Airbnb (the picture where I stayed is below to make you hate me). The house I rented was modified from its original function, thus it has a private pool, and modern working spaces with the latest digital facilities to support the digital nomad like myself so I can do my works after the meditation. The house also has an on-call private butler and chef to cook my dinner. The house has its on-site property manager so I know whom to call for assistance.

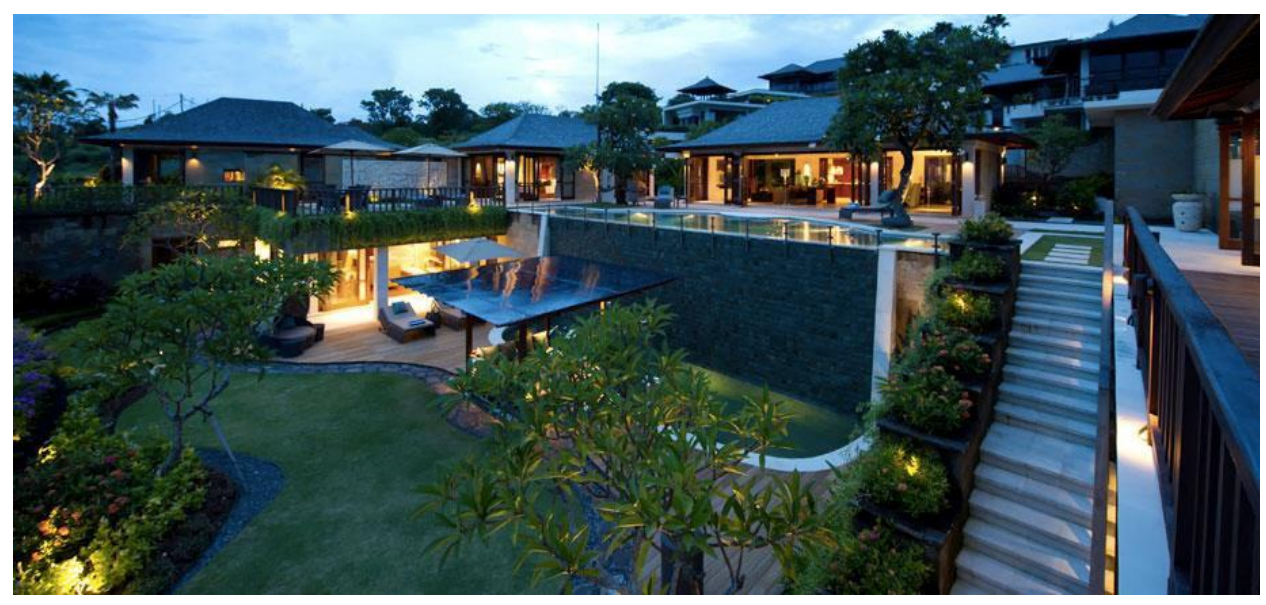

Having the private butler and chef are such a nice privilege but I am more into exploring the legendary mouthwatering dishes or the street vendors, therefore Airbnb is the first to help. It is true that Airbnb specialized in home sharing back in the early days of their launch, but now you can book a dinner and guided-tour, or even purchase the local services and products through this all-in-one platform-that means no need to use different platforms for different needs. But not everything is for everyone. Today's local newspaper reports how a group of hotel employees along with their counterparts from restaurants and travel agents have gathered more than 10,000 signatures in an effort to combat the increasing disruption of sharing economy platforms and want to hold the platforms accountable for the effect it has on traditional tourism industry and employment.

This story reflects and presents a number of key issues and trends that could shape the sharing economy in accommodation in Bali including: 
- A number of national aviation companies opening up new low cost carrier flights to Bali with premium cabin and services from all over Indonesia.

- The increase of domestic tourists with high spending power.

- The need to rejuvenate natural resources after overexploitation of the tourism industry through strict zoning regulations in the form of, among other optional strategies, the transfer of development rights (TDR) to segregate the development zone in the city and the conservation zone outside the city.

- Interconnectivity and ubiquitous Internet could be sacrificed to obtain a wellmanaged conservation zone.

- The global recognition of Balinese wellness philosophy to enrich the quality of life will attract an abundance of wellbeing seekers and students to repeatedly visit this island in search of personal enrichment.

- The rise of purpose-built second homes with exclusive facilities, personalized services, and modern devices installed as interior design, to be further shared and 'commercialized' in the sharing economy platforms owned by foreigners.

- The potential of clustering such purpose-built second homes for the wealthier market but which might cause the gentrification of native residential areas.

- The disruption of the sharing economy in accommodation platforms to the wider tourism industry such as restaurant and online travel agents (OTA), as they expand their services.

\subsection{Conclusion}

This chapter described four exploratory scenarios based on the core drivers of infrastructure development and ubiquitous Internet. The four scenarios were developed to stimulate the future thinking and creative imagination about what the future of the sharing economy in accommodation in Bali might become. Given the highly uncertain nature of the sharing economy, the key learning point from the scenarios is the need to develop different strategies relevant to the future context in order to cope with unexpected circumstances. Related stakeholders need to prepare policy responses with forward-looking principles at the center of it. For that purpose, alternative policies for each scenario will be discussed in Chapter 6 . 


\section{Chapter 6}

\section{Strategic Implications}

\subsection{Introduction}

Chapter 5 discussed the construction of four scenarios, from local to global, the joint first prize, the volte-face, and what's yours is mine. Although at some point the scenarios were built upon and represented similar attributes, each portrayed a different future pathway of the sharing economy in accommodation in Bali by 2030. These scenarios should expose very different situations within the current state by which future thinking and creative imagination among the readers and everyone involved in the sharing economy in accommodation in Bali can be stimulated and encouraged.

Already mentioned in chapter 3, the subsequent step of Bishop et al.'s (2007) approach after forecasting is visioning, of which the utmost outcome is to propose possible strategies or policy responses regarding the constructed scenarios. In this study each of the panelists was asked some default questions reflecting upon the scenarios and was asked to suggest the main implications of the scenario followed by the strategic decision that should be considered by Bali tourism stakeholders to deal with such implications. For that aim, two different questions were set out. The first question revolves around the general key issues looking for uniform answers about managing the sustainability of the sharing economy in accommodation in Bali throughout the four scenarios. The second questions are directed at the individual scenarios in search of insightful reflections and recommendations on policy responses. The specific questions are formulated subjectively by the researcher after evaluating the emerging issues developed during the interviews and reviewing the distinctive character of each scenario.

6.2 Overall strategies to manage the sustainability of the sharing economy in accommodation in Bali

The first question is structured as follows: "In general, can you identify the key strategies that need to be undertaken by Bali tourism stakeholders in order to 
successfully manage the sustainability of the sharing economy in accommodation in the future?"

Considering the vast scope and different interpretation of 'sustainability', in answering this question, the researcher first determines the extent of 'sustainability' preferred as the outcome, which was explained to each panelist during the interview. Three major aspects are involved: how to ensure protections for the house owners and their neighborhood, how to deal with current issues and complaints especially tax and legality, and how to provide safety and enjoyment for guests. This question is answered systematically, discussing potential actions and strategies in the form of four important particulars: definition, collaboration of actors, smart regulation, and coordinating institution.

\section{Definitions}

Regardless of the different form of the shared houses in the four scenarios, a common language and its definition to describe such a unit or compound is required because, in practice, the language "shared properties" or "listing" that refer to spare houses or rooms are not commonly used in major cities where local governments have actively maintained special laws for such practice. In Portland, for instance, the term accessory short-term rental is used to define "(a place where) an individual or family resides in a dwelling unit and rents a bedroom to overnight guests for fewer than 30 days". Portland ordinance also divides such dwellings into two types: Type $A$ is any accessory shortterm rental where no more than 2 bedrooms are 'shared' to guests or tourists, whilst Type $B$ has 3 or more bedrooms to share (Miller, 2015). The same clear definition is essential for the Bali context in order to act as a regulation tool that maintains the presence of the house owner in their residential unit and determines the maximum number of days the house can be shared during each calendar year.

One panelist suggested using the term "online homestay" as it is structurally similar to names adopted by other sharing economy platforms that have been popular and accepted throughout Indonesia, such as online ojek to refer to motorbike ride-sharing platforms such as GoJek, or online taxi to mean ride-sharing platforms such as Uber and Grab. A uniform decision on both the day limit of rental rooms and houses, and the minimum period that owners can stay in their property, established and disseminated throughout tourism actors and broader stakeholders, would be a 
successful step forward for the sharing economy in accommodation in Bali. For instance by adopting what San Francisco ordinance have already applied, where residential units can only be shared with tourists for less than 30-day occupancies while the residents are required to stay for no fewer than 275 days out of a calendar year (Homeshares of San Francisco, 2016).

\section{It demands collaboration of actors}

Throughout the four future scenarios, some panelists have stressed that controlling such sharing practices require collaboration and integration of roles embodied in different ministries. In general, the Ministry of Communication and Informatics (MCI) administer the ordinance regulating Internet-based companies and digital transactions. However MCI does not have the authority to regulate the shared properties, as they are tourism accommodation providers, regulated and monitored by the Ministry of Tourism (MT). Similarly, MCI has left the responsibility of regulating all participating cars in ride-hailing networks like Uber to the Ministry of Transportation (MTP).

In summary, it is safe to say that Indonesia has already had common understanding regarding the differentiated regulatory response because separate Ministries have been appointed to regulate some of the sharing economy activities based on their rights, authorities and competencies. For the sharing economy in accommodation, despite current minimal intervention, the Ministry of Tourism is at the forefront of regulating the technical aspect of this sector, particularly in detailing the minimum standards that apply to shared properties in Bali, licenses and permits, registries, "good neighbor" regulations, and indeed the relevant taxes and exactions. However, as suggested by a panelist, collaboration and integration with the Ministry of Communication and Informatics is necessary to ensure digital transaction transparency, as well as to monitor payment systems and individual data protection.

\section{Smart regulation}

Referring to the changeability of the sharing economy in accommodation in Bali as depicted in the four scenarios, managing this sector needs a regulation that adapts to the innovative business models. To that end, the "smart regulation" can offer the solutions. Despite the assumption that smart regulation is closely linked and associated with “self-regulation" (Eccles \& Pointing, 2011), smart regulation is in fact a broader 
concept, at the heart of which is a combination of complementarily designed instruments with the flexibility to adapt to contemporary changes. Further, these interconnected instruments are intended to ensure that this sector has minimum safety and quality standards through which consumer safety and greater call to participation could be achieved (Dervojeda et al., 2013). Adopting Gunningham and Grabosky (1998), regulating the sharing economy in accommodation in Bali could follow a mixture of these instruments:

a. Self-regulation

This is roughly defined as a process of applying the rules and codes of practices set by an organized group through a self-assessment mechanism in order to regulate the behavior of its members (Gunningham \& Grabosky, 1998). The self-regulation applied by ride sharing platforms like Uber urge participating drivers to firstly undergo criminal history screening and a review of drivers' vehicle records before they can start operating (Dyal-Chand, 2015). Uber drivers are individually required to provide documents and review the record in person with the help of a third-party background check provider performed on behalf of Uber.

Different from Uber, in the context of the sharing economy in accommodation in Bali, some minimum requirements might apply to the interior or appliance quality, but also go further to take into account the creation of a "good neighbor" environment, as Miller (2015) exemplifies:

- The availability of functioning smoke detector and carbon monoxide alarm

- Adequate lighting in every bedroom and communal space

- Adequate dustbin and trash guidelines

- Parking guidelines including special parking permits

- Maximum number of rooms permissible to be shared

- Maximum number of guests must not exceed the relevant household definition in the particular area

- Registering food or alcohol that are served to the guests

- Registering any non-resident employees, who are usually hired for food preparation and house cleaning

- Noise control guidelines that comprise instruction to limit loud, confusing sounds, and commercial activity during certain hours 
Considering how technological advancement allows this sector to spread and evolve in an unexpected manner, minimum requirements do not seem to follow a default model of standardization but are subject to continuous evaluation and updating to ensure compatibility with the latest developments. Koopman et al. (2015) believe that in addition to bottom-up participants' aspirations, the modern online reputation and rating system play an important role in updating standards and self-policing as it permits guests to regulate hosts' behavior by guiding other guests to make marketplace choices. The result is a dynamic, self-regulating market with strong peer pressure and checks on substandard behavior.

b. Command and control

To be effective and reliable, a self-regulation process needs to meet more than adequate minimum requirements. A clearly defined procedure and audit, as well as the penalties for non-compliance, are the essential components to be incorporated (Dredge \& Jenkins, 2007). In the case of ride sharing for example, the traditional licensing requirements, which allegedly do not fit the dynamic of sharing practices, still serve an important function to ensure that ride providers comply with a set of requirements to protect the safety of both riders and passengers. Here the involvement of government in the form of issuing the driving permit/license is appropriate (Dyal-Chand, 2015). The permit/license is an example of command and control applied to provide adequate monitoring and enforcement, therefore the desired behavior can be specified with considerable clearness and any violation punished accordingly.

In the sharing economy in accommodation in Bali, government intervention through command and control could adopt the following models compiled by Miller (2015):

- License and permits

As emerged in the interviews with panelists, every participating host is required to hold the basic business license/certificate, valid for a certain period, and which can only be obtained through abiding by such self-regulation assessment.

- Information sharing

To complete the license and permits application, some critical information related to sharing practices are to be submitted as a means for effective regulation. Panelists highlighted the need for information about how hosts can 
be contacted and also the importance of completing the "guests logbook", which includes the personal identity of guests, dates of stay, and the room assigned to each guest. Additionally, the "guests logbook" has to include a copy of the legal identity of each guest (i.e. passport for international tourists or resident identity card for domestic tourists) and must be available for online or offline inspection at any time.

- Taxes

Panelists addressed the importance of the collection of taxes although the rate might vary from the hotel tax paid by Indonesia's traditional lodging providers. As emphasized by one of the panelists, platforms for the sharing economy in accommodation are now open to assist and simplify tax collection by collecting any kind of occupancy taxes on behalf of the hosts. On a different note, Miller (2015) notes that some cities consider pursuing tax evasion by hosts in case platforms are unable to collect tax through the online records of commercial transactions when applying for licenses and permits.

\section{Coordinating Institution}

From the self-regulation mechanism discussed earlier, we can see that setting up such a mechanism needs an organized group or coordinating institution for the purpose of supporting hosts in order to enable their development into self-sufficient businesses, but also to monitor and sanction substandard behavior of members within the network. This coordination institution indeed acts as what Dredge and Jenkins (2007) refer to as a pressure group or interest group, defined as the formal collective of non-governmental actors organized around common interest. In the tourism industry, this means groups that are usually formed as the peak body to represent tourism-related business such as travel agents, hoteliers and hospitality industry or park operators (i.e. the Australian Hotels and Hospitality Association in Australia or the Travel Agent Association of New Zealand in New Zealand). In this context, the coordinating institution would represent the sharing economy in accommodation in Bali to serve several functions:

- Formulating minimum standard requirement for a self-regulation mechanism based on the dynamic online reputation and rating system. 
- Serving as a forum for information and resource sharing, which might include circulating reports about scams or malfunctions as well as discussing, for example, contemporary issues about upcoming requirements and how to meet them.

- Serving as an advisor for policy-making by channelling the aspirations of participants in the sharing economy in accommodation to authorized officials.

- Partnering with educational institutions to prepare basic guidelines in managing micro lodging businesses (Dyal-Chand, 2015).

- Partnering with incumbent accommodation providers in product development collaboration.

The previous four important strategies regarding definition, differentiated regulatory responses, smart regulation, and the role of a coordinating institution, leads to the development of a relationship diagram depicting a proposed management flow for the sharing economy in accommodation in Bali (see figure 6.1). In the center of the diagram is the implementation of the smart regulation and the interconnection of three main actors: the government, the coordinating institution, and the participants of the sharing economy in accommodation in Bali. 
Figure 6.1: proposed management flow of the sharing economy in accommodation in Bali

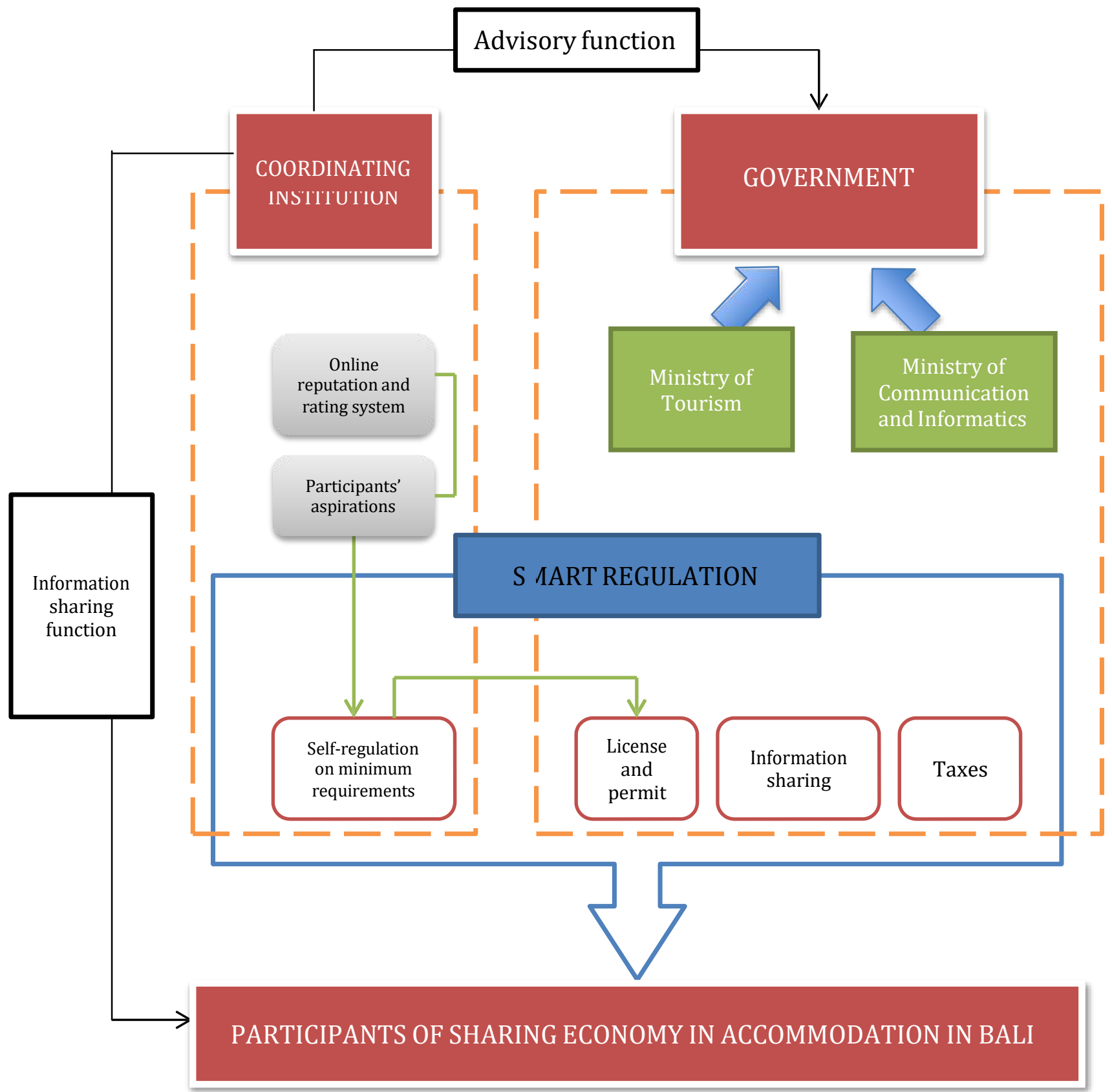

\subsection{Implications and strategic decisions based on the individual scenarios}

In addition to the general strategies, the next step is to look at the potential implications and key strategies of all scenarios. In short, the implications reflect the potential consequences and risks that evolved from the key issues and trends of each scenario as discussed in chapter 5, whilst the key strategies offer guidance to deal with such implications. To acquire different implications and strategies, the questions being asked 
to panelists differ in the sense that each scenario has been developed to envision different pathways for the future.

\subsubsection{Implications and strategic decisions for the from local to global}

The question for this scenario is structured as follows: "Taking into account the key issues and trends in this scenario particularly the vision of local-owned sharing platforms, smart homes, and the competition with established hotels providing shared economy in accommodation, what would be the most important implications and strategies the Bali tourism stakeholder might need to consider?". The answers for that question are presented below:

Table 6.1 Implications and key strategies of from local to global

Implications

Another intensive land exploitation and native land loss as a result of shared houses

\section{Key strategies}

- Apply a strong law that governs land use throughout Bali (e.g. the Comprehensive Zoning Ordinance in the US) to regulate areas where such shared houses are allowed to be built or operate.

- The land use regulation can be combined with minimum standards for rentals such as a minimum square meter floor area of the building (e.g. Japan has set a minimum of 25 square meters for homes looking to share), the availability of prerequisite facilities, or the minimum period the house owners should stay in the property.
The potential cyber-attack on smart houses that might threaten the security of house owners as well as the guest.
Foster a strong collaboration between the coordinating institution, relevant stakeholders, and sharing platforms to use the like of registered biometric or fingerprints to authenticate the house owners and potential guests.
The need to encourage the establishment of other local platforms or entrepreneurs with similar concepts as they might contribute more to the domestic economy from employment and corporate income tax.
Develop a supportive environment for new players in this field on different levels:

- Simplify the administrative procedures including the number of days to start business

- Financial aid

- Tax subsidies

- Incubator program that provides business development resources such as legal support, mentors, and networking opportunities with the prospect to attract investment

- Publication in the media 
The choice overload where the set of options with similar features become overwhelmingly large for tourists and creates confusion.

The stiff head-to-head competition between shared houses and the new small size hotels offering a similar experience.
An aspect of land use regulation should control the proximity restriction which limits the density of shared houses in a region on a performance or minimum standard compliance basis.

- An aspect of the land use regulation should also control the ratio of shared houses to those new hotels.

- Each region in Bali needs to intensively diversify its products from others to entice more visitors, thus ensuring sufficient demand for such enormous supply. 


\subsubsection{Implications and strategic decisions for the joint first prize}

The question for this scenario is structured as follows: "Taking into account the key issues and trends in this scenario, particularly the partnership between hotel and traditional villages, the integrative rating system, and the realization of environmental and cultural restoration in Bali, what would be the most important implications and strategies the Bali tourism stakeholder might need to consider?"

The answers for that question are presented in below table:

Table 6.2 Implications and key strategies of the joint first prize

Implications
Key strategies
As sharing economy in accommodation encourages engagement with locals, intensive interactions between guests and hosts may impact on rural community character, also a rural neighborhood may lost its sense of place.
- Regulating how many guests can occupy a house along with the hosts in order to uphold residential neighbourhood values.

- The establishment of the diffuse hotel may not eliminate parts or design of original Balinese housing compounds, as well as not modify the visible public realm and aesthetic tranquillity of the village.
The potential of uncontrolled rise in the land price to hinder the development of the Diffuse hotel.
The government might need to offer incentives to the land/house owner not only financial but also by giving them free access to health services and education
The development of the Diffuse hotel needs a clear agreement ensuring a fair and sustainable economic benefit for local residents.
Prior to the execution, a joint or participated feasibility study must be undertaken that lead to the creation of a legal mutual agreement arranging the rights and responsibilities of each party, as well as punishment for noncompliance.
The potential inclusion of false review when classifying the shared houses or the diffuse hotels.
Automatizing the detection of false review through the use of Artificial Intelligence (AI) that able to examine questionable reviews, those designed to mimic unbiased reviews, or even the incentivized ones. 


\subsubsection{Implications and strategic decisions for the volte-face}

The question for this scenario is structured as follows: "Taking into account the key issues and trends in this scenario, particularly how Bali lost the conducive tourism environment and the Internet connectivity restriction that is the main prerequisite for the shared economy in accommodation, what would be the most important implications and strategies the Bali tourism stakeholder might need to consider?"

The answers for that question are presented in below table:

Table 6.3 Implications and key strategies of the volte-face

Implications

The need to recover Bali's competitiveness as a worldwide tourism destination, which eventually will revive the existence of sharing economy in accommodation.

\section{Key strategies}

Transform Bali into a safe 'sharing island' by taking into account these aspects:

- Creating more inclusive spaces that maximize residents' activities in public areas to "crowd out crime".

- Providing more employment and entrepreneurship opportunities through sharing personal goods scheme such as cars, meals, land for garage, household tools, shop-fronts, kitchens, and rooms or houses for accommodation.

- Challenging the individualism culture through a more participative politics.

- Improving the shared use of infrastructure and services as a mean to build mutual respect and solidarity, such as public transport, libraries, healthcare, education, and childcare. 


\subsubsection{Implications and strategic decisions for the what's yours is mine}

The question for this scenario is structured as follows: "Taking into account the key issues and trends in this scenario, particularly the exclusive second homes 'regional differentiation', and the all-in-one tourism services offered by the sharing economy in accommodation platforms, what would be the most important implications and strategies the Bali tourism stakeholder might need to consider?". The answers for that question are presented in below table:

Table 6.4 Implications and key strategies of what's yours is mine

Implications

The development of exclusive second homes clusters may cause massive gentrification and displacement

\section{Key strategies}

- Instead of reducing exclusive second homes clusters, it might be important to use the money the government receive from taxing the clusters to build more affordable housing with supreme facilities and free of charge modern transportation. The housing itself located in the buffer-zone between the city and the rural.

- The need to appoint on-site property manager from native resident in every cluster as a mean of local community empowerment.

Despite the valuable tax, such clusters may create the 'enclave tourism' characterized by highly concentrated development that enclosed, selfcontained, and separated from existing communities. Enclave tourism is notorious for its leakage effect and very weak benefit to local economy.
Preventing high leakage effect by creating stronger local infrastructure and regulation:

- Making guests aware about the issue of enclave tourism so they spend their money for nonaccommodation needs such as activities and dine out in the local economy.

- Supporting local business especially food provider and building material suppliers to become more sustainable and have the bigger business structure.

- Strengthening local workforce capacity through training and education.

- Monitoring the consumption of clusters on local products to ensure local value creation
The potential of sharing economy in accommodation platform to completely dominate the domain for booking tourism facilities on the sharing basis and threat many other tourism enterprises beyond the accommodation sector.
This situation need to be seen as a way to foster more visitation that has positive impacts on the broader tourism economy not the opposite.

- Encouraging non-sharing sector to emphasize the human touch, tech-free, authentic, and engaging environment in order to remains competitive

- Ensuring all players to pay the taxes with proportional mechanism that will be used to attract more tourists' visitations. 


\subsection{Conclusion}

In essence this chapter has conveyed the strategic implications for the future scenario of the sharing economy in accommodation in Bali through answering two specific questions. The first question dealt with general key requirements to maintain the sustainability of the sharing economy in accommodation in Bali, which drew out four main strategic responses: to set out a clear definition and common language, a differentiated regulation must be carried out by a collaborative action of different authorized actors, to establish a smart regulation, and to activate the coordination institution.

The second questions were based around the identification of potential consequences and risk, as well as the key strategies of the individual scenarios. The approach in each scenario differs as different issues were raised in each scenario. Fundamentally, the strategic implications have been raised in order to stimulate the key players with a guideline for strategic development and to address a comprehensive strategic analysis and decision-making. 


\section{Chapter 7}

Conclusion

\subsection{Introduction}

This chapter aims to bind together the entire study by referring to the research question and sub-questions, the contribution and value of the study, and concludes by providing recommendations for future research in the field of the sharing economy in accommodation.

\subsection{Summary of the study}

The sharing economy in accommodation emerges into one of the most important trends in tourism as a result of advanced technological evolution and the modern cultural changes that heavily adopt the spread of digital information. Its wide spectrum of benefit and burden, coupled with the increasing contingencies of the world, urge the need to explore the future of the sharing economy in accommodation to reduce the complexity of the potential evolution of this sector in the decades lying ahead. Undertaking Delphi-based scenario planning, this study responded to the research question, 'What will the sharing economy in accommodation in Bali look like in 2030?', with three different sub-questions addressing, in order: the drivers of change that shape the future of this sector; the possible scenarios; and the strategic implication of each scenario.

For the first sub-question, in light of two semi-structured interviews and two online questionnaires with 14 panelists, a total of 14 basic drivers of change were identified. From these, two prominent drivers were found (being considered by panelists the most important and the most likely to have an influence). From these, a four-quadrant scenario planning matrix was constructed. The first driver, infrastructure development, is positioned on the vertical axis, whereas the second driver, ubiquitous Internet, is placed on horizontal axis. Subsequently, relevant literature and statistics are added to the 14 drivers so they present a comprehensive picture of current and future circumstances. It is also worth noting that all the drivers have significance for the scenarios despite the different level of impact. 
In general, managing the sharing economy in accommodation in Bali necessitates a clear definition that describes clearly the type of properties allowed to share, for how long, and the minimum period owners must stay in those properties. Then, a smart regulation, essentially a combination of instruments that appoint minimum quality standards and flexible enough to adapt to changeable circumstances, must be carried out by a collaboration of authorized stakeholders. Lastly, a coordinating institution that represents the sharing participants is required to be established to assist its members and liaise with government agencies.

The second question addresses implications and key strategies of individual scenarios as summarized in the following figure:

Figure 7.2: the four-quadrant scenario-planning matrix and their implications and key strategies

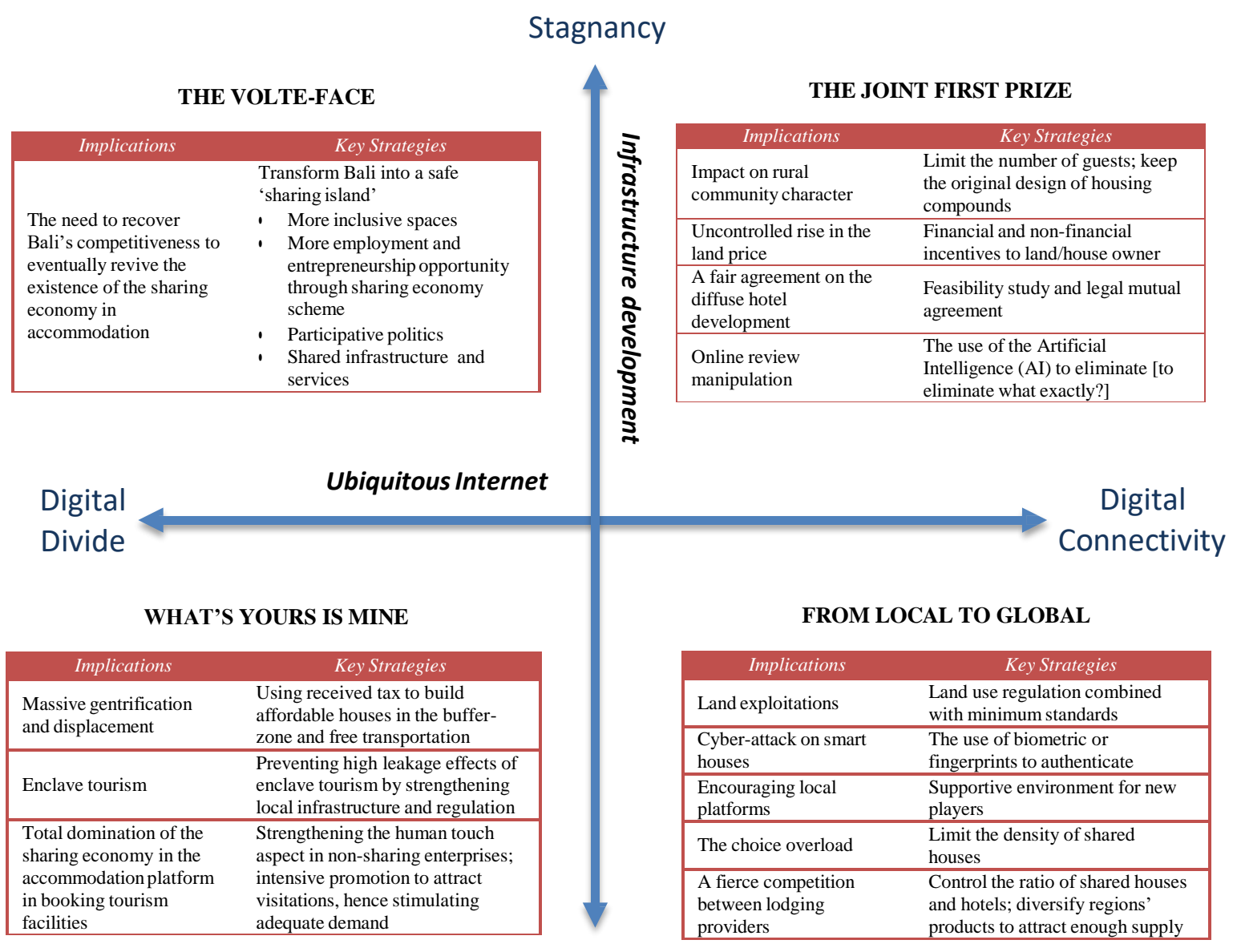

Improvement 


\subsection{Contribution and value of the study}

Already mentioned in chapter 1 , this study has two main contributions: a theoretical contribution and a practical contribution. The former is about offering a document that contributes to the overall academic literature as this study does by capturing the following values:

a. Current main academic researches focused on this topic have attempted to understand the embedded traits of the sharing economy in accommodation, such as desirable attributes of shared houses (Tussyadiah \& Zach, 2015), guests' trust and their decision-making (Ert et al., 2016; Finley, 2013), drivers and deterrents of participating in a travel-related sharing economy (Tussyadiah, 2015; Hamari et al., 2015; Tussyadiah \& Pesonen, 2016), consumer protection (Koopman et al., 2015; Katz, 2015; Miller, 2015), sustainability of sharing business (Daunoriene et al., 2015); and implications on the present state, such as the impact on tourism industry employment (Fang et al., 2016) and the impact on incumbent hotel industry (Guttentag, 2015; Zervas et al., 2014). However, none of these studies cover the future evolution and possible upcoming implications of the sharing economy in accommodation, which, the researcher thinks, is of importance considering how this sector has grown to establish itself within the worldwide accommodation sector at a rapid rate, its disruptive effect and impacts on wider sectors, and given the uncertainty and contingency of the postmodern era. Employing scenario planning, this study goes beyond the strictly rational of what seems thinkable today to systematically present a series of tomorrow's evolutions - that is, the implications of the sharing economy in accommodation in Bali that are currently unseen or undervalued. The ability to unravel unknown possibilities of the future is the key strength of this study and thus this study can contribute to a greater understanding of the nature of this sector.

b. Oskam and Boswijk (2016) have thoroughly mapped the potential further developments of the sharing economy in accommodation platforms, and the impact that such developments will have upon the city destinations in general. However, given their focus on 'the city' destination, they have not really incorporated the unique characteristics of non-city destinations, nor have they looked at the current trends and issues emerging in a specific destination. The result is a very broad study which may not be applicable for all destinations; destinations which, after all, will embody distinctive traits and problems that influence the transformation of the 
sharing economy in accommodation in those destinations. On the other hand, this study is context-specific, bounded to Bali, grasping the status quo of Bali and the Balinese, as well as local and factual issues. Thus, this study expands the outcome of Oskam and Boswijk's research in the sense that it provides a different future vision of a non-city destination and incorporates the unique character of a specific destination. A result comparison between this study and Oskam and Boswijk's would be beneficial to better understand the sharing economy in the accommodation sector.

c. In his research, Guttentag (2015) has underlined the need for future research to discuss the possible evolution of the sharing economy in accommodation platforms and how such evolution further disrupts other areas of tourism that go far beyond the lodging provider to achieve greater understanding of its disruptive emergence. In this study, the what's yours is mine scenario portrays how the sharing platforms accommodate the core services offered by Online Travel Agents (OTAs), restaurants, and souvenir shops, while from local to global emphasizes the rise of local-owned platforms that disrupt globally-recognized platforms such as Airbnb. In essence, both scenarios respond to the suggestion of Guttentag's research, and overall this study is of great importance if destinations are to better respond to future challenges created by such disruptions, by providing a series of evolution forms.

d. Much of the value in this study lies in the way it presents a wealth of in-depth and up-to-date data on both the sharing economy in the accommodation field, and the key drivers of change. The research of Barnes and Mattson (2016) has similarly identified key drivers to investigate the likely future developments of collaborative consumption, each of which was presented in a summary sentence, derived from the explanations of research's participants without integrating further evidence from statistical data or available literature. Each driver in this study, on the other hand, presents a range of relevant statistics, studies, industry reports, and experts' insights, not only to indicate the emergence of drivers in the current state, but also to signal a coherent perspective on future possibilities. Therefore, this study has more comprehensive evidence, viewing the sector from multiple perspectives. Also, given the in-depth data, the drivers of change in this study can be used individually for further discussion and reflective thinking on different topics.

e. Part of the value of this study lies in the use of its methodology in scenario construction. Nowack et al.'s (2011) method, that incorporates the Delphi technique 
into the generic scenario planning approach, is a favorable alternative technique to cope with the robust subjectivity of scenario planning. While the future study adopts the scenario paradigm, called simply the 'foresight', based on a constructivism epistemology that is grounded in the subjective constructs of individuals (Postma, 2015; Lincoln et al., 2000), this study improves the quality of the future envisioned by adding objectivity and credibility throughout the scenario construction. In some stages of data collection, the iteration of questionnaires is employed, aimed at acquiring a collective voice and consensus from individual participants in this study, so a stronger selection of the most important drivers can be achieved in a more objective manner. Also, the involvement of all participating individuals in enriching the scenario traits and its implications gives credibility and assurance to the overall scenario as a collective rather than individual work. A modification of Nowack et al.'s (2011) method used in this study might be recognized as cuttingedge, inviting replication in different areas of tourism and future study.

The practical contribution is achieved as each scenario gives value in the following ways:

a. This study not only envisages the potential implications of each scenario but also covers some of impending threats. From the perspective of risk management, a list of possible risks with respect to the sharing economy in accommodation are identified, among which are social impacts (the changing culture and missing the sense of place), security impacts from the use of advanced technology, enclave tourism, and land-related issues due to the prevalence of sharing practices. The previous empirical studies on the sharing economy in the accommodation sector urge the need for better policies regulating the sharing economy that include risk management (Hotrec, 2015; Wosskow, 2014). Therefore, having the potential risks of this sector assessed in advance, this study helps all related stakeholders in Bali to elaborate risk control in order to allocate a rational basis of resources, so all risks are cost-effectively managed.

b. From the government perspective, the richness of future possibilities in this study can serve as the basis for formulating policy responses in order to strive for a winwin and non-zero sum game of the sharing economy. Despite the fact that all aspects of this study at some point are of help considering their relevance to the policymaking process, the strategies discussed in chapter 6 simultaneously provide a detailed and contextual input to formulate policies that support the sustainability of 
this sector and impacted sectors surrounding it. For example, if a closer look is taken at the proposed management flow pictured in Figure 6.1, the researcher believes that the hierarchy and function shown in this figure can help direct key governments to develop a clear idea of 'who is doing what', including job descriptions of related actors, particularly in government and coordinating institutions.

c. From the perspective of shared houses owners or other accommodation entrepreneurs, this study can serve as a diagnostic tool on the dynamics of the sharing economy in the accommodation sector. Each side can comprehend how their counterparts react to the development of this sector, what the profitable opportunities are, and the potential threats. By using the scenario, each side will be able to challenge their prevailing mindset and to draw forward-looking business plans that integrate new ideas, risks assessment, and uncertainties in order to leverage their market shares.

d. Essentially this study also envisions a much bigger picture of the possible future of Bali as a destination other than just the sharing economy in accommodation. This has relevance to the regulatory body to carefully think through what plan needs to be taken and how that plan impacts the future of Bali. Is it going to be an arena for intensified modern development, back to traditional roots, or not having tourism at all due to the failure of some critical systems? As a small island with carrying capacity, yet that makes an important contribution to the Indonesia economy, it is crucial to decide, with caution, what Bali will look like in the future as it strives for destination competitiveness - which also impacts the existence and form of the sharing economy in accommodation.

\subsection{Avenue for future research}

As this study becomes the first to unravel the future of the sharing economy in accommodation in Bali, there are some of the worthwhile opportunities for future research:

a. This study focuses only on the sharing economy in accommodation in Bali as one of Indonesia's tourist destination flagships, and is only relevant for the Bali context; thus it is important to provide frameworks that portray the future state of the sharing economy in accommodation in a broader context or in different settings (i.e. national or regional ASEAN settings). Findings from the perspective of other 
countries might provoke national stakeholders to come up with more holistic ways of thinking in this sector.

b. Since the sharing economy in accommodation is only one part of the much more extensive sharing economy in tourism, future studies may also seek to view the position of the sharing economy in accommodation in the overarching system of Indonesia's sharing economy in tourism, and offer future projection. Understanding this aspect with regard to total spending and total participation of tourists in each sector will contribute to a deeper understanding of the nature of the sharing economy in tourism.

c. Referring to the paradigm of this study, which strongly falls into 'foresight' with the use of self-conscious reflexivity and empirical knowledge produced in other disciplines, future research should consider the inclusion of quantitative data such as the yearly changes in the number of hosts and guests and the economic impact of the sharing economy in accommodation to incumbent lodging providers. This would build a more robust narrative in the scenario, giving a stronger argument and credibility for key players.

d. To tackle the limitations of this study, particularly the time-consuming process of scenario-building, different methods can be applied in forthcoming research, such as developing fewer storylines through selecting two of the most probable scenarios out of the four available. Another option is to shorten the scenario building process to a half-day or one day activity, but to use a set of projections prepared earlier by means of the assisting software.

\subsection{Conclusion}

By utilizing the Delphi-based scenario planning methodology, this study has developed the future scenario of the sharing economy in accommodation in Bali in order to illustrate a range of possible multiple futures for this sector. Not only is the scenario of use in reducing the complexity of the future, but through the strategic implication, the study gives insight to the key players in Bali about the need to challenge the linear ways of thinking and to level the playing field in the context of 2030. Nevertheless, this study is a small piece of work in the vast and unpredictable field of the sharing economy, therefore there is every reason to believe that more research in this field is needed to firmly establish greater understanding and practical value. 


\title{
Appendices
}

\author{
Appendix 1: Invitation for participation in Master Thesis (In Bahasa Indonesia)
}

Wellington, 1 Juni 2016

Kepada Yth:

Nama saya Arya Galih Anindita (Arya). Saya bekerja di Kementerian Pariwisata Republik Indonesia, tetapi saat ini sedang menyelesaikan studi Master of Tourism Management di Victoria University of Wellington, Selandia Baru. Sebagai salah satu syarat untuk menyelesaikan studi, saya sedang melakukan penulisan tesis dengan judul: 2030: A Scenario Analysis of the Sharing Economy in Bali Accommodation. Pembimbing tesis adalah Associate Professor lan Yeoman (http://www.victoria.ac.nz/som/about/staff/ian-yeoman).

\section{Latar Belakang}

Didasari oleh semakin tingginya motivasi untuk berbagi aset pribadi yang tidak banyak digunakan untuk sejumlah uang, serta didorong oleh aplikasi online yang lebih variatif, aktivitas sharing economy menunjukkan peningkatan signifikan serta menjadi alternatif konsumsi konsumen global. Sebuah study dari PricewaterhouseCoopers di tahun 2015 menyebutkan bahwa lima sektor utama sharing economy - akomodasi, car sharing, keuangan, staffing, serta streaming musik dan video berpotensi menghasilkan total pendapatan global hingga $\$ 335$ miliar pada 2025 dari sekitar $\$ 15$ miliar pada 2015. Airbnb merupakan pionir sharing economy di bidang akomodasi ditengah berkembangnya platform sejenis seperti HomeAway, Wimdu, dan Tuija. Airbnb pada dasarnya memfasilitasi setiap orang yang memiliki ruangan/rumah/lahan yang tidak digunakan (dikenal sebagai "host) untuk disewakan sebagai tempat menginap bagi wisatawan, dan tercatat telah melayani lebih dari 30 juta "tamu" sejak awal didirikan pada 2008. Meskipun demikian, terdapat tantangan seputar legalitas, pajak, potensi gangguan terhadap industri akomodasi yang lebih dahulu eksis, hingga isu seputar keberlanjutan fenomena ini. Didasari hal-hal tersebut, saya melakukan riset mengenai masa depan sharing economy di sektor akomodasi untuk membantu mengurai kompleksitas fenomena tersebut melalui sejumlah skenario.

\section{Tujuan dan sasaran riset}

Tujuan riset adalah menjawab pertanyaan "Bagaimana masa depan sharing economy sektor akomodasi di Bali pada 2030?". Jawaban pertanyaan akan disusun dalam format skenario-skenario yang masing-masing mencakup dampak kepada industri akomodasi, Bali sebagai destinasi pariwisata unggulan, serta stakeholder terkait di masa yang akan datang.

Adapun sasaran riset adalah:

a. Kontribusi teoritis berupa tersusunnya model konseptual masa depan sharing economy sektor akomodasi di Bali.

b. Kontribusi praktis berupa teridentifikasinya konsekuensi dari skenario masa depan sharing economy sektor akomodasi di Bali bagi stakeholder terkait, serta tersedianya rekomendasi yang relevan dan aplikatif. 


\section{Permohonan partisipasi}

Dalam upaya mencapai tujuan dan sasaran riset tersebut, dibutuhkan pendapat, pikiran serta ide dari para ahli dan pembuat kebijakan. Mempertimbangkan latar belakang dan keahlian Bapak, saya memohon kesediaannya untuk berpartisipasi dalam riset ini dalam bentuk (maksimal) 2 kali wawancara masing-masing selama 60 menit, serta pengisian 2 survei online masing-masing selama 15 menit, yang diselenggarakan antara tanggal 21 Juni hingga 30 October 2016.

Besar harapan saya bahwa saat riset ini telah selesai dilakukan dan hasilnya dibagikan, partisipasi Bapak terganti oleh keluaran riset yang menarik, inspiratif, dan aplikatif. Apabila Bapak berkenan untuk berpartisipasi, dipersilahkan untuk memberikan balasan ke alamat email saya di anindiarya@myvuw.ac.nz, sehingga saya dapat memberikan informasi lebih lanjut mengenai prosedur, kode etik, serta penjadwalan. Dimohon pula agar tidak sungkan menghubungi saya untuk pertanyaan dan klarifikasi lebih lanjut.

Saya mengucapkan banyak terima kasih atas kesediannya mempertimbangkan permohonan partisipasi ini.

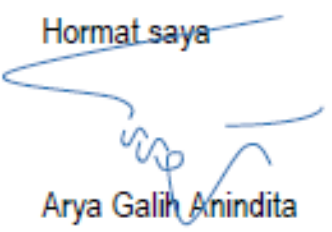


VICTORIA UNIVERSITY OF WELLINGTON

Te Whare Wananga o te Qpoko o te Ika a Müui

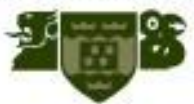

Thank you for showing an interest in this research. Please read this information sheet carefully before deciding whether or not to participate. If you decide to participate I thank you. If you decide not to take part, I thank you for considering my request.

\section{The research}

I (Arya Galih Anindita) am a Masters of Tourism Management student a Victoria University of Wellington and I am undertaking a thesis study on the future of the sharing economy in Bali accommodation. Owing to the disruptive nature of the sharing economy, a better understanding is needed by Bali tourism stakeholders to make sense of the complexities in order to develop strategies and policies. This research involves the construction of four scenarios that are set in 2030 . The outcome of this research is to develop a series of recommendations for stakeholders based upon the scenarios.

\section{The task}

This research involves four rounds of interactive expert based panel:

- The first round is organised to seek opinions and feedbacks on drivers of change of sharing economy,

- The second round is carried out to rank the likelihood of drivers from core member of panel with additional 8 experts. By doing so, the researcher could construct the consensus of most important drivers into the axes of scenario-planning matrix;

- The third round is carried out to seek final agreement on the axes of scenario-planning matrix;
- The fourth round is undertaken to determine meanings, impacts, and implications of scenario-planning matrix for different stakeholders Please be aware that there are two different positions in the expert panel. The core members are requested to participate in all rounds of expert panel, whereas the additional members are requested to participate only in the second and third round.

\section{Participation in the research}

Should you agree to take part in this research and sign the attached consent form, you will be asked to participate as the core member of expert panel:

- The first round: to partake in face-to-face interview of circa $45-60$ minutes

- The second round: to rank the shortlist of drivers on an online form

- The third round: to give written agreement or disagreement and comments on an online form

- The fourth round: to participate in face-to-face or online interview (via Skype, Google Hangout, and similar) of circa 45 - 60 minutes

Processing of data and confidentiality

1. This research is confidential. The interview transcripts, summaries, digital recordings, and feedback files will be securely stored in such a way that only me and thesis supervisor (Associate Professor lan Yeoman) will be able to gain access to it.

2. Your role or association with an organisation will used to report data and quotations. 
VICTORIA UNIVERSITY OF WELLINGTON Te Whare Wänanga o te Q̂poko o te Tka a Mäui

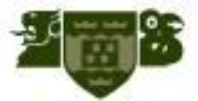

3. At the end of the interview in each round, a transcript and/or summary of your interview will be available for examination upon request as indicated on the consent form.

Outputs of the research

1. At the conclusion of the research, findings will be published in the Victoria University of Wellington library and may be included in academic publications and/or academic conferences.

2. You will be provided with a 1000 words extended abstract of the study and a link to the e-copy in the university library.

3. Interview transcripts, digital recordings, and online forms will be stored for up to 3 years before destruction.

Contact

If you for any reason have any questions about the research, either now or

in the future, please feel free to contact the researcher or research supervisor.

Researcher:

Arya Galih Anindita

School of Management - Victoria University of Wellington, New Zealand

anindiarya@myvuw.ac.nz

$+64-223984351 / /+6282122584110$

Associate Professor lan Yeoman

School of Management - Victoria University of Wellington

lan.yeoman@vuw.ac.nz

$+64-4-4635717$

If you have any queries about ethics policies, please feel free to contact HEC Convener.

Human Ethics Committee (HEC) Convener

Associate Professor Susan Corbett

Susan.corbett@vuw.ac.nz

$+64-4-4635480$

This research has been reviewed and approved by the Human Ethics Committee of Victoria University of Wellington. 
VICTORIA UNIVERSITY OF WELLINGTON

Te Whare Wänanga o te Ûpoko o te Ika a Mäut

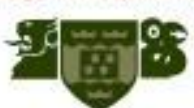

I have been provided with adequate information relating to the nature and objectives of this research (see 'Information Sheet'). I have understood that information and have been given the opportunity to seek further clarification or explanations.

\section{I understand that:}

1. My participation in this research is entirely voluntary. I may withdraw from participation in the research before final analysis of data without providing reasons. I also understand that if I withdraw from the research, information provided during the interview will be returned and destroyed. Conversely, information about ranking of the drivers and written agreement cannot be destroyed as it is deemed shared and collective.

2. Any information or opinions I provide will be kept confidential and reported only by mentioning my role or association with an organisation

3. All audio digital recordings and transcripts will be stored for up to three years after the research is completed.

4. The findings derived from this research will be published in the Victoria University Library and may be included in academic publication

5. In the event that the line of questioning during the interview develops in such a way that I feel hesitant or uncomfortable I may decline to answer any particular question(s) and/or may withdraw from the research immediately.

I consent to (please tick box)

- The interview(s) conducted by the researcher to be digitally recorded
I would like (please tick box as required)

a A summary and transcript of the interview(s) in each round

A summary of ranking of drivers

a A summary of agreement on the axes of scenario-planning matrix

a A 1000 words extended abstract of the study and a link to the e-copy in the university library

I agree to take part in this research.

(Name of business)

(Signature of participant)

(Date)

Researcher consent:

I confirm that I will act in accordance with all confidentiality requirements as outlined in the information sheet for this research.

(Researcher) 
Appendix 4: Example of interview questions of the first round (translated into

English)

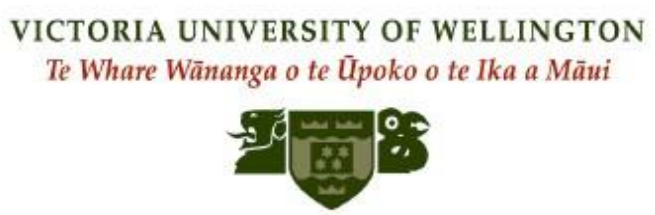

\section{INTERVIEW PLAN}

1. Outline of question plan

a. Personal perspective

- One of the most popular sharing economy in Indonesia is the motorbike ride sharing namely Go-Jek. In your own words, can you describe 'the sharing economy'?

- What are the key characteristics of the sharing economy?

- What do you think about the sharing economy in Accommodation sector that is popularized by Airbnb?

b. Future-related questions

- Back to 20 years ago in 1996 when sharing economy was not existed, what changes have you noticed in 2016?

- Why are these changes occurring?

- What lessons do should we learn from this?

- Drivers of change are those trends, which are occurring in society that have impact on industry and people.

- What are the key drivers of change that may shape the future of the sharing economy?

$\circ$ Why?

- What are the warning signal/signposts of those drivers?

- How significant is the implication of that driver/s to the sharing economy in accommodation sector?

- Apart from drivers that have been mentioned, can you comment on other most prominent drivers in my shortlist that may also shape the future of the sharing economy in accommodation sector in Bali?

- Why?

- What are the warning signal/signposts of those drivers?

- How significant is the implication of that driver/s to the sharing economy in accommodation sector?

- There is a lot of uncertainty in the future. What are the key uncertainties that provide threats to the future of the sharing economy in accommodation sector in Bali?

- What are the key uncertainties that provide opportunities to the future of the sharing economy in accommodation sector in Bali?

- What are the key issues/concerns surrounding the sharing economy in accommodation sector in Bali? 


\section{VICTORIA UNIVERSITY OF WELLINGTON \\ Te Whare Wãnanga o te Ūpoko o te Ika a Mãui

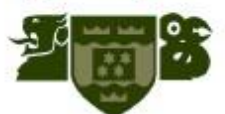

- What kind of regulations, actions, or strategies has to be considered to deal with such issues?

- Looking into the year of 2030, what is the "good" future scenario for the sharing economy in accommodation in Bali?

$\circ$ Why?

$\circ$ How?

- What will it look like?

- Looking into the year of 2030, what is the "bad" future scenario for the sharing economy in accommodation in Bali?
$\circ$ Why?
- How?
- What will it look like?

c. Other questions

- Is there anything else you would like to discuss or any suggestion that I should incorporate into my research?

2. HEC notes
a. Give the copies of thesis information sheet
b. The interviewee is requested to sign the consent form
c. Explain permission to cite at the end of the interview

3. Other points
a. Remind the interviewee about the interview schedule one day prior to appointed time
b. Send the initial list of drivers to interviewee's email (or his/her personal assistant) 3 days prior to interview schedule


Appendix 5: Example of questionnaire of the second round (translated into English)

\author{
VICTORIA UNIVERSITY OF WELLINGTON \\ Te Whare Wananga o te Üpoko o te Ika a Müui

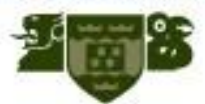 \\ QUESTIONNAIRE FOR THE SECOND ROUND OF THE DELPHI METHOD \\ 2030: A Scenario Planning of the Sharing Economy in Bali Accommodation
}

Thank you for the constructive interview in the first round. I have elaborated key points from the previous interviews with all interviewees/experts, academic literatures, and tourism industry reports into a shortlist of 15 most commonly mentioned drivers of change of the sharing economy in accommodation in Bali as seen in the table below. The second round aims to narrow down below shortlist into 4 key drivers of changes that remain for the next round. In this phase, I would ask your participation to rate on "how important is the driver of change in influencing the development of the sharing economy in accommodation in Bali?" Please give a cross ( $x$ ) in the box reflecting your viewpoint.

Please be informed that on a scale of 1 to 7 , with 1 being "extremely unimportant" and 7 being "extremely important". Your participation is very much appreciated.

\begin{tabular}{|c|c|c|c|c|c|c|c|c|}
\hline \multirow{2}{*}{ No } & \multirow{2}{*}{ Drivers of Change } & 1 & 2 & 3 & 4 & 5 & 6 & 7 \\
\hline & & 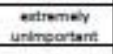 & & & 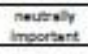 & & & importart \\
\hline 1 & $\begin{array}{l}\text { Indonesia as a developing economy } \\
\text { The enhancement of Indonesia's stage of development that leads to the increase of average } \\
\text { income and the availability of disposable income for travel. }\end{array}$ & & & & & & & \\
\hline 2 & $\begin{array}{l}\text { Infrastructure development } \\
\text { Government's initiatives to develop both of hard infrastructure (new airport, highway, etc) } \\
\text { and soft infrastructure (free visa entry regulation, etc) that attract more tourists to Bali }\end{array}$ & & & & & & & \\
\hline 3 & $\begin{array}{l}\text { Variety of low cost airplanes } \\
\text { The availability of various low cost airplanes to travel into/within Indonesia }\end{array}$ & & & & & & & \\
\hline 4 & $\begin{array}{l}\text { Ubiquitous Internet } \\
\text { The importance of Internet to facilitate sharing, to enhance connectivity among humans, and } \\
\text { to facilitate the rise of peer-to-peer social networks in accommodation such as Airbnb }\end{array}$ & & & & & & & \\
\hline 5 & $\begin{array}{l}\text { Smart technologies domination } \\
\text { Increasing sophistication of mobile phones and smart technologies by which support the } \\
\text { sharing economy activity such as the big data, cloud computing, Bitcoin, and PayPal }\end{array}$ & & & & & & & \\
\hline 6 & $\begin{array}{l}\text { Political decision related to the sharing economy in accommodation } \\
\text { Indonesia government and political leader's decision on whether to support or not to }\end{array}$ & & & & & & & \\
\hline
\end{tabular}


VICTORIA UNIVERSITY OF WELLINGTON

Te Whare Wananga o te Upoko o te Ika a Müui

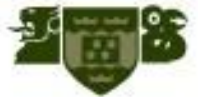

support the sharing economy in accommodation through regulations like legality, standards, taxation, or a ban

Domination of Generation Y/Millennial Generation

7 Potential domination of Generation Y/Millennial Generation with their global mindset and technology wise, to drive the tourism product design in the future and to lead the massive sharing economy movement

'Living like a local' tourists

8 Prevalent change of global tourist preferences into the desire to gain rich social experiences by staying and connecting with local residents

Innovation of sharing economy in accommodation platform

9 Sustainable transformation and innovation done by the sharing economy in accommodation platform like Airbnb, by which simplify the hosting and booking procedures, provide wider exposure, and comply the user's needs

Cultural tradition of Bali

10 The ability of Balinese to preserve their unique rituals and cultural values on their daily activities, as the primary attractiveness of Bali

\section{Oversupply of hotel rooms in Ball}

11 Continuous expansion of new hotels in Bali leads to the oversupply of hotel rooms that implicates in the inadequate waste management, water shortage, and tariff war among accommodation suppliers.

Abundance of idling capacity in Bali

12 The abundance of idling capacity in Bali in the form of spare rooms, houses, and other properties which enlarge the potential of sharing economy activity in accommodation The disruptive innovation of the sharing economy in accommodation

13 The disruptive effect of houses rented out/shared in the sharing economy in accommodation platform like Airbnb, on the level occupancy of hotels and other incumbent accommodation providers in Bali

Popularity of reputation and rating system

14 Increasing popularity of reputation and rating system to mediate trust and secure between strangers in the sharing economy in accommodation platform like Airbnb 
Appendix 6: Example of questionnaire of the third round (translated into English)

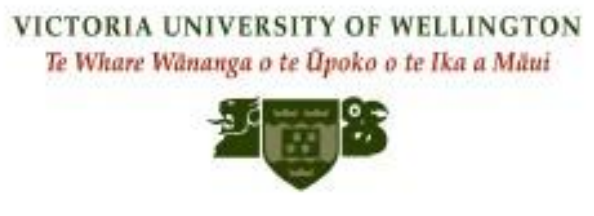

QUESTIONNAIRE FOR THE THIRD ROUND OF THE DELPHI METHOD

2030: A Scenario Planning of the Sharing Economy in Bali Accommodation

Thank you for completing the questionnaire on previous round of this research. I have analyzed all returned questionnaires and sorted out 4 key drivers of change, which are presented in a random order in below table. In this phase, I would ask your participation to rank those drivers of change based on the likelihood to occur in influencing the development of the sharing economy in accommodation in Bali by putting number 1 to 4 on the rank column.

Please be informed that number 1 indicates the driver with the highest propensity to occur which influence the development of the sharing economy in accommodation in Bali, whereas 4 indicates the lowest. Your participation is very much appreciated.

\begin{tabular}{|c|c|c|}
\hline No & Drivers of Change & Rank \\
\hline 2 & $\begin{array}{l}\text { Ubiquitous Internet } \\
\text { Increasing spread of Internet in Bali to facilitate sharing, to enhance connectivity among humans, and to } \\
\text { popularize the peer-to-peer social networks in accommodation such as Airbnb }\end{array}$ & \\
\hline 4 & $\begin{array}{l}\text { Cultural tradition of Bali } \\
\text { The Balinese's unique rituals and cultural values preservation on their daily activities, as the primary } \\
\text { attractiveness of Bali }\end{array}$ & \\
\hline
\end{tabular}




\section{Reference:}

Airbnb. (2016). about us. Retrieved October 2, 2016 from https://www.airbnb.co.nz/about/about-us

Airbnb. (2016a). Airbnb economic impact in Japan. Retrieved October 2, 2016 from http://blog.airbnb.com/airbnb-economic-impact-in-japan/

Airbnb. (2016b). Airbnb economic impact in France. Retrieved October 2, 2016 from http://blog.airbnb.com/airbnb-economic-impact-in-france-paris/

Airbnb. (2016c). Airbnb professional photography. Retrieved October 20, 2016 from https://www.airbnb.com/info/photography

Airbnb. (2016d). How does providing identification on airbnb work?. Retrieved October 20, 2016 from https://www.airbnb.com/help/article/1237/how-doesproviding-identification-on-airbnb-work

Airbnb. (2016e). what's a guidebook. Retrieved October 20, 2016 from https://www.airbnb.com/help/article/249/what-s-a-guidebook

Airbnb. (2016f). Neighborhoods. Retrieved October 20, 2016 from https://www.airbnb.com/locations

Airbnb. (2016g). what is instant book. Retrieved October 20, 2016 from https://www.airbnb.co.nz/help/article/523/what-is-instant-book

Airbnb. (2016h). How do I become a superhost?. Retrieved October 20, 2016 from https://www.airbnb.co.nz/help/article/829/how-do-i-become-a-superhost

Airbnb. (2015). the greener way to travel: environmental impacts of home sharing. Retrieved March, 8, 2016 from http://blog.airbnb.com/environmental-impactsof-home-sharing/

Airdna. (2016). Airbnb data and analytics. Retrieved August 10, 2016 from https://www.airdna.co/city/id/bali

Airline Leader. (2016). Indonesia: Slower growth in the world's fifth largest domestic airline market. Retrieved October 5, 2016 from http://www.airlineleader.com/categories/regions/indonesia-slower-growth-inthe-worlds-fifth-largest-domestic-airline-market-270806 
Amer, M., Daim, T. U., \& Jetter, A. (2013). A review of scenario planning. Futures, 46, 23-40.

Arias Sans, A., \& Quaglieri Domínguez, A. (2016). Unravelling Airbnb. Urban perspectives from Barcelona. Reinventing the local in Tourism. Bristol: Channel View.

Balea, J. (2016). The latest stats in web and mobile in Indonesia. Retrieved October 7, 2016 from https://www.techinasia.com/indonesia-web-mobile-statistics-we-aresocial

Bardhi, F., \& Eckhardt, G. (2012). Access-Based Consumption: The Case of Car Sharing. Journal of Consumer Research, 39(4), 881-898.

Barnes, S. J., \& Mattsson, J. (2016). Understanding current and future issues in collaborative consumption: A four-stage Delphi study. Technological Forecasting and Social Change, 104, 200-211.

Batey, A. (2014). Mobile + sharing economy + internet of things = the coming economic boom. Retrieved May, 2, 2016 form https://www.entrepreneur.com/article/237646

Bechmann, A., \& Lomborg, S. (2014). The Ubiquitous Internet: User and Industry Perspectives (Vol. 25). United Kingdom: Routledge.

Belk, R. (2013). You are what you can access: Sharing and collaborative consumption online. Journal of Business Research, Journal of Business Research.

Bell, W. (2011). Foundations of Futures Studies: Human Science for a New Era: Values, Objectivity, and the Good Society. Transaction Publishers.

Bialski, P. (2016). Authority and Authorship: Uncovering the Sociotechnical Regimes of Peer-to-Peer Tourism. Reinventing the Local in Tourism: Producing, Consuming and Negotiating Place, 73, 35.

Bird, M. (2015). Airbnb users want cheap hotel alternatives - but data suggest it's actually more expensive. Retrieved May, 2, 2016 from http://www.businessinsider.com.au/bank-of-america-says-airbnb-not-reallycheaper-than-hotels-2015-11?r=UK\&IR=T

Bishop, P., Hines, A., \& Collins, T. (2007). The current state of scenario development: an overview of techniques. Foresight, 9(1), 5-25. 
Blablacar. (2016). Blablacar at a glance. Retrieved April 5, 2016 from https://www.blablacar.co.uk/about-us?

Bohang, F. K. (2016). Bukan cuma Uber dan Grab, ini "perusak” industri lainnya. Retrieved August 17, 2016 from http://tekno.kompas.com/read/2016/03/24/10040067/Bukan.Cuma.Uber.dan.Gr ab.Ini.Perusak.Industri.Lainnya

Boeing. (2016). Current market outlook 2016-2035. Retrieved March 7, 2016 from http://www.boeing.com/resources/boeingdotcom/commercial/about-ourmarket/assets/downloads/cmo_print_2016_final_updated.pdf

Börjeson, L., Höjer, M., Dreborg, K. H., Ekvall, T., \& Finnveden, G. (2006). Scenario types and techniques: towards a user's guide. Futures, 38(7), 723-739.

Botsman, R. (2010). The case for collaborative consumption. Retrieved March 7, 2016 from

https://www.ted.com/talks/rachel_botsman_the_case_for_collaborative_consum ption\#t-519665

Botsman, R. (2013). The sharing economy lacks a shared definition. Retrieved April 5, 2016 from http://www.collaborativeconsumption.com/2013/11/22/the-sharingeconomy-lacks-a-shared-definition/

Botsman, R. (2014). Collaborative economy services: changing the way we are travel. Retrieved April 5, 2016 from http://rachelbotsman.com/work/collaborativeeconomy-services-changing-the-way-we-travel-collaborativeconsumption-com/

Botsman, R. (2015). Defining the sharing economy: what is collaborative consumption and what isn't?. Retrieved April 5, 2016 from https://www.fastcoexist.com/3046119/defining-the-sharing-economy-what-iscollaborative-consumption-and-what-isnt

Botsman, R., \& Rogers, R. (2010). What's mine is yours: The rise of collaborative consumption. New York, NY: HarperBusiness

Brady, D. (2014). The environmental case for the sharing economy. Retrieved May, 2, 2016 from http://www.bloomberg.com/news/articles/2014-09-24/theenvironmental-case-for-the-sharing-economy-i0gsboom

Brummit, C., Purnomo, H., Rahadiana, R. (2015). Indonesian hotels face carnage from Widodo's spending cuts. Retrieved April, 15, 2016 from http://www.bloomberg.com/news/articles/2015-02-08/indonesian-hotels-facecarnage-from-widodo-s-state-spending-cuts 
Buhalis, D., \& Amaranggana, A. (2013). Smart tourism destinations. InInformation and communication technologies in tourism 2014 (pp. 553-564). Springer International Publishing

Cahyafitri, R. (2014). Java, Bali to face power crisis soon. Retrieved October 7, 2016 from http://www.thejakartapost.com/news/2014/08/14/java-bali-face-powercrisis-soon.html

Campbell, D. F. (2008). The basic concept for the democracy ranking of the quality of democracy. Vienna: Democracy Ranking, 10, 21.

Chang, Y. H., \& Cheng, H. C. (2013). Analying the strategies of LCCs and FSCs in Southeast Asia. Retrieved October 5, 2016 from https://aerlinesmagazine.files.wordpress.com/2013/01/36_cheng_lccs_fscs_sea. pdf

Chermack, T., Lynham, S. A., \& Ruona, W. (2001). A review of scenario planning literature. Futures Research Quarterly, 17(2).

Christensen, C., M., Raynor, M., E. (2003). The innovator's solution: creating and sustaining successful growth. Boston, United States: Harvard Business School Press

Chung, J. Y., \& Whang, T. (2011). The impact of low cost carriers on Korean Island tourism. Journal of Transport Geography, 19(6), 1335-1340.

Citi GPS. (2015). Disruptive innovation III. Retrieved November 15, 2016 from https://codex.com/wp-content/uploads/2015/11/Citi-Disruptive-InnovationReport-July-2015.pdf

Cohealo. (2016). What is Cohealo?. Retrieved April 5, 2016 from http://cohealo.com/

Cole, S. (2012). A political ecology of water equity and tourism: A case study from Bali. Annals of tourism Research, 39(2), 1221-1241.

Colliers International. (2015). Bali hotel market report 2015. Retrieved April, 15, 2016 from http://www.colliers.com//media/files/marketresearch/apac/indonesia/balihotel-researchforecastreport1h2015.pdf?la=en-GB

Cunha, M. P. E. (2004). Time traveling: organizational foresight as temporal reflexivity. Managing the future: foresight in the knowledge economy, 133-149. 
Cushman \& Wakefield. (2014). Hotel views 2015 Asia Pacific. Retrieved April, 15, 2016 from http://www.cushmanwakefield.com/en-gb/research-andinsight/2014/hotel-views-2015/

Dalkey, N., \& Helmer, O. (1963). An experimental application of the Delphi method to the use of experts. Management science, 9(3), 458-467.

Darmawan, I. (2016). The practice of sharing economy in Indonesia. Retrieved February 9, 2017 from https://medium.com/@indradarmawan/the-practice-ofsharing-economy-in-indonesia-1f6d6824ba21\#.6gp87e0wu

Daconto, G., \& Sherpa, L. N. (2010). Applying scenario planning to park and tourism management in Sagarmatha National Park, Khumbu, Nepal. Mountain Research and Development, 30(2), 103-112.

Dapp, T. (2011). The digital society: new ways to more transparency, participation and innovation. Retrieved September 20, 2016 from http://www.dbresearch.com/PROD/DBR_INTERNET_ENPROD/PROD0000000000276332.PDF

Dator, J. (1995). What future studies is, and is not. Retrieved September 20, 2016 from http://www.futures.hawaii.edu/publications/futures-studies/WhatFSis 1995.pdf

Dator, J. (2009). Alternative futures at the Manoa School. Journal of Futures Studies, 14(2), 1-18.

Daunoriene, A., Drakšaite, A., Snieška, V., \& Valodkiene, G. (2015, April). Evaluating sustainability of sharing economy trade market business models. In International scientific conference" Economics and Management, ICEM"(Vol. 1, No. 1).

De Filippi, P. (2015). Community Mesh Networks: Citizens Participation in the Deployment of Smart Cities. Social, Economic, and Environmental Sustainability in the Development of Smart Cities. IGI Global.

Deil, S. A. (2015). Industri perhotelan nasional tengah krisis. Retrieved from http://bisnis.liputan6.com/read/2252848/industri-perhotelan-nasional-tengah$\underline{\text { krisis }}$

Dolnicar, S., \& Otter, T. (2003). Which hotel attributes matter? A review of previous and a framework for future research. In Griffin, T \& Harris, R (eds). Proceedings of the $9^{\text {th }}$ Annual Conference of the Aisa Pacific Tourism Association (APTA), University of Technology Sydnet, 2003, 1, 176-188 
Dredge, D., \& Gyimóthy, S. (2015). The collaborative economy and tourism: Critical perspectives, questionable claims and silenced voices. Tourism Recreation Research, 40(3), 286-302.

Drescher, M., Perera, A. H., Johnson, C. J., Buse, L. J., Drew, C. A., \& Burgman, M. A. (2013). Toward rigorous use of expert knowledge in ecological research. Ecosphere, 4(7), 1-26.

eMarketer. (2014). 2 billion consumers worldwide to get smart (phones) by 2016. Retrieved May, 2, 2016 from http://www.emarketer.com/Article/2-BillionConsumers-Worldwide-Smartphones-by-2016/1011694

Ert, E., Fleischer, A., Magen, N. (2016). Trust and reputation in the sharing economy: the role of personal photos in Airbnb. Tourism Management, 55, 62-73

Euromonitor. (2014). Travel and the sharing economy. Retrieved from http://www.euromonitor.com/travel-and-the-sharing-economy/report

Euromonitor. (2016). Flows in Indonesia. Retrieved January 2, 2016 from http://www.portal.euromonitor.com.helicon.vuw.ac.nz/portal/analysis/tab

Euromonitor. (2016). Digital consumer landscape: Indonesia. Retrieved November 15, 2016 from http://www.portal.euromonitor.com.helicon.vuw.ac.nz/portal/analysis/tab

Fairview. (2015). the sharing economy: sharing access instead of ownership. Retrieved March, 7, 2016 from http://fairviewcapital.com/downloads/Fairview_Capital_Sharing_Economy_Ne wsletter.pdf

Fang, B., Ye, Q., \& Law, R. (2016). Effect of sharing economy on tourism industry employment. Annals of Tourism Research, 57, 264-267.

Ferenstein, G. (2014). Airbnb's stealth home-dining experiment is going to be awesome. Retrieved November 15, 2016 from http://venturebeat.com/2014/06/10/airbnbs-stealth-home-dining-experiment-isgoing-to-be-awesome/

Finley, K. (2013). Trust in the sharing economy: an exploratory study. Retrieved March, 7, 2016 from https://www2.warwick.ac.uk/fac/arts/theatre_s/cp/research/publications/madiss/ ccps_a4_ma_gmc_kf_3.pdf 
Fix, R. (2016). The future of Airbnb: 56 industry experts reveal their outlook. Retrieved November 14, 2016 from http://getpaidforyourpad.com/blog/the-future-ofairbnb/

Freedom House (2015). Freedom in the world 2016. Retrieved November 15, 2016 from https://freedomhouse.org/sites/default/files/FH_FITW_Report_2016.pdf

Gartner. (2014). Gartner says 8.4 billion connected 'things' will be in use in 2017. Retrieved July 3, 2016 from http://www.gartner.com/newsroom/id/3598917

Gansky, L. (2010). The Mesh. New York, NY: PortfolioPenguin

Geerts, W. (2016). The sharing economy in lodging. Retrieved August 15, 2016 from http://blog.euromonitor.com/2016/06/new-global-briefing-the-sharingeconomy-in-lodging.html

Getz, D. (1986). Models in tourism planning: Towards integration of theory and practice. Tourism management, 7(1), 21-32.

Gladwell, M. (2006). The tipping point: How little things can make a big difference. Boston, United States: Little, Brown.

Global Democracy Ranking. (2016). Democracy ranking 2013. Retrieved July 3, 2016 from http://democracyranking.org/wordpress/

Godet, M. (2000). The art of scenarios and strategic planning: tools and pitfalls. Technological forecasting and social change, 65(1), 3-22.

Gössling, S., \& Scott, D. (2012). Scenario planning for sustainable tourism: an introduction. Journal of Sustainable Tourism, 20(6), 773-778.

Goldman Sachs. (2015). The Chinese tourist boom. Retrieved July 3, 2016 from http://www.goldmansachs.com/our-thinking/pages/macroeconomic-insightsfolder/chinese-tourist-boom/report.pdf

Guttentag, D. (2015). Airbnb: Disruptive innovation and the rise of an informal tourism accommodation sector. Current Issues in Tourism, 18(12), 1192-1217.

Hamari, J., Sjoklint, M., Ukkonen, A. (2015). The sharing economy: why people participate in collaborative consumption. Journal of the Association for Information Science and Technology, (forthcoming 2015).

Hall, C. M. (2010). Crisis events in tourism: subjects of crisis in tourism. Current issues in Tourism, 13(5), 401-417. 
Hensens, W. (2015). The future of hotel rating. Journal of Tourism Futures, 1(1), 6973.

Hiltunen, M. J. (2007). Environmental impacts of rural second home tourism-case Lake District in Finland. Scandinavian Journal of Hospitality and Tourism, 7(3), 243265.

Himawan, A., \& Hapsari, D., K. (2016). Program 35 ribu MW mandek, Jawa dan Bali terancam krisis listrik. Retrieved April, 15, 2016 from http://www.suara.com/bisnis/2016/01/22/145228/program-35-ribu-mw-mandekjawa-dan-bali-terancam-krisis-listrik

Hitchcock, M., \& Darma Putra, I. N. (2007). Tourism, development and terrorism in Bali. Ashgate Publishing Ltd.

Hobsbawm, E. (2000). History and understanding the past. Retrieved from http://www.bbc.co.uk/programmes/p00546qd

Hodal, K. (2013). In Bali, rich foreigners are sparking a property frenzy, but who benefits?. $\quad$ Retrieved 12 August, 2016 from https://www.theguardian.com/world/2013/mar/09/bali-property-frenzyislanders-boom

Holden, C. (2005). Time's up on time travel. Science, 308(5725), 1110-1110.

Horwarth. (2015). Hotel \& branded residences Bali 2015. Retrieved April, 15, 2016 from http://www.c9hotelworks.com/downloads/bali-hotel-branded-residences2015-12.pdf

Hotrec. (2015). Levelling the playing field. Retrieved January 13, 2016 from http://www.toposophy.com/hotrec

HVS. (2015). Indonesia hotel watch 2015. Retrieved April, 15, 2016 from http://www.hvs.com/article/7462/indonesia-hotel-watch-2015/

Hynek, A. (2016). How millenials are driving the sharing economy. Retrieved May, 2 , 2016 from http://marketrealist.com/2016/03/millennials-driving-sharingeconomy/

Islam, N., \& Want, R. (2014). Smartphones: Past, present, and future. IEEE Pervasive Computing, 13(4), 89-92. 
Iqbal, S., \& Pipon-Young, L. (2009). The Delphi Method. Retrieved September 20, 2016 from https://thepsychologist.bps.org.uk/volume-22/edition-7/delphimethod

Indonesia-investments.com. (2016b). Foreign ownership landed hoses \& apartments in Indonesia (Update). Retrieved 12 August, 2016 from http://www.indonesiainvestments.com/news/news-columns/foreign-ownership-landed-housesapartments-in-indonesia-update/item6728

Internetlivestats.com (2016). Internet users in the world. Retrieved October 7, 2016 from http://www.internetlivestats.com/internet-users/

Jennings, G. (2005). Interviewing: A focus on qualitative techniques. In Ritchie, B. W., Burns, P. M., \& Palmer, C. A. (Eds.). (2005). Tourism research methods: integrating theory with practice. Cabi.

Justpark. (2016). Justpark: car parking for the digital age. Retrieved April 5, 2016 from https://www.justpark.com/about/

Kalanick, T. (2016). Uber's plan to get more people into fewer cars. Retrieved March, 7 , 2016 from https://www.ted.com/talks/travis_kalanick_uber_s_plan_to_get_more_people_i nto_fewer_cars\#t-768824

Kaplan, R., Nadler, M. (2015). Airbnb: A case study in occupancy regulation and taxation. $\quad$ Retrieved May, 2, 2016 from https://lawreview.uchicago.edu/page/airbnb-case-study-occupancy-regulationand-taxation

Karlsen, J., Øverland, E. F., \& Karlsen, H. (2010). Sociological contributions to futures' theory building. Foresight, 12(3), 59-72.

Katz, V. (2015). Regulating the sharing economy. Berkeley Technology Law Journal, 30(4), 1067.

Kemenpar. (2015). Press release promosi Wonderful Indonesia di Singapore, 6-8 November 2015, strategi meningkatkan jumlah wisatawan asing. Retrieved April 5, 2016 from http://kemenpar.go.id/asp/detil.asp?id=3013

Knight Frank. (2015). the wealth report 2015. Retrieved November 15, 2016 from https://kfcontent.blob.core.windows.net/research/83/documents/en/wealthreport-2015-2716.pdf 
Kompas. (2016). Ngurah Rai Airport more crowded foreign investors eye new airport in Buleleng. Retrieved April, 15, 2016 from http://print.kompas.com/baca/2016/02/13/Ngurah-Rai-Airport-morecrowdedForeign-investors-e

Koopman, C., Mitchell, M. D., \& Thierer, A. D. (2015). The sharing economy and consumer protection regulation: The case for policy change. The Journal of Business, Entrepreneurship \& the Law, 8(2).

Kuhn, B. (2011). What is downzoning and when is it compensable. Retrieved November 15, 2016 from http://www.jdsupra.com/legalnews/what-is-downzoning-andwhen-is-it-compen-72826/

Kuosa, T. (2011). Evolution of futures studies. Futures, 43(3), 327-336.

Liem, C. (2016). The rise of the sharing economy in Indonesia. Retrieved May, 2, 2016 from $\quad$ https://www.weforum.org/agenda/2016/01/the-rise-of-the-sharingeconomy-in-indonesia/

Lietaer, B. (2003). A world in balance. Reflections: The Journal of the Society for Organisational Learning.

Lietaer, B., \& De Meulenaere, S. (2003). Sustaining cultural vitality in a globalizing world: the Balinese example. International Journal of Social Economics, 30(9), 967-984.

Lincoln, Y. S., Lynham, S. A., \& Guba, E. G. (2011). Paradigmatic controversies, contradictions, and emerging confluences, revisited. The Sage handbook of qualitative research, 4, 97-128.

Linstone, H. A., \& Turoff, M. (Eds.). (1975). The Delphi method: Techniques and applications (Vol. 29). Reading, MA: Addison-Wesley.

Linneman, R. E., \& Klein, H. E. (1983). The use of multiple scenarios by US industrial companies: a comparison study, 1977-1981. Long range planning, 16(6), 94101.

Lion Air. (2016). Lion Air flight routes. Retrieved July 3, 2016 from http://www.lionair.co.id/promotion/flight-routes

Long, V. H., \& Wall, G. (1993). Balinese 'homestays': An indigenous response to tourism. In 13th INTERNATIONAL Congress of Anthropological and Ethnological Sciences, Mexico. 
Lub, X. D., Rijnders, R., Caceres, L. N., \& Bosman, J. (2015). The future of hotels The Lifestyle Hub. A design-thinking approach for developing future hospitality concepts. Journal of Vacation Marketing, 1356766715623829.

Lunny, O. (2015). Mobile tech: building the sharing economy. Retrieved May, 2, 2016 from http://www.theguardian.com/media-network/2015/sep/04/mobile-techeconomic-revolution-smartphones

Macgougan, P. (2016). Sharing economy driving growth in mobile payment technology. Retrieved March, 7, 2016 from http://go-mashmobile.com/mcommerce-2/newsmcommerce-2/sharing-economy-driving-growth-in-mobile-paymenttechnology-3362/

Mannermaa, M. (1991). In search of an evolutionary paradigm for futures research. Futures, 23(4), 349-372.

Marshall, P. (2015). The sharing economy. Retrieved May, 2, 2016 from http://businessresearcher.sagepub.com/sbr-1645-96738-2690068/20150803/thesharing-economy\#NOTE[7]

Maycotte, H. (2015). Millennials are driving the sharing economy-and so is big data. Retrieved March, 7, $\quad 2016$ from http://www.forbes.com/sites/homaycotte/2015/05/05/millennials-are-drivingthe-sharing-economy-and-so-is-big-data/\#7c56e3182991

McKinsey. (2012). the archipelago economy: unleashing Indonesia's potential. Retrieved March 7, 2016 from http://www.mckinsey.com/global-themes/asiapacific/the-archipelago-economy

McLennan, C. L., Pham, T. D., Ruhanen, L., Ritchie, B. W., \& Moyle, B. (2012). Counter-factual scenario planning for long-range sustainable local-level tourism transformation. Journal of Sustainable Tourism, 20(6), 801-822.

Middleton, C. (2014). Building a digital society. Retrieved September 20, 2016 from http://telsoc.org/ajtde/2014-03-v2-n1/a27

Mietzner, D., \& Reger, G. (2005). Advantages and disadvantages of scenario approaches for strategic foresight. International Journal of Technology Intelligence and Planning, 1(2), 220-239.

Miller, S. R. (2016). First principles for regulating the sharing economy. Retrieved August 17, 2016 from http://harvardjol.com/wpcontent/uploads/2016/02/HLL107_crop.pdf 
Mishra, S. (2015). The Economy in Indonesia's Ascent: Making Sense of it All. In Indonesia's Ascent (pp. 40-68). Palgrave Macmillan UK

MP3EI. (2011). Indonesia Master Plan Acceleration and Expansion. Retrieved April, 15, 2016 from http://www.aseanbriefing.com/search.html?s=mp3ei

Nengah, I., M. (2013). Basa-basi moratorium pembangunan hotel di Bali. Retrieved April, $\quad 15, \quad 2016$ from https://www.academia.edu/13279508/Basa_Basi_Moratorium_Pembangunan_H otel_di_Bali

Nielsen. (2011). State of the media: social media report Q.3. Retrieved March, 7, 2016 from http://www.nielsen.com/us/en/insights/reports/2011/social-media-reportq3.html

Nielsen. (2014). Is sharing the new buying?. Retrieved March, 7, 2016 from http://www.nielsen.com/content/dam/nielsenglobal/apac/docs/reports/2014/Niel sen-Global-Share-Community-Report.pdf

Nowack, M., Endrikat, J., \& Guenther, E. (2011). Review of Delphi-based scenario studies: quality and design considerations. Technological Forecasting and Social Change, 78(9), 1603-1615.

OECD. (2014). Airline competition: note by Indonesia. Retrieved October 5, 2016 from http://www.oecd.org/officialdocuments/publicdisplaydocumentpdf/?cote=DAF/ $\underline{\text { COMP/WD(2014)70\&docLanguage }=\text { En }}$

OECD. (2001). Understanding the digital divide. Retrieved September 20, 2016 from https://www.oecd.org/sti/1888451.pdf

Okoli, C., \& Pawlowski, S. D. (2004). The Delphi method as a research tool: an example, design considerations and applications. Information \& management, 42(1), 15-29.

Oskam, J., Boswijk, A. (2016). Airbnb: the future of networked hospitality business. Journal of tourism futures, 2(1), 22-42.

Oskam, J., \& Zandberg, T. (2016). Who will sell your rooms? Hotel distribution scenarios. Journal of Vacation Marketing, 22(3), 265-278.

Owyang, J. (2013). The three market drivers: causes for collaborative economy. Retrieved March, 7, 2016 from http://www.webstrategist.com/blog/2013/05/09/the-three-market-drivers-causes-for-thecollaborative-economy/ 
Parsons, A. (2014). The sharing economy: a short introduction to its political evolution. Retrieved May, 2, $\quad 2016$ from https://www.opendemocracy.net/transformation/adam-parsons/sharingeconomy-short-introduction-to-its-political-evolution\#

Peeters, P., Dijkmans, C., Mitas, O., Strous, B., Vinkensteijn, J. (2015). Research for tran committee - tourism and the sharing economy: challenges and opportunities for the EU. Retrieved April, 15, 2016 from http://www.europarl.europa.eu/RegData/etudes/STUD/2015/563411/IPOL_STU (2015)563411_EN.pdf

Picard, M. (1990). "Cultural Tourism" in Bali: Cultural Performances as Tourist Attraction. Indonesia, (49), 37-74.

Picard, M. (2008). Balinese identity as tourist attraction from cultural tourism'(pariwisata budaya) to Bali erect'(ajeg Bali). Tourist Studies, 8(2), 155173.

Piscicelli, Cooper, \& Fisher. (2015). the role of values in collaborative consumption: Insights from a product-service system for lending and borrowing in the UK. Journal of Cleaner Production, 97, 21-29.

Pitkänen, K., \& Vepsäläinen, M. (2008). Foreseeing the future of second home tourism. The case of Finnish media and policy discourse. Scandinavian Journal of Hospitality and Tourism, 8(1), 1-24.

Porges, S. (2015). This is the future of Airbnb: A candid conversation with the company's head of hospitality. Retrieved November 14, 2016 from http://www.forbes.com/sites/sethporges/2015/12/29/this-is-the-future-of-airbnba-candid-conversation-with-the-companys-head-of-hospitality/\#4edec33c15db

Postma, A. (2013). Anticipating the future of European tourism. In Postma, A., Yeoman, I., Oskam, J. (eds). The future of European tourism, Leeuwarden, the Netherland: Stenden University of Applied Sciences

PricewaterhouseCoopers. (2015), the sharing economy: consumer intelligence series. Retrieved April 5, 2016 from http://www.pwc.com/us/en/industry/entertainmentmedia/publications/consumer-intelligence-series/sharing-economy.html

PricewaterhouseCoopers. (2016). shared benefits: how the sharing economy is reshaping business across Europe. Retrieved November 18, 2016 from http://www.pwc.co.uk/issues/megatrends/collisions/sharingeconomy/future-ofthe-sharing-economy-in-europe-2016.html 
Psarros, M. (2015). The new sharing economy: is this the end of tourism as we know it?. Retrieved March, 7, 2016 from http://www.slideshare.net/mpsarros/sharingeconomy-tourism

Pulina, M., \& Cortés-Jiménez, I. (2010). Have low-cost carriers influenced tourism demand and supply? The case of Alghero, Italy. Tourism Analysis, 15(6), 617635 .

Putra, I. N. D., \& Hitchcock, M. (2006). The Bali bombs and the tourism development cycle. Progress in Development Studies, 6(2), 157-166.

Putra, E., P. (2015). Renovasi Bandara Ngurah Rai, Angkasa Pura siapkan Rp 3 triliun. Retrieved April, 15, $\quad 2016$ from http://www.republika.co.id/berita/nasional/daerah/15/02/24/nk98ek-renovasibandara-ngurah-rai-angkasa-pura-siapkan-rp-3-triliun

Rainie, L (2016). Digital divides 2016. Retrieved September 20, 2016 from http://www.pewinternet.org/2016/07/14/digital-divides-2016/

Richardson, K. (2003). International Education: Homestay theory versus practice. In Proceedings for the International Education Research Conference AARENZARE (pp. 27-35).

Rinne, A. (2013). Young global leaders sharing economy working group position paper 2013. Retrieved from https://thecirculars.org/documents/04\%20Sharing\%20Economy\%20Paper.pdf

Romanos, M., \& Jenkins, L. D. (2013). Changing cultural developments along a tourist route in Bali. Almatourism-Journal of Tourism, Culture and Territorial Development, 4(8), 19-31.

Schoemaker, P. J. (1995). Scenario planning: a tool for strategic thinking. Sloan management review, 36(2), 25.

Schmidt-Rinehart, B. C., \& Knight, S. M. (2004). The homestay component of study abroad: Three perspectives. Foreign Language Annals, 37(2), 254-262.

Schroer, J., W. (2016). Generation X, Y, Z and the others. Retrieved March, 7, 2016 from http://www.socialmarketing.org/newsletter/features/generation3.htm

Schwartz, P. (1991). The Art of the Long View: Planning for the Future in an Uncertain World. New York, the United States: Currency Doubleday 
Singapore Tourism Board. (2015). Capturing the Asian millennial traveller. Retrieved July 3, 2016 from

http://www.yoursingapore.com/content/dam/MICE/Global/bulletinboard/travel-rave-reports/Capturing-the-Asian-Millennial-Traveller.pdf

Skift. (2016). State of travel 2016. Retrieved May 16, 2016 from https://skift.com/2016/04/06/new-skift-deck-the-state-of-global-travel-2016/

Sondeijker, S. (2009). Imagining sustainability: Methodological building blocks for transition scenarios. Retrieved May 16, 2016 from http://repub.eur.nl/pub/17462/

Solnet, D. J., Baum, T., Kralj, A., Robinson, R. N., Ritchie, B. W., \& Olsen, M. (2014). The Asia-Pacific tourism workforce of the future: Using Delphi techniques to identify possible scenarios. Journal of Travel Research, 53(6), 693-704.

Stephany, A. (2015). The business of sharing. New York, NY: Palgrave Macmillan

Sutawa, G. K. (2012). Issues on Bali tourism development and community empowerment to support sustainable tourism development. Procedia economics and finance, 4, 413-422.

The Economist. (2013). All eyes on the sharing economy. Retrieved December 20, 2015 from http://www.economist.com/news/technology-quarterly/21572914collaborative-consumption-technology-makes-it-easier-people-rent-items

The Jakarta Post. (2015). A range of views on foreign property ownership. Retrieved 12 August, 2016 from http://www.thejakartapost.com/news/2015/10/03/a-rangeviews-foreign-property-ownership.html

The World Bank. (2016). Indonesia. Retrieved October 7, 2016 from http://data.worldbank.org/country/indonesia

Ting, D. (2016). Airbnb's proposed tax agreements with cities raise more questions than answers. Retrieved May, 2, 2016 from https://skift.com/2016/04/18/airbnbs-proposed-tax-agreements-with-citiesraise-more-questions-than-answers/

Trivett, V., \& Staff, S. (2013). What the sharing economy means to the future of travel. Retrieved from http://skift.com/wp-content/uploads/2014/07/skift-what-thesharing-economy-means-to-the-future-of-travel.pdf

Trochim, W., Donnelly, J. P., \& Arora, K. (2015). Research methods: The essential knowledge base. Nelson Education. 
Tuominen, P. P., \& Ascenção, M. P. (2016). The hotel of tomorrow: A service design approach. Journal of Vacation Marketing, 1356766716637102.

Tussyadiah, I., \& Zach, F. (2015). Hotels vs. peer-to-peer accommodation rentals: text analytics of consumer reviews in Portland, Oregon. Retrieved from http://scholarworks.umass.edu/cgi/viewcontent.cgi?article $=1009 \&$ context $=$ ttra

Tussyadiah, I. (2015). An exploratory study on drivers and deterrents of collaborative consumption in travel. Retrieved March, 7, 2016 from https://www.researchgate.net/publication/272023008_An_Exploratory_Study_o n_Drivers_and_Deterrents_of_Collaborative_Consumption_in_Travel

Tussyadiah, I., \& Pesonen, J. (2016). Drivers and barriers of peer-to-peer accommodation stay - an exploratory study with American and Finnish travellers. Current Issues in Tourism, 1-18.

UNWTO. (2016). Asia tourism trend 2016. Retrieved July 3, 2016 from http://asiapacific.unwto.org/publication/unwtogterc-annual-report-asia-tourism$\underline{\text { trends-2016-edition }}$

Van Asselt, M. (2012). Foresight in action: developing policy-oriented scenarios. United Kingdom: Routledge.

Van't Klooster, S. A., \& van Asselt, M. B. (2006). Practising the scenario-axes technique. Futures, 38(1), 15-30.

Van der Heijden, K., Bradfield, R., Burt, G., Cairns, G., \& Wright, G. (2002).The sixth sense: Accelerating organizational learning with scenarios. John Wiley \& Sons.

Vermesan, O., \& Friess, P. (Eds.). (2014). Internet of things-from research and innovation to market deployment (pp. 74-75). Aalborg: River Publishers.

Walhi. (2007). Fakta krisis-krisis di Bali. Retrieved April, 15, 2016 from http://www.walhibali.org/terbaru/fakta-krisis-krisis-di-bali.html

Walhi. (2014). Meneropong impelementasi moratorium akomodasi pariwisata Bali Selatan. $\quad$ Retrieved April, 15, 2016 from http://www.walhibali.org/tag/meneropong-implementasi-moratoriumakomodasi-pariwisata-bali-selatan

Walls, M. (2007). Transfer of development rights in the US Communities. Retrieved November

15 , 2016 from 
http://www.rff.org/files/sharepoint/WorkImages/Download/Walls_McConnell_ Sep_07_TDR_Report.pdf

Wall, G., \& Long, V. (1996). Balinese homestays: an indigenous response to tourism opportunities. Tourism and indigenous peoples. 27-48

World Economic Forum. (2015). Deep shift technology: tipping points and societal impact. $\quad$ Retrieved April 6, 2016 from http://www3.weforum.org/docs/WEF_GAC15_Technological_Tipping_Points_ report_2015.pdf

World Travel and Tourism Council. (2015). Indonesia economic impact 2015. Retrieved July 3, 2016 from https://www.wttc.org//media/files/reports/economic\%20impact\%20research/countries\%202015/indon esia2015.pdf

Wosskow, D. (2014). Unlocking the sharing economy: An independent review. Retrieved July 3, 2016 from https://www.gov.uk/government/uploads/system/uploads/attachment_data/file/3 78291/bis-14-1227-unlocking-the-sharing-economy-an-independent-review.pdf

Yeoman, I., Galt, M., \& Mcmahon-Beattie, U. (2005). A case study of how VisitScotland prepared for war. Journal of Travel Research, 44(1), 6-20.

Yeoman, I. (2008). Tomorrow's Tourist-Scenario and Trends. Oxford: Elsevier.

Yeoman, I., Hsu, C., Smith, K. and Watson, S. (2010). Tourism and demography. Oxford: Goodfellow Publishers.

Yeoman, I. (2012). 2050-tomorrow's tourism (Vol. 55). Channel View Publications.

Yeoman, I. (2013) Tomorrows tourist and the case of New Zealand. In Leight, J., Webster, J. and Stanislav, I. (Eds). Future Tourism: Political, Social and Economic Challenges. London, Routledge.

Zekanovic-Korona, L., \& Grzunov, J. (2014). Evaluation of shared digital economy adoption: Case of Airbnb. In Information and Communication Technology, Electronics and Microelectronics (MIPRO), 2014 37th International Convention on (pp. 1574-1579). IEEE.

Zervas, G., Proserpio, D., \& Byers, J.W. (2015). The rise of sharing economy: estimating the impact of Airbnb on the hotel industry. Retrieved from: http://papers.ssrn.com/sol3/papers.cfm?abstract_id=2366898 